\title{
Hydrogel tracer beads as potential proxies for non-aqueous phase liquids in karst: Development of an optical quantification method for fluorescent beads
}

Habib Bravo-Ruiz

Follow this and additional works at: https://researchrepository.wvu.edu/etd

\section{Recommended Citation}

Bravo-Ruiz, Habib, "Hydrogel tracer beads as potential proxies for non-aqueous phase liquids in karst: Development of an optical quantification method for fluorescent beads" (2015). Graduate Theses, Dissertations, and Problem Reports. 5256.

https://researchrepository.wvu.edu/etd/5256

This Thesis is protected by copyright and/or related rights. It has been brought to you by the The Research Repository @ WVU with permission from the rights-holder(s). You are free to use this Thesis in any way that is permitted by the copyright and related rights legislation that applies to your use. For other uses you must obtain permission from the rights-holder(s) directly, unless additional rights are indicated by a Creative Commons license in the record and/ or on the work itself. This Thesis has been accepted for inclusion in WVU Graduate Theses, Dissertations, and Problem Reports collection by an authorized administrator of The Research Repository @ WVU. For more information, please contact researchrepository@mail.wvu.edu. 
Hydrogel tracer beads as potential proxies for non-aqueous phase liquids in karst: Development of an optical quantification method for fluorescent beads

\title{
Habib Bravo-Ruiz
}

\author{
Thesis submitted to the \\ Eberly College of Arts and Sciences \\ at West Virginia University \\ in partial fulfillment of the requirements for the degree of \\ Master of Science in \\ Geology
}

\author{
Dorothy J. Vesper, Ph.D., Chair \\ Joseph J. Donovan, Ph.D. \\ Harry Edenborn, Ph.D. \\ Nicolas Zegre, Ph.D. \\ Department of Geology and Geography
}

Morgantown, West Virginia

2015

Keywords: non-aqueous phase liquid, NAPL, fate, transport, karst

Copyright 2014 Habib Bravo-Ruiz 


\begin{abstract}
Hydrogel tracer beads as potential proxies for non-aqueous phase liquids in karst: Development of an optical quantification method for fluorescent beads
\end{abstract}

\author{
Habib Bravo-Ruiz
}

Sinkholes and sinking streams are examples of karst features that can serve as direct pathways for contaminants, including non-aqueous phase liquids (NAPLs), to quickly enter karst aquifers. Once NAPLs are in karst aquifers, their fate and transport is difficult to predict and is not well understood. In this study, floating hydrogel tracer beads (HTBs) are developed and tested to help gain a better understanding of the fate and transport of NAPLs. The HTBs are formed by cross-linked sodium alginate polymers that can be made with different fluorescent pigments and density-modifying additives. The focus of this research was on the development and testing of an optical method for quantifying HTB transport. This optical quantification method records the transport of fluorescent HTBs as they move under an apparatus holding ultraviolet lights and a camera. HTBs transport is video recorded and then quantified using an image analysis algorithm. The method was validated in tracer tests of short duration at the Experimental Stream Facility in Milford, $\mathrm{OH}$ and applied in tracer tests of long duration at Buckeye Creek Cave, WV. The results of these tests agreed well, but suggest that the optical quantification method is better suited for tracer tests of short duration in controlled environments.

Comparative tracer tests using sodium chloride and buoyant HTBs were conducted at both sites when the optical quantification method was being tested. In the Experimental Stream Facility tests, the buoyant HTBs traveled at a higher velocity and lower mean transit time than did the sodium chloride. The faster travel time for the particle tracers agreed with what is reported in the literature. In contrast, in the Buckeye Creek Cave tests, which were conducted under low-flow conditions, the buoyant HTBs traveled at a lower velocity and a higher mean transit time than did the sodium chloride. These findings suggest that the relative transport of particle and solute tracers may vary with hydraulic conditions. 


\section{Acknowledgements}

I would like to thank every person that helped throughout the completion of this research. It is needless to say that without their help, the completion of this project would not have been possible. In particular, I would like to thank my adviser, Dr. Dorothy Vesper for her patience and guidance towards me. My committee members: Drs. Joseph Donovan, Nicolas Zegre and Harry Edenborn for their input and expertise. My past and present lab mates: Jill Riddell, Kendi Waltemyer, John Tudek and Amanda Laskoskie for their help in the field and/or laboratory. And last, but not least, my wonderful wife and family for their encouragement throughout this process.

A special thanks to Donald Brown, Balaji Ramakrishnan and Christopher Nietch from the US Environmental Protection Agency for allowing me to work in the Experimental Stream Facility and for their advice and technical support.

This work was supported through and award (\# P42ES017198) from the National Institute of Environmental Health Sciences to the PROTECT research project. The content is solely the responsibility of the authors and does not necessarily represent the official views or policies of the National Institute of Environmental Health Sciences, or the US Environmental Protection Agency. 


\section{Table of Contents}

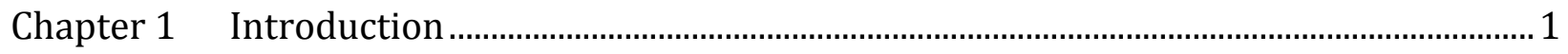

1.1 Statement of purpose

Chapter 2 Background .....................................................................................................

2.1 Fate and transport of NAPLs in karst: Examples of case studies ................................... 4

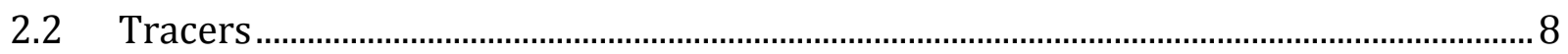

2.2.1 Solute tracers........................................................................................................

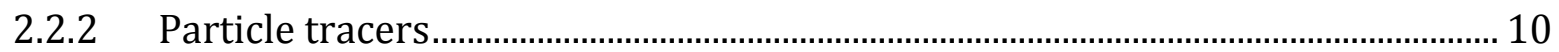

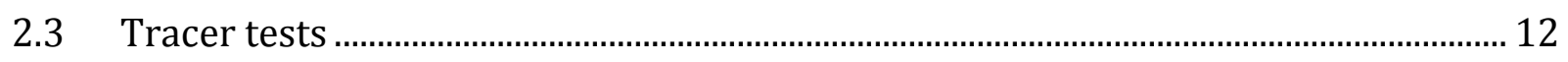

2.4 Optical methods for HTB detection ………………………………………………..... 13

2.5 Purpose and objectives ............................................................................................... 15

Chapter 3 Materials and methods ……………………....................................................... 16

3.1 Materials used as tracers ................................................................................................... 16

3.2 Overview of optical quantification method ...................................................................... 16

3.2.1 Setup of the experimental system ……….............................................................. 19

3.2.2 Image processing ................................................................................................. 21

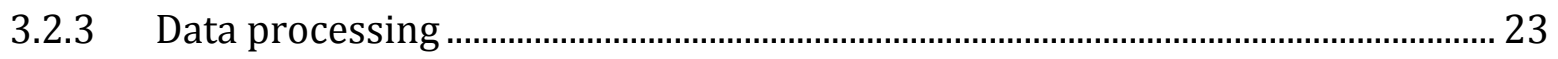

3.2.4 Calculation of transport parameters …………...................................................... 25

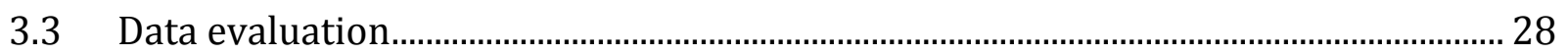

3.4 Research sites ......................................................................................................... 29

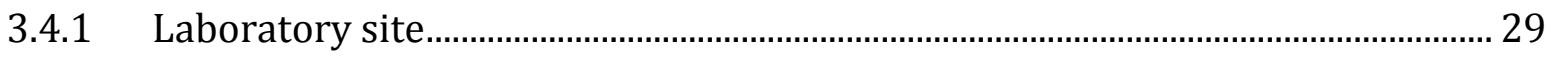

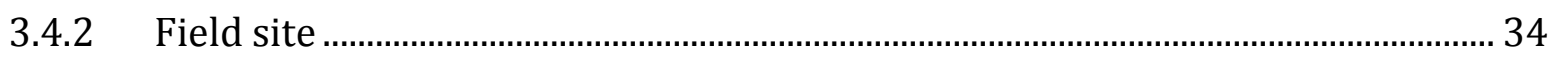

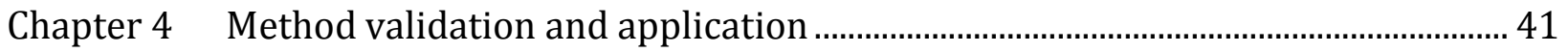

$4.1 \quad$ Experimental design...................................................................................................... 41

4.2 Laboratory experiments in the Experimental Stream Facility .................................... 44

4.2.1 Results from the optical quantification method ...................................................... 44

4.2.2 Precision of the optical detection method ............................................................... 46

4.2.3 Comparison of bead and solute tracers in the Experimental Stream Facility.. 59

4.3 Field experiments in Buckeye Creek Cave........................................................................... 65

4.3.1 Applicability of the optical quantification method ................................................. 65

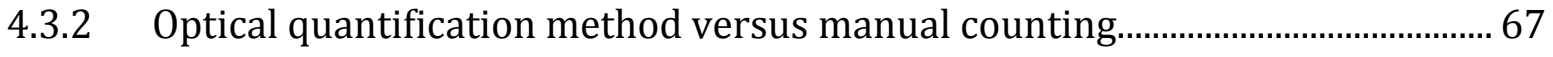


4.3.3 Comparison of bead and solute tracers in the field ............................................... 76

Chapter 5 Discussion......................................................................................................... 78

5.1 Optical quantification method for the transport of HTBs............................................ 78

5.1.1 Method evaluation................................................................................................. 78

5.1.2 Optical quantification method versus manual counting......................................... 82

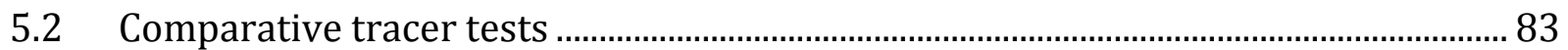

5.2.1 Comparative tracer tests with HTBs ……………………………………………….. 83

5.2.2 Comparative tracer tests with other particle tracers ............................................. 85

Chapter 6 Conclusions ......................................................................................................... 89

6.1 Optical quantification method for the transport of HTBs............................................ 89

6.2 Comparative tracer tests .............................................................................................. 90

Chapter $7 \quad$ Future work ……………………………………………………………………... 92

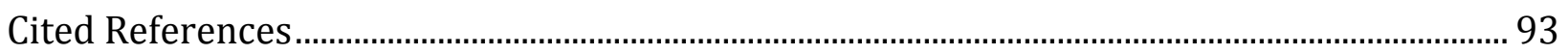

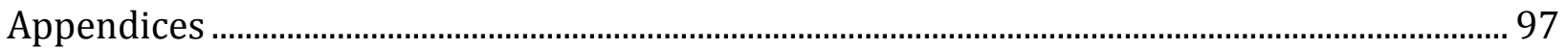

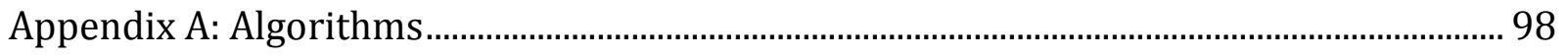

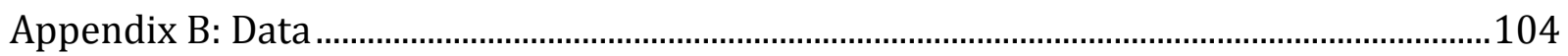

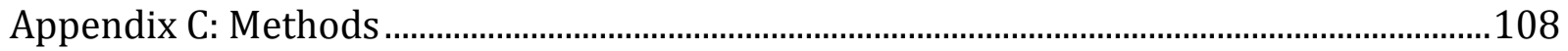




\section{List of Figures}

Figure 1: Schematic illustration of the fate and transport of LNAPLs (green) and DNAPLs (orange) in karst aquifers. Modified from Vesper (2008).

Figure 2: Excitation and emission wavelengths of the fluorescent pigments used to make the HTBs. This data was obtained from solutions in which $10 \mathrm{~g}$ of the pigments were partially dissolved in $0.05 \mathrm{~mL}$ of glycerol. These solutions were analyzed in a Fluorolog-3 Spectrofluorometer (Horiba Scientific, Irvine, CA).................................................................... 17

Figure 3: Experimental design of the optical quantification method. Step 4b is an optional

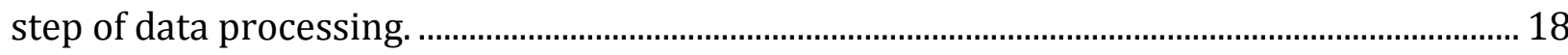

Figure 4: Schematic illustration of the setup for optical quantification method. .................... 20

Figure 5: Particle distortion at (a) $30 \mathrm{fps}$, (b) $60 \mathrm{fps}$, and (c) $120 \mathrm{fps}$ for tracer tests conducted at a flow rate of $1.9 \mathrm{~L} / \mathrm{s}$ In the Experimental Stream Facility. Flow direction is to

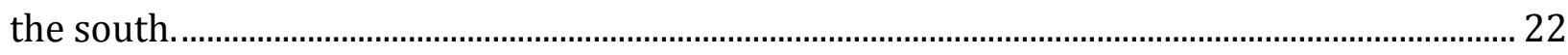

Figure 6: Image analysis process: (a) original image, (b) enhanced image, (c) red channel, (d) green channel, and (e) blue channel.

Figure 7: Relationship between specific conductivity and sodium chloride ( $\mathrm{NaCl}$ ) concentration in solutions at $25^{\circ} \mathrm{C}$. Graph made with data from OAKTOWN Instruments (1997)

Figure 8: Setup in the (a) tile section and (b) and gravel section of a flume in the Experimental Stream Facility

Figure 9: (a) Oblique- and (b) side-view of the experimental system setup in the Experimental Stream Facility 33

Figure 10: Map of field research site. 37

Figure 11: Stratigraphy of the field research site - The Greenbrier series. Modified from Dasher and Balfour (1994). 38

Figure 12: Canyon section in Buckeye Creek Cave. The width of this section is approximately 1 meter (Photo taken by Ellen Herman).

Figure 13: Setup of the experimental system in Buckeye Creek Cave. 40

Figure 14: Experimental design for tests conducted in the Experimental Stream Facility and Buckeye Creek Cave. The low flow tests in the Experimental Stream Facility were conducted with HTBs of different color (see Table 2).. 42

Figure 15: Example results from test \#2 showing that the normalized pixel intensity data of the red color channel is almost equal to that of the green color channel. 49 
Figure 16: Breakthrough curves from selected tests conducted at (a) the low and (b) the high flow rate with the HTBs. These breakthrough curves are of from the mean pixel intensity results of the red channel.

Figure 17: Breakthrough curves from tests \#22 and \#28 - Comparing results from the red color channel to the green color channel..................................................................................... 51

Figure 18: Example breakthrough curves of a tests (a) \#19 and (b) \#29 - Comparing the transport of the HTBs to the solute tracer. 63

Figure 19: Normalized results of the tests conducted in Buckeye Creek Cave. Plot (a) is from test \# 1 and plot (b) is from test \#2............................................................................................... 69

Figure 20: Results of the optical method for test \#1 in Buckeye Creek Cave after the normalized data was interpolated, and then smoothed with (a) 50, 100, (b) 150, and 200 points.

Figure 21: Raw and interpolated manual counting results for (a) test \#1 and (b) test \#2 in Buckeye Creek Cave. .

Figure 22: BTCs for Buckeye Creek Cave test (a) \#1 and (b) \#2 including data from optical method and manual counting of HBTs.

Figure 23: BTCs for Buckeye Creek tests (a) \#1 and (b) \#2 including data from the solute tracer and the optical method.

Figure 24: Ultraviolet light reflection of the water surface is present in (a) enhanced images and (b) red color channel image, but not in (c) green color channel images of test \#22 in the Experimental Stream Facility. 81 


\section{List of Tables}

Table 1: Summary of other solute and particulate tracers.

Table 2: Description of tracer tests conducted in the Experimental Stream Facility during the $12^{\text {th }}$ and $13^{\text {th }}$ of March, 2014. Tests $1-21$ were conducted at a lower flow rate $(1.9 \mathrm{~L} / \mathrm{s})$, whereas tests 22-30 were conducted at a higher flow rate $(3.2 \mathrm{~L} / \mathrm{s})$.

Table 3: Results of the HTB traces as calculated by QTRACER2 for experiments conducted at the lower flow rate $(1.9 \mathrm{~L} / \mathrm{s})$ in the Experimental Stream Facility.

Table 4: Results of HTB traces as calculated by QTRACER2 for experiments conducted at the higher flow rate $(3.2 \mathrm{~L} / \mathrm{s})$ in the Experimental Stream Facility.

Table 5: Percent recovery of HTBs for tracer tests conducted in the Experimental Stream Facility. Tests 1-20 were conducted at the lower flow rate $(1.9 \mathrm{~L} / \mathrm{s})$, whereas tests $22-30$ were conducted at the higher flow rate $(3.2 \mathrm{~L} / \mathrm{s})$.

Table 6: Results of ANOVA on the transport parameters obtained from the tracer tests conducted at the lower flow rate in the Experimental Stream Facility.

Table 7: Results of ANOVA on the transport parameters obtained from the tracer tests conducted at the higher flow rate in the Experimental Stream Facility.

Table 8: Results of tests 22 and 28 as calculated by QTRACER2 from BTCs made with data from the red and green color channels. Absolute percent difference between the results of the red and green color channels is also shown.

Table 9: Results of ANOVA on mean travel velocity and mean transit time after analyzing the BTCs of the green channel for tests 22 and 28 in QTRACER2............................................... 58

Table 10: Results of the solute traces as calculated by QTRACER2 for experiments conducted at the lower flow rate $(1.9 \mathrm{~L} / \mathrm{s})$ in the Experimental Stream Facility.

Table 11: Results of the solute traces as calculated by QTRACER2 for experiments conducted at the higher flow rate $(3.2 \mathrm{~L} / \mathrm{s})$ in the Experimental Stream Facility.

Table 12: Mean results from QTRACER2 for the tracer tests conducted with HTBs and solutes at the low- and high-flow rates in the Experimental Stream Facility. The absolute \% difference between the tracers each shown for each of the transport parameters. 64

Table 13: QTRACER2 results from the analysis of BTCs generated with different quantities of central points for the tests conducted in Buckeye Creek Cave.

Table 14: Parameters as calculated by QTRACER2 for the tracer tests conducted in Buckeye Creek Cave.

Table 15: Absolute percent difference between and within the results of the optical and manual methods as well as within the results of the solute traces in Buckeye Creek Cave. 75 


\section{Acronyms and abbreviations}

NAPL - non-aqueous phase liquid

DNAPL - dense non-aqueous phase liquid

LNAPL - light non-aqueous phase liquid

UV - ultraviolet

HTBs - hydrogel tracer beads

PIV - particle image velocimetry

PTV - particle tracking velocimetry

BTC - breakthrough curve

ANOVA - analysis of variance 


\section{Chapter 1 Introduction}

\subsection{Statement of purpose}

Karst aquifers, formed by the dissolution of carbonate rocks such as limestone or dolomite, are important groundwater resources in many regions of the world. However, they are highly vulnerable to contamination because of surface features (e.g. thin soils, sinking streams, and sinkholes) that may be directly connected to the aquifer and thereby limit the possibility of filtration, degradation, and sorption of contaminants (Ewers et al., 1991; Uhlman and Barner, 1996). Once contaminants get into the aquifer, their fate and transport may be complicated to predict because karst aquifers are highly heterogeneous subsurface systems, often characterized by networks of interconnected fissures, fractures, and conduits (Ford and Williams, 2007). Fate and transport predictions may be even more complicated to make if there is a poor understanding on the transport behavior of the contaminants, such as there is with non-aqueous phase liquids (NAPLs) (e.g. Ewers et al., 1991; Crawford and Ulmer, 1994; Stephenson et al., 2004).

NAPLs are liquids that exist as a separate and slightly soluble phase when in contact with water. Their movement is mostly governed by the viscosity and density of the organic compounds that form the NAPL (Mackay et al., 1985). The viscosity of an NAPL influences its resistance to flow. The density of an NAPL determines if it floats on or sinks through water. NAPLs that float on the water surface, such as those formed by gasoline, diesel, and benzene, are termed light NAPLs (LNAPLs), whereas NAPLs that sink through the water column, such as those formed by tetrachloroethene, trichloroethene, and halogenated alkenes, are termed dense NAPLs (DNAPLs). 
Tracers are matter or energy carried by water which can be used to gain a better understanding on the transport of NAPLs. Since density plays a critical role on the movement of NAPLs, the transport of commonly used dissolved tracers such as fluorescent dyes and salts or non-dissolved tracers such as microspheres is not applicable to that of NAPLs. Therefore, in order to better predict the behavior of NAPLs, Laskoskie (2013) developed a particle tracer named hydrogel tracer beads (HTBs). These are millimetersized particles formed by cross-linked sodium alginate polymers that can be made with different fluorescent pigments and density-modifying additives.

Qualitative tests have been conducted with buoyant and non-buoyant HTBs (Laskoskie, 2013). In those tests the buoyant HTBs were transported quickly on the water surface, whereas non-buoyant HTBs sank close to their release point, which suggests that the transport of HTBs is partly controlled by density. However, more tests need to be conducted in order to determine if HTBs move similarly to NAPLs. The problem is that there is no automated method for quantitative data collection to conduct these tracer tests. Therefore, the objective of the present study was to develop an automated method that collects quantitative data of the HTBs during tracer tests.

Particle image velocimetry (PIV) and particle tracking velocimetry (PTV) are optical methods that have been widely used to obtain flow velocity measurements in rivers and streams (e.g. Fujita et al., 1998; Kim et al., 2008; Tang et al., 2008). The experimental procedure for these two optical methods is very similar. It consists of releasing particle tracers upstream from an optical device (e.g. camera) that acquires image sequences of the water surface as the particle tracers flow by. The image sequences are then analyzed with a 
image analysis algorithm that calculates the displacement of the particles in each successive image in order to obtain determine flow velocity (Adrian, 2005; Raffel et al., 2007). The main drawback of PIV and PTV is that the accuracy of the flow velocity measurements can be affected by insufficient illumination (Raffel et al., 2007). In order to account for insufficient illumination, Tauro et al. (2012c) developed a PIV system that uses ultraviolet (UV) lights to excite fluorescent particles. The UV lights made the fluorescent particles visible as they moved by the field of view of the optical device. Since HBTs can be made with fluorescent pigments, an optical method similar to the one developed by Tauro et al. (2012c) could be used to detect the transport of HTBs. However, to quantify the transport of the HTBs, an image analysis algorithm has to be developed. 


\section{Chapter 2 Background}

\subsection{Fate and transport of NAPLs in karst: Examples of case studies}

In karst terrains, NAPLs can move into the subsurface indirectly through thin soils or directly through sinkholes and swallow holes. Once they get into the subsurface, various trapping mechanisms may store the NAPLs for long periods of time (Figure 1, Crawford and Ulmer, 1994; Stephenson et al., 2004). For example NAPLs that seep through the soil zone may adsorb onto soil grains or become trapped in between pore spaces, whereas NAPLs that move through karst conduits will be transported according to their density. In partially submerged conduits, LNAPLs will flow with groundwater and may become temporarily trapped when water ponds (Vesper et al., 2003), but DNAPLs will not necessarily flow with groundwater. Instead, they will continue to move vertically through water column and may become trapped in pores, fractures, solution cavities, and sediment in the base of the conduit (Loop and White, 2001). In completely submerged conduits the movement of NAPLs can be different than in partially submerged conduits. For example, LNAPLs can be lifted and pressed against ceiling, where they can get trapped in or forced through obstructions in the ceiling (Ewers et al., 1991; Vesper et al., 2003), while DNAPLs will be dragged along the base of the conduit in sediment piles or become entrained and transported in suspension (Loop and White, 2001; Vesper et al., 2003).

Various case-studies highlight the difficulty of tracking NAPL contaminants in karst. On Interstate 65 near Park City, Kentucky, a tanker truck carrying 3,700 gallons of diesel fuel (LNAPL) spilled adjacent to Parker Cave, in the up-gradient portion of the Tumhole Spring groundwater basin (Stephenson et al., 2004). To delineate subsurface karst features 


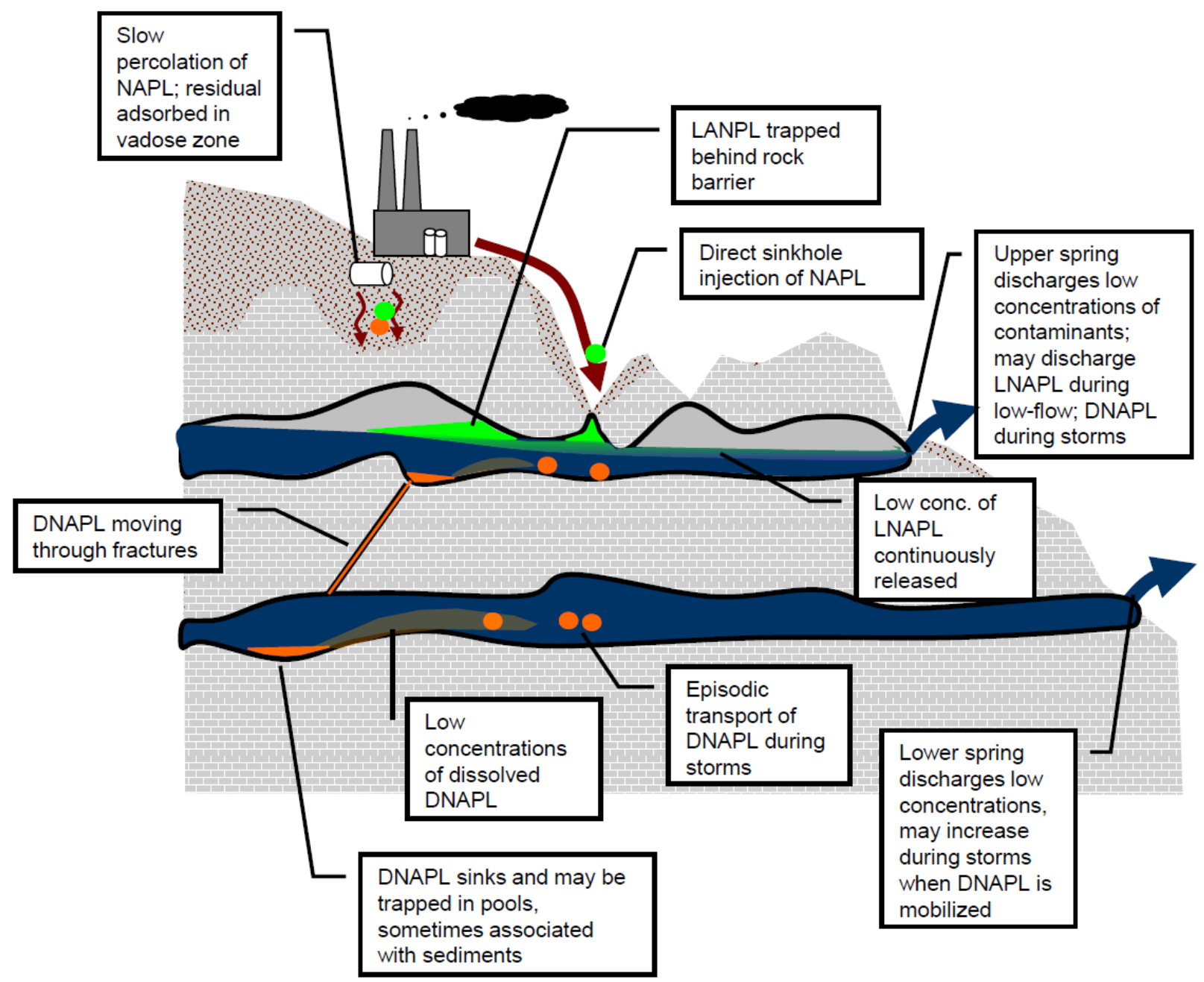

Figure 1: Schematic illustration of the fate and transport of LNAPLs (green) and DNAPLs (orange) in karst aquifers. Modified from Vesper (2008). 
capable of storing or transporting diesel fuel, the researchers conducted four types of geophysical surveys: electromagnetic conductivity, electrical resistivity imaging, spontaneous potential, and microgravity. They also drilled exploratory wells to observe the conditions in the subsurface and conducted multiple dye tracer tests to estimate how much time it would have taken the diesel to travel from the Parker Cave to a known connection, Mill Hole Spring. The dye traces took between 2 to 42 hours to travel from the cave to the spring. Visual, odor and water analysis results revealed that no diesel product was present in the exploratory wells or in Mill Hole Spring, but the difference in time between when the spill occurred and when sampling began was not given. The researchers concluded that the diesel product remained localized to soils around the spill area, but the diesel could have also been trapped in the conduit leading to the spring.

Near Lewisburg, Tennessee, a train carrying 15,000 gallons of chloroform (DNAPL) and 4,000 gallons of styrene (LNAPL) derailed, resulting in the release of these compounds into an underlying karst aquifer (Crawford and Ulmer, 1994). The possible flow routes of the compounds were determined with dye traces, which were conducted both in the lowand high-flow periods to account for temporal variability in discharge rates. The researchers found that the tracers flowed to one spring during the low-flow period and 3 springs during the high-flow period. They also drilled exploratory wells near the derailment site, which revealed that chloroform was moving down-dip along weathered bedding planes instead of in the direction of groundwater flow. The chloroform eventually became trapped when the beddings planes became less weathered and recovery wells were drilled to extract it. It was later discovered that a small amount of both compounds 
also moved vertically through an uncased well to an underlying confined aquifer, which the authors attributed to a downward vertical gradient.

During the train derailment investigation near Lewisburg, Tennessee, three wells were found to be contaminated with trichloroethylene (DNAPL) (Crawford and Ulmer, 1994). In order to determine the source of TCE, the researchers conducted dye traces from various potential sources within a $5 \mathrm{~km}$ area. The dye traces revealed that the likely source of contamination for one of the wells was a manufacturing facility, which had spilled approximately 4,000 gallons of TCE in the past. However, the dye traces did not revealed what the source of TCE was in the two other wells. Similar to the train derailment case, the researchers concluded that the TCE found in these two wells might have had migrated vertically through uncased wells from an underlying confined aquifer.

In the Campbell Army Airfield, located in Christian County, Kentucky, spilled jet fuel (LNAPL) moved through a sinkhole into a karst aquifer, forming a $4.9 \mathrm{~m}$ free-phase pool that was detected by monitoring wells (Ewers et al., 1991). Dye traces revealed that the sinkhole was connected to Quarles Spring, but repeated sampling at the spring failed to confirm the presence of dissolved jet fuel. The researchers concluded that the jet fuel remained trapped and immobile in the epikarst.

In another case-study, a leaky underground storage tank released gasoline (LNAPL) into a karst aquifer in Richmond, Kentucky (Ewers et al., 1991). Dye traces revealed that the tank was connected to Tennis Court Spring and to Little Caesar Spring. Both springs were sampled during low- and high-flow periods. However, gasoline was only found in the Tennis Court Spring. The researchers concluded that the gasoline was free to move 
towards Tennis Court Spring, but not towards Little Caesar Spring because the conduit leading to it was submerged and able to trap LNAPL.

These case-studies highlight how difficult it is to track or predict the fate and transport of NAPLs in karst aquifers. However, since NAPLs are used in large quantities by many industries around the world, it is important that an effort is made to study their fate and transport. This may be done by conducting experiments with tracers that better mimic NAPL behavior.

\subsection{Tracers}

Tracers can be used to obtain information on hydraulic conditions or to quantify hydraulic parameters of a system (Davis et al., 1980). They are classified by their physical nature (soluble versus particle) or by their transport behavior (conservative versus reactive) (Käss et al., 1998). Conservative tracers do not interact chemically or physically with the system they are in and follow water movement. In contrast, reactive tracers can interact chemically or physically with the system they are in, thus their transport can be retarded or enhanced relative to the water in the system.

\subsubsection{Solute tracers}

Solute tracers are fully dissolved in water. They can be used to study the transport of dissolved contaminants (Goldscheider et al., 2008) such as water-soluble organic and inorganic compounds. Examples of solute tracers include salts, dyes, stable isotopes, radioactive isotopes, gases, and aromas. 
Salts (e.g. potassium bromide and sodium chloride) are substance the entirely ionize when dissolved in water, resulting in an increase in electrical conductivity, which is a measure of a material's ability to conduct an electric current (Ford and Williams, 2007). This increase in electrical conductivity can be measured by electrodes in order to determine the presence of the salt tracer. The use of salt tracers can be affected by natural background concentrations of salts (Davis et al., 1980; Käss et al., 1998). If natural background concentrations are high, a high concentration of the salt tracer has to be used, which can be harmful to the ecology of the water system (Käss et al., 1998). Other problems with salt tracers include absorption or ion exchange from interactions with aquifer solids, which can retard the movement of the salt tracer relative to the movement of water (Goldscheider et al., 2008).

Fluorescent dyes are organic compounds that absorb light energy at specific wavelengths and re-emit it at longer wavelengths (Goldscheider et al., 2008). These organic compounds are considered practical and convenient groundwater tracers due to their low to negligible toxicities, low detection limits, low purchase costs, relatively conservative behaviors, and low cost of analysis (Field, 2002). However, problems can sometimes arise when fluorescent dyes are used in tracer tests. Depending on their properties, dyes and their fluorescence intensity can be affected by changes in $\mathrm{pH}$, decomposition by sunlight and natural organic matter, temperature fluctuations, or absorption onto solid surfaces (Smart and Laidlaw, 1977; Davis et al., 1980). These problems can affect how much dye is recovered and can eventually lead to incorrectly calculated results in a quantitative tracer test (Field, 2002). 
Other solute tracers include stable and radioactive isotopes, surfactants, aromas, and gases (Table 1). The use of stable isotopes (e.g. ${ }^{2} \mathrm{H}$ ) as tracers is becoming more common. However, sample analysis can increase experiment cost. Radioactive isotopes (e.g. ${ }^{3} \mathrm{H}$ ) can be toxic at high concentrations. Therefore, they are not used as frequently as other types of soluble tracers. Surfactants and aromas (e.g. polyaromtatic sulfonates) can be highly toxic as well. Additionally, they can breakdown through time. The use of gases (e.g. $\mathrm{SF}_{6}$ ) as tracers is limited by natural background concentrations (Käss et al., 1998).

\subsubsection{Particle tracers}

Particle tracers do not dissolve in water. Their presence can be determined visually and/or by analytical instruments. These tracers can be used to study the transport of nondissolved contaminants such as pathogenic bacteria (Goldscheider et al., 2008). Examples of particle tracers include spores, microspheres, modified clays, and other drift particles.

Buoyant spores from the club moss (Lycopodium) have been used as drift-particle tracers in karst regions (Käss et al., 1998). The diameter of the spores ranges from 26 to 39 $\mu \mathrm{m}$. The Lycopodium spores are environmentally safe, since they are a natural product, and extremely resistant to chemical and microbiological influences because of a protective outer layer. In addition, they can be dyed with fluorescent or non-fluorescent pigments to facilitate in detection (Käss et al., 1998). However, the problem of using Lycopodium spores in tracer tests is their collection, thus they are not used for quantitative tracer tests.

Microspheres are microscopically-small synthetic particles that exist in a variety of sizes, surface charges and fluorescent colors, which allows for various tracing options (Goldscheider et al., 2008). Microspheres have been used to study the transport of 
Table 1: Summary of other solute and particulate tracers.

\begin{tabular}{|c|c|c|c|}
\hline Type & Tracer & Example & General problems \\
\hline \multirow{3}{*}{ Solute } & $\begin{array}{l}\text { Surfactants } \\
\text { and aromas }\end{array}$ & $\begin{array}{l}\text { Surfactant: } \\
\text { Alkyl benzene } \\
\text { sulfonates } \\
\text { Aroma: Limonene }\end{array}$ & $\begin{array}{l}\text { a) Toxic at high } \\
\text { concentrations } \\
\text { b) May breakdown over } \\
\text { time }\end{array}$ \\
\hline & $\begin{array}{l}\text { Stable and } \\
\text { radioactive isotopes }\end{array}$ & $\begin{array}{l}\text { Stable: }{ }^{2} \mathrm{H},{ }^{13} \mathrm{C},{ }^{15} \mathrm{~N} \\
\text { Radioactive: }{ }^{3} \mathrm{H}\end{array}$ & $\begin{array}{l}\text { a) Radioactive isotopes are } \\
\text { hazardous at high } \\
\text { concentrations }\end{array}$ \\
\hline & Gases & Sulfur hexafluoride & $\begin{array}{l}\text { a) Natural background } \\
\text { levels }\end{array}$ \\
\hline \multirow{4}{*}{ Particulate } & $\begin{array}{l}\text { Club moss } \\
\text { spores }\end{array}$ & Lycopodium & $\begin{array}{l}\text { a) Sample collection is } \\
\text { complicated }\end{array}$ \\
\hline & Bacteria & S. marcescens, E. coli & $\begin{array}{l}\text { a) Sample collection and } \\
\text { analysis are complicated } \\
\text { b) Toxicological concerns }\end{array}$ \\
\hline & Bacteriophages & $\begin{array}{l}\text { H40/1, phages of } S . \\
\text { marcescens and } E . \\
\text { coli }\end{array}$ & $\begin{array}{l}\text { a) Sample collection and } \\
\text { analysis are complicated }\end{array}$ \\
\hline & Clays & $\begin{array}{l}\text { DNA- and } \\
\text { lanthanide-labeled } \\
\text { clays }\end{array}$ & $\begin{array}{l}\text { a) Gravitational settling } \\
\text { under low flow conditions } \\
\text { b) Unstable in carbonate } \\
\text { waters }\end{array}$ \\
\hline
\end{tabular}

Data compiled from Davis et al. (1980) and Käss et al. (1998). 
pathogenic bacteria because of they are similar in size to microbes, non-toxic, less costly and easier to apply and subsequently detect than other particulate tracers used for the same purpose (Käss et al., 1998). Microspheres have been successfully used in karst systems to investigate colloid transport under low and high-flows (Göppert and Goldscheider, 2008), microbial flow to wells (Harvey et al., 2008), microbial mobility in the subsurface (Sinreich et al., 2009), and to identify recharge zones from which microbes can be transported to springs (Auckenthaler et al., 2002).

Hydrogel beads are millimeter-sized particles that can be formed by cross-linked polymers such as alginate, agarose and chitosan. They are generally used for drug entrapment and delivery applications because they can hold a significant volume of liquid (Bajpai and Sharma, 2004), but they have also been developed and tested as tracers by Laskoskie (2013). HTBs are easily-made made in the laboratory at a relatively low cost. They can be made with different fluorescent pigments that aid in detection and with different density modifying additives that help to match to different types of NAPLs.

Other particle tracers include clays (Mähler et al., 1998a; Mähler et al., 1998b) bacteria (Harvey et al., 2008), and bacteriophages (Auckenthaler et al., 2002; Sinreich et al., 2009) (Table 1). Tracer tests with bacteria and bacteriophages are difficult because samples must be analyzed within a 24 hour period (Käss et al., 1998). There are also toxicological concerns with some of the bacterial tracers (e.g. Serratia marcescens).

\subsection{Tracer tests}

Tests with tracers can be qualitative or quantitative. Qualitative tracer tests are based on observation. They are usually conducted before quantitative tests in order to identity 
connections between recharge and discharge points (Mull et al., 1988). Quantitative tracer tests are more detailed and require data collection. The data collected from quantitative tracer tests can be analyzed with software packages like QTRACER2, which was developed by the US Environmental Protection Agency (Field, 2002). QTRACER2 analyzes the area below breakthrough curves (BTCs), which are curves that show how the concentration of the tracer changes through time. By determining the area below BTC and using a series of equations, QTRACER2 can yield numerical information on the physical properties of the water system such as transport zone volume and surface area as well as the transport parameters of the tracer such as transit time, mean velocity, and longitudinal dispersion.

Quantitative tracer tests need to be conducted to determine if HTBs are really transported similarly to NAPLs. In order to complete these tests in an efficient manner, an optical method can be used to detect and quantify the transport of buoyant and fluorescent HTBs.

\subsection{Optical methods for HTB detection}

PIV and PTV are optical methods used to obtain velocity measurements of whole flow fields instantaneously and non-intrusively (e.g. not altering natural flow) (Adrian, 2005; Raffel et al., 2007). The experimental procedure for these optical methods is very similar. It consists of releasing particle tracers upstream from an optical device (e.g. camera) that acquires image sequences of the water surface as the particle tracers flow by. However, the setup of the system used to detect the movement of the particle tracers varies by researcher (e.g. Fujita et al., 1998; Muste et al., 2008; Tauro et al., 2012a). It typically consists of (a) a light source, used to illuminate the particles intermittently, (b) an 
arrangement of optical lenses, used to limit the physical region illuminated, and (c) one, two, or three cameras, used to capture the movement of natural of artificial tracer particles released into the flow field in one-, two-, or three dimensions, respectively (Raffel et al., 2007)

PIV and PTV systems have been used to measure discharge in streams of various sizes. For example, Fujita et al. (1998) developed a PIV system that can measure discharge in large perennial streams. This system uses natural light instead of a light source and it is setup along stream banks. The camera is mounted high and inclined in order to cover a large portion of the water surface ( 4 to $45,000 \mathrm{~m}^{2}$ ). On the other hand, Tauro et al. (2012a) developed a fluorescence-based PIV system than can measure the runoff discharge in hill slopes of densely forested areas. This PIV system covers less water surface area $\left(1 \mathrm{~m}^{2}\right)$ than the LSPIV system because it the camera is setup directly above and parallel to the stream surface. However, it excels in areas where there is insufficient illumination because it uses an UV light to excite fluorescent particle tracers such as HTBs.

The effect of certain factors, such height of the camera from the water surface, presence of wavelength limiting filters, and camera resolutions and acquisition rates, on the detection of fluorescent particles has been investigated by Tauro et al. (2012b). The height of the camera from the water surface has an effect on the field of view of the camera and the size of the particles in an image. If a camera is set at a short distance from the water surface, its field of view would be smaller, and the size of the particles in an image would appear larger than if the camera is set at greater distances from the water surface. Wavelength limiting filters have an effect on the range of light spectrum that can be 
detected by the camera. Thus, they can be useful for filtering undesired light reflected on the water surface (e.g. UV light). The camera resolution and acquisition rate has an effect on image quality. High resolutions and acquisition rates result in better quality images and in more data to process than lower resolutions and acquisition rates. For tests in dark environments, as those planned in this research, Tauro et al. (2012b) suggested the following configuration: (a) a camera height of 40 to $70 \mathrm{~cm}$ from the water surface, (b) no wavelength filter, and (c) a camera with a 1080 pixel resolution and an acquisition rate of 30 frames per second (fps).

\subsection{Purpose and objectives}

The goal of the present research was to design and test an optical method that quantifies the transport of buoyant and fluorescent HTBs automatically or semiautomatically. The specific research objectives that were addressed include:

1) To write an image analysis algorithm that quantifies the transport of buoyant and fluorescent HTBS

2) To test the optical quantification method in the laboratory and apply it in the field

3) To compare results from the optical quantification method to the manual collection and counting of HTBs in order to determine the relative effectiveness of the two approaches

4) To evaluate and compare the transport behavior of buoyant HTBs with a solute tracer 


\section{Chapter 3 Materials and methods}

\subsection{Materials used as tracers}

For this study, only buoyant HTBs were used. These were made using the procedure described in Laskoskie (2013). The solution used to make the HTBs consisted of $3 \mathrm{~g}$ sodium alginate (Sigma Aldrich, St. Louis, M0) per $100 \mathrm{~g}$ of water, and $1 \mathrm{~g}$ of fluorescent pigment (Risk Reactor Inc., Santa Ana, CA) as well as $1 \mathrm{~g}$ of glass bubbles (3M, St. Paul, MN) per 100 g of sodium alginate solution. The HTBs were made with three different fluorescent pigments. These are yellow, pink, tropical orange. Each of the pigments has an excitation and emission maximum (Figure2). In each tracer test, the pigments were excited with a $395 \mathrm{~nm}$ wavelength UV light source. For this study, it was assumed that the three pigments have equal density.

In each test, the HTBs were released together with a salt tracer. The salt traces were conducted following the guideline by Moore (2005), which is $1 \mathrm{~L}$ of a $15-20 \%$ salt solution per $\mathrm{m}^{3} / \mathrm{s}$. In this study, the salt used as tracer was $\mathrm{NaCl}$ (Thermo Fisher Scientific Inc., Waltham, MA). In order to account for natural background concentrations, the $\mathrm{NaCl}$ solutions were prepared by dissolving the salt in $1000 \mathrm{~mL}$ of water from the system being traced. A calibrated YSI 556 Multiprobe System (YSI Inc., Yellow Springs, OH) was used to measure changes in electrical conductivity and temperature.

\subsection{Overview of optical quantification method}

The optical quantification method developed in the present study consists of five steps (Figure 3). The first step is the excitation of the fluorescent HBTs. This step was 

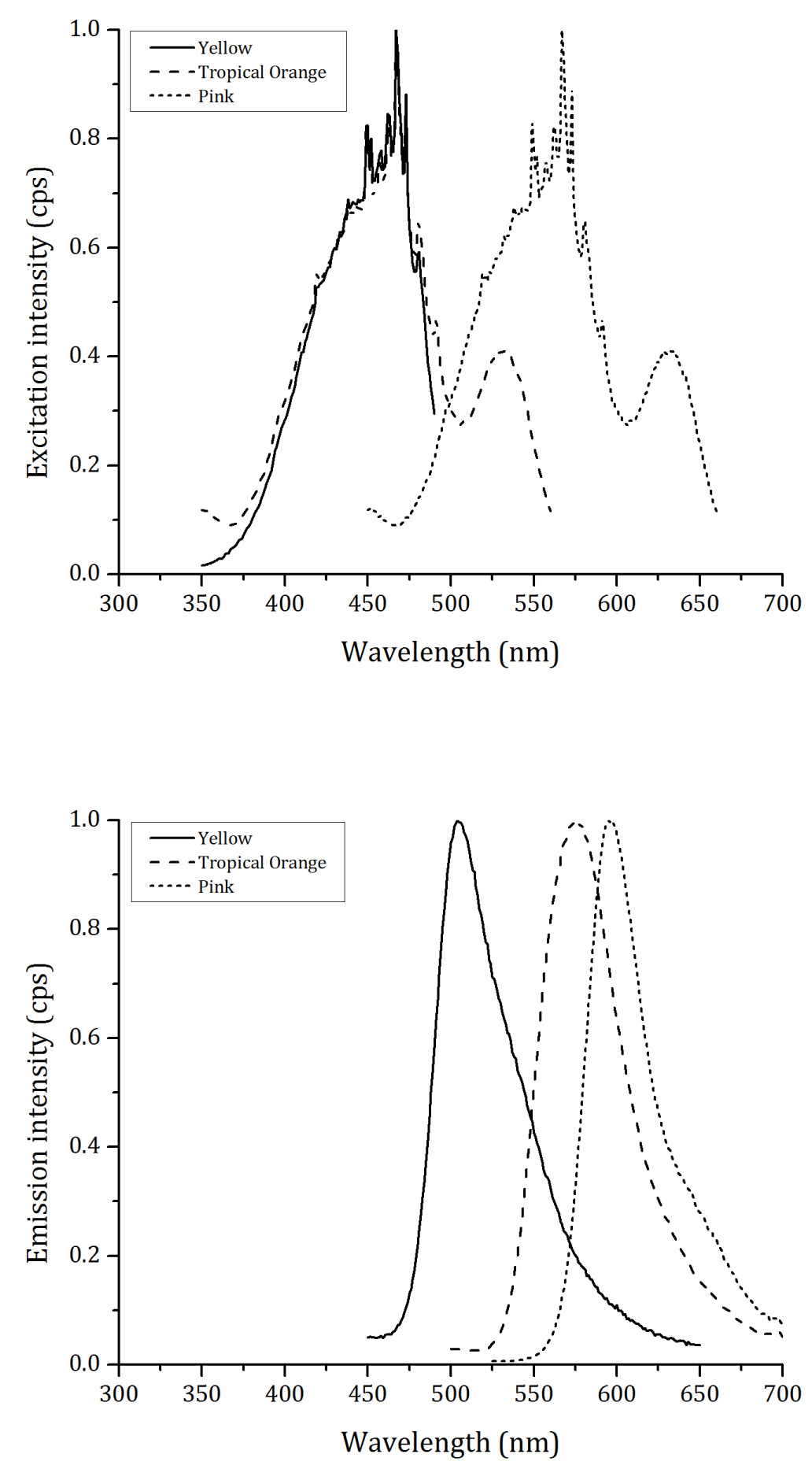

Figure 2: Excitation and emission wavelengths of the fluorescent pigments used to make the HTBs. This data was obtained from solutions in which $10 \mathrm{~g}$ of the pigments were partially dissolved in $0.05 \mathrm{~mL}$ of glycerol. These solutions were analyzed in a Fluorolog-3 Spectrofluorometer (Horiba Scientific, Irvine, CA). 


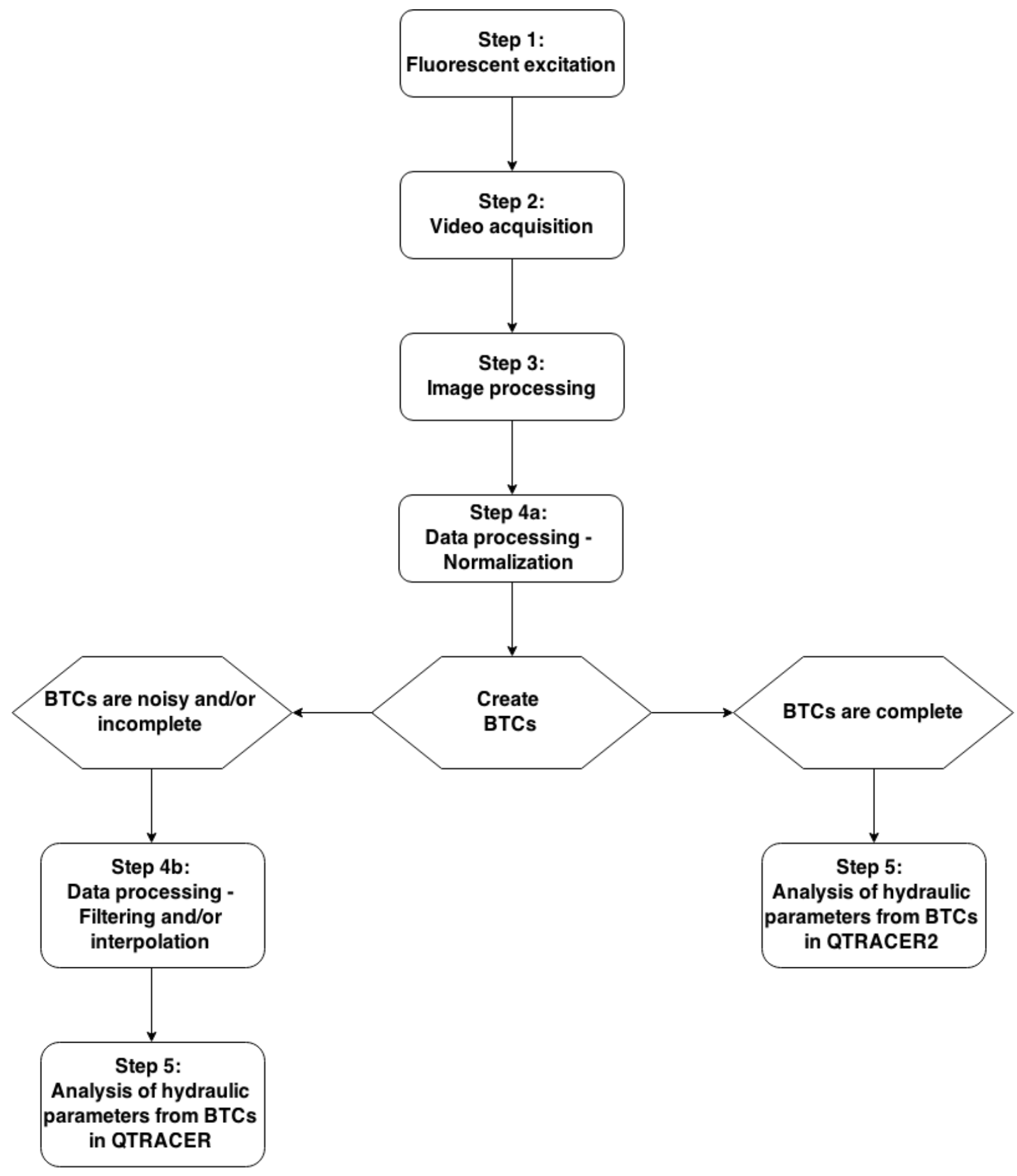

Figure 3: Experimental design of the optical quantification method. Step 4b is an optional step of data processing. 
completed with a UV light strip that was attached to a experimental system (Figure 4). The second step is the acquisition of video recordings of the excited HTBs movement. This step was completed with a camera that was also attached to the experimental system. The third step is the analysis of the video recordings. This step was completed with an image analysis algorithm that calculates the mean pixel intensity of each image in a video. The fourth step is the processing of the data obtained from the analysis of the video recordings. This step was completed by normalizing and occasionally smoothing and/or interpolating the data. The fifth and final step is the analysis of breakthrough curves (BTCs) generated with the normalized data for estimation of tracer transport parameters. This was completed with QTRACER2 (Field, 2002). Each of these five steps in discussed in more detail in the following sections.

\subsubsection{Setup of the experimental system}

The first and second steps of the optical quantification method are exciting the HTBs and acquiring video recordings of their movement. These steps were completed with an experimental system that hosts a weatherproofed UV LED light strip (24 watts and $395 \mathrm{~nm}$ ג) (Super Bright LEDs, Model NFLS-X3, St. Louis, MO) and a GoPro HERO3+ Black Edition camera (GoPro, San Mateo, CA). The experimental system, which is composed of an elongated piece of metal pipe or wood, was placed across the water surface horizontally. The UV light strip hosted to the experimental system was used to make the beads fluoresce and thereby enhance the signal to noise ratio in the images acquired by the camera.

The camera was configured following some of the suggestions by Tauro et al. (2012b) for tests in dark environements. The parameters that were modified include the 


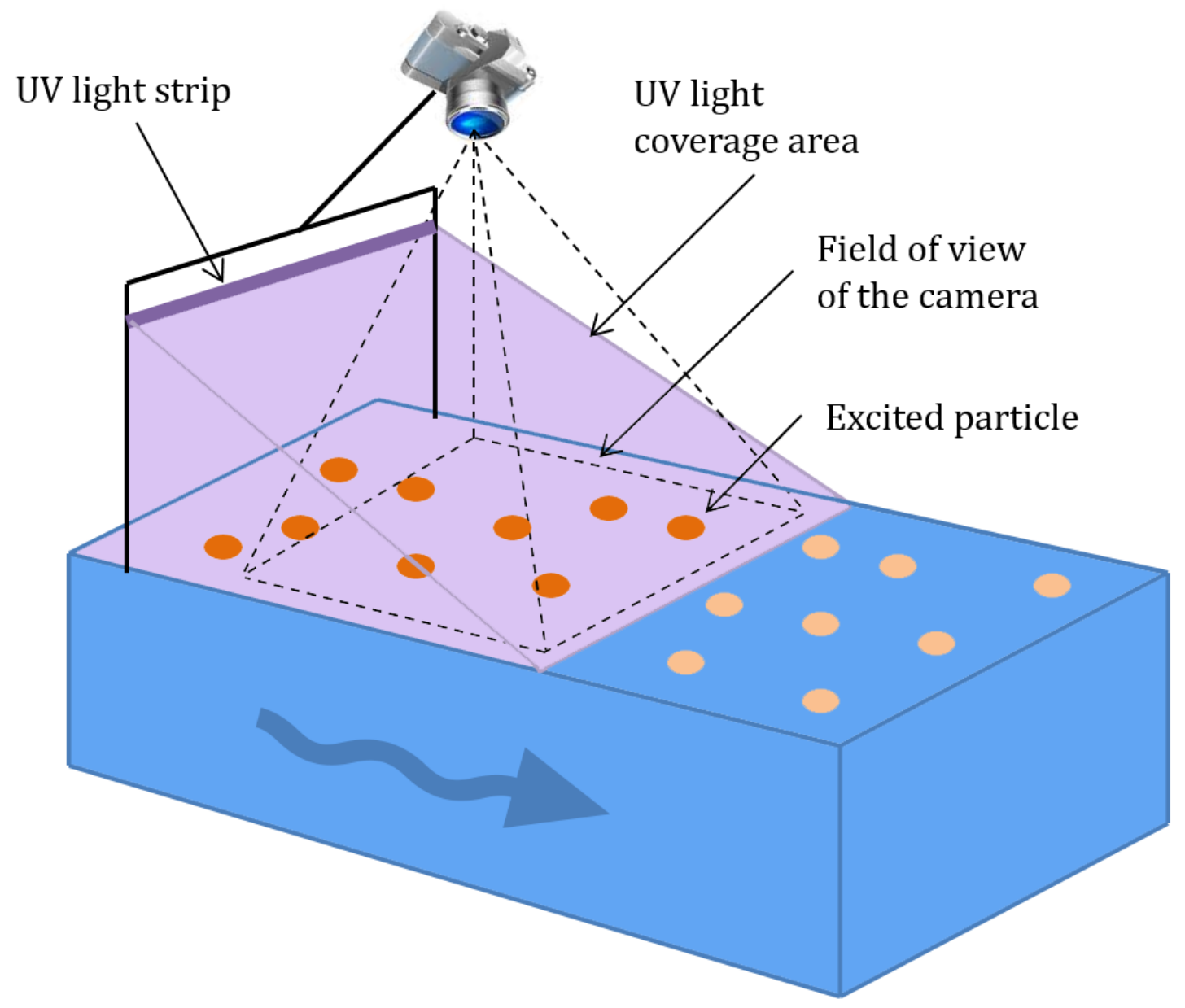

Figure 4: Schematic illustration of the setup for optical quantification method. 
camera height from the water surface and camera acquisition rates. Shorter camera heights $(30-45 \mathrm{~cm})$ than the recommended $(40-70 \mathrm{~cm})$ were preferred because the width of the area of study was narrow. Higher acquisition rates (60 - $120 \mathrm{fps}$ ) were favored over $30 \mathrm{fps}$ because they significantly decrease the amount of particle distortion (Figure 5), thus making the quantification of HTBs with an image analysis algorithm possible. For all tests in this study, the videos were stored in an MP4 format. In order to minimize particle distortion due to camera inclination (Tauro et al., 2012a; Tauro et al., 2012b), the camera was leveled with respect to the water surface before each test.

\subsubsection{Image processing}

The third step of the optical quantification method is the analysis of the video recordings acquired in second step. In this step, the videos are processed using an image analysis algorithm developed in MATLAB (R2013a, The Mathworks Inc., Natick, MA). This algorithm (Appendix A) uses commands from the Image Processing Toolbox to pre-process each image in a video recording before calculating their mean pixel intensity value. The input recordings are in an RGB color space (Figure 6a).

In the RGB color space each pixel in an image is represented by three arrays of values that indicate the amount of red (R), green (G), and blue (B) components (Marques, 2011). Each of these three components is known as a color channel, which is simply a grayscale image where each pixel is represented by a single value that ranges from 0 (completely black image) to 255 (completely white image)(Marques, 2011). The value of each pixel represents the amount of light detected by a color channel. The greater the amount of light detected, the higher the pixel value. 

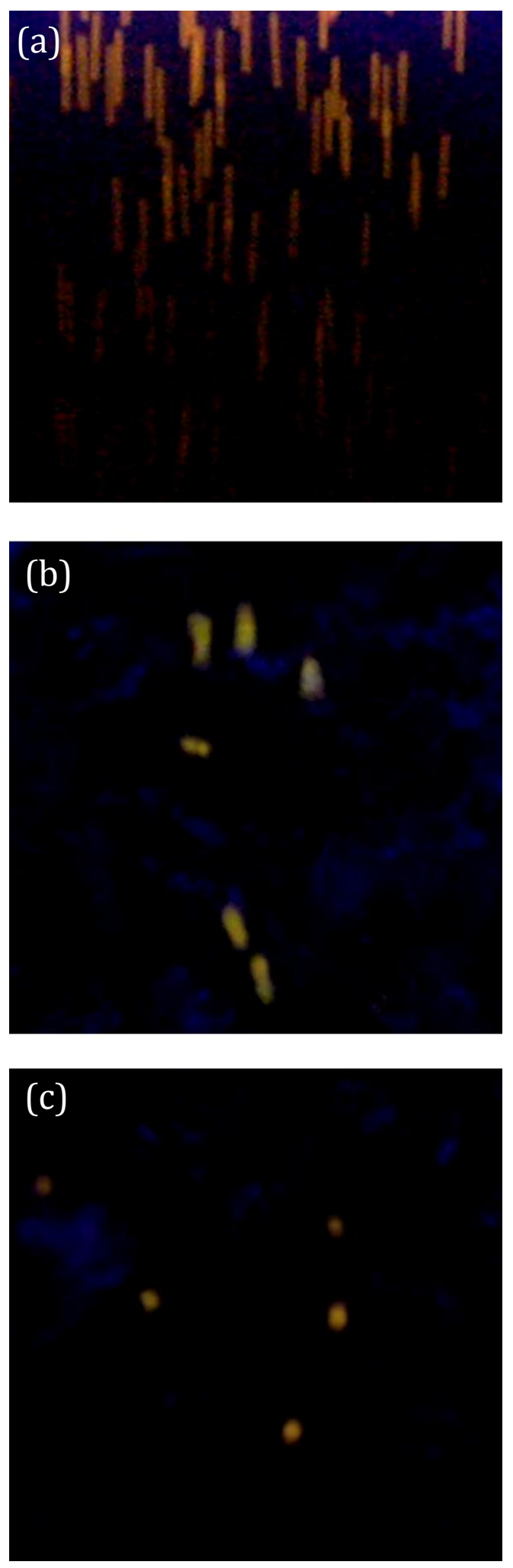

Figure 5: Particle distortion at (a) $30 \mathrm{fps}$, (b) $60 \mathrm{fps}$, and (c) $120 \mathrm{fps}$ for tracer tests conducted at a flow rate of $1.9 \mathrm{~L} / \mathrm{s}$ In the Experimental Stream Facility. Flow direction is to the south. 
The algorithm separates the video into a sequence of images. Next, it performs two pre-processing steps to the individual images. The first pre-processing step uses the "image adjust" command to enhance the contrast of each image and emphasize brighter pixels, which correspond to the HTBs (Figure 6b). The second pre-processing step separates the enhanced images into the red (Figure 6c), green (Figure 6d), and blue (Figure 6e) color channels. After the two pre-processing steps, the algorithm uses the "mean" command to calculate the pixel intensity of the red and green channels. Subsequently, the algorithm uses the "reshape" and "sum" commands to calculate the pixel intensity per second and per half of a second. The algorithm concludes the run by writing the mean pixel intensity data of each image as well as the mean pixel intensity data per second and per half of a second for the green and red color channels into an Excel file. In this study, the mean pixel intensity data per half a second was used for QTRACER2 analysis.

\subsubsection{Data processing}

The fourth step of the optical quantification method is the processing of the raw mean pixel intensity data obtained from the image analysis algorithm. In this step, the mean pixel intensity is normalized in order to have the data for all the experiments within a specific range. Normalization was achieved by scaling between 0 and 1 using the following formula:

$$
z_{i}=\frac{\left(x_{i}-\min (x)\right)}{(\max (x)-\min (x))}
$$

where $x_{i}=\left(x_{1}, \ldots, x_{n}\right)$ is the variable to be normalized, $\min (x)$ is the minimum value for variable $x, \max (x)$ is the maximum value for variable $x$, and $z_{i}$ is the $\mathrm{i}^{\text {th }}$ normalized data. 

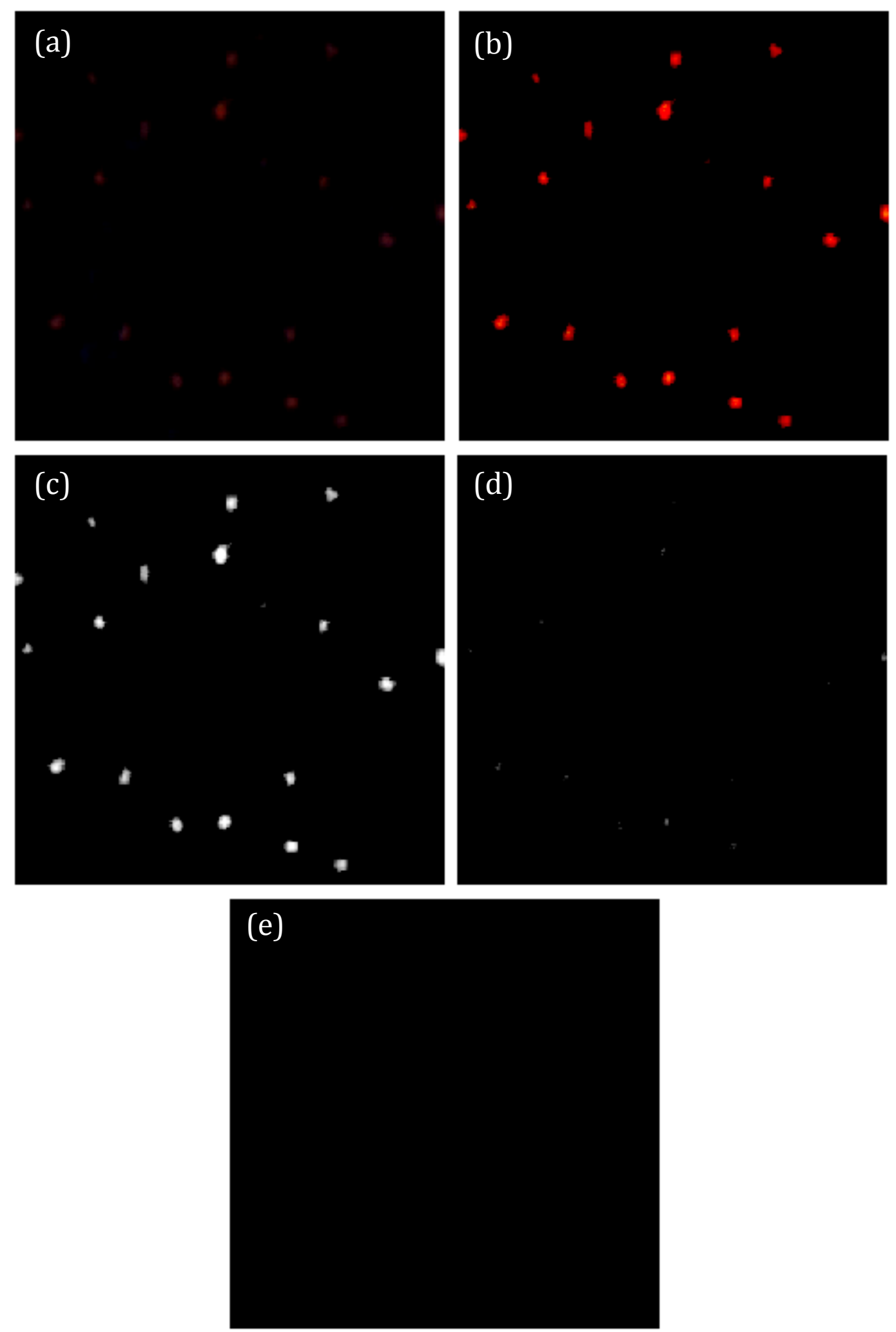

Figure 6: Image analysis process: (a) original image, (b) enhanced image, (c) red channel, (d) green channel, and (e) blue channel. 
In tests longer duration ( $>30$ minutes), the Savitzky-Golay smoothing filter was applied in order to improve the signal to noise ratio of the normalized data. The SavitzkyGolay smoothing filter removes noise without affecting the overall shape of the curve by performing a least squares fit of a small set of consecutive data points to a polynomial and taking the calculated central point of the fitted polynomial curve as the new smoothed data point (Savitzky and Golay, 1964). The number of central points have an influence on the degree of smoothing. A high amount of central points, results in a high degree of smoothing of a curve, and vice versa. In this study, a $2^{\text {nd }}$ order polynomial was used to fit and smooth the normalized data with four different central points $[50,100$, 150, and 200). This resulted in four breakthrough curves with different degrees of smoothing. These four breakthrough curves were analyzed in QTRACER2 to determine how their shape influenced the calculation of tracer transport parameters. The normalized data was also interpolated using a linear method in cases where data points were missing due to camera failure. The linear interpolation method uses linear polynomials to generate straight lines that connect data points. It was used because other interpolations methods (e.g. neighbor-based operations) did not interpolated the missing data points in a manner that made sense. The normalized data was interpolated and smoothed using a MATLAB algorithm (Appendix B).

\subsubsection{Calculation of transport parameters}

The fifth and final step of the optical quantification method is analysis of BTCs generated with the processed mean pixel intensity data. In this step, time and processed concentration data are exported to QTRACER2, which is a U.S. Environmental Protection 
Agency computer program that can be used to calculate tracer transport parameters such as time of first detection, time of peak detection, and mean tracer velocity (Field, 2002). This program calculates the tracer transport parameters, as well as the physical properties of the water system, based on user-generated input files that contain information about both the tracer (e.g. time and concentration) and the water system (e.g. discharge) being traced. The program can be used to analyze tracer test data from all types of hydrological systems including surface and subsurface channels as well as fractured and granular aquifers. In the present study, input files generated for each test were analyzed by QTRACER2 in order to determine time of first detection, time of peak detection, mean tracer velocity, maximum tracer velocity, mean tracer transit time, and longitudinal dispersion of the tracers.

In order to use QTRACER2 for the analysis of data from tests with the HTBs and the salt solutions, assumptions were necessary. For the HTBs, it was assumed that the quantity of HTBs collected was equal to the concentration. For the salt solutions, it was assumed that the electrical conductivity at the measured temperature was equal to the sodium chloride concentration at $25^{\circ} \mathrm{C}$ through the equation of the line in Figure 7 :

$$
[\mathrm{NaCl}]_{25}=\frac{E C_{25}-82.212}{1.7628} ;
$$

which is the equation of the line in Figure 7, solved for the sodium chloride concentration at $25{ }^{\circ} \mathrm{C}$. In the latter equation, the electrical conductivity at $25{ }^{\circ} \mathrm{C}\left(E C_{25}\right)$ can be expressed as:

$$
E C_{25}=\frac{E C_{t}}{[1+a(t-25)]}
$$




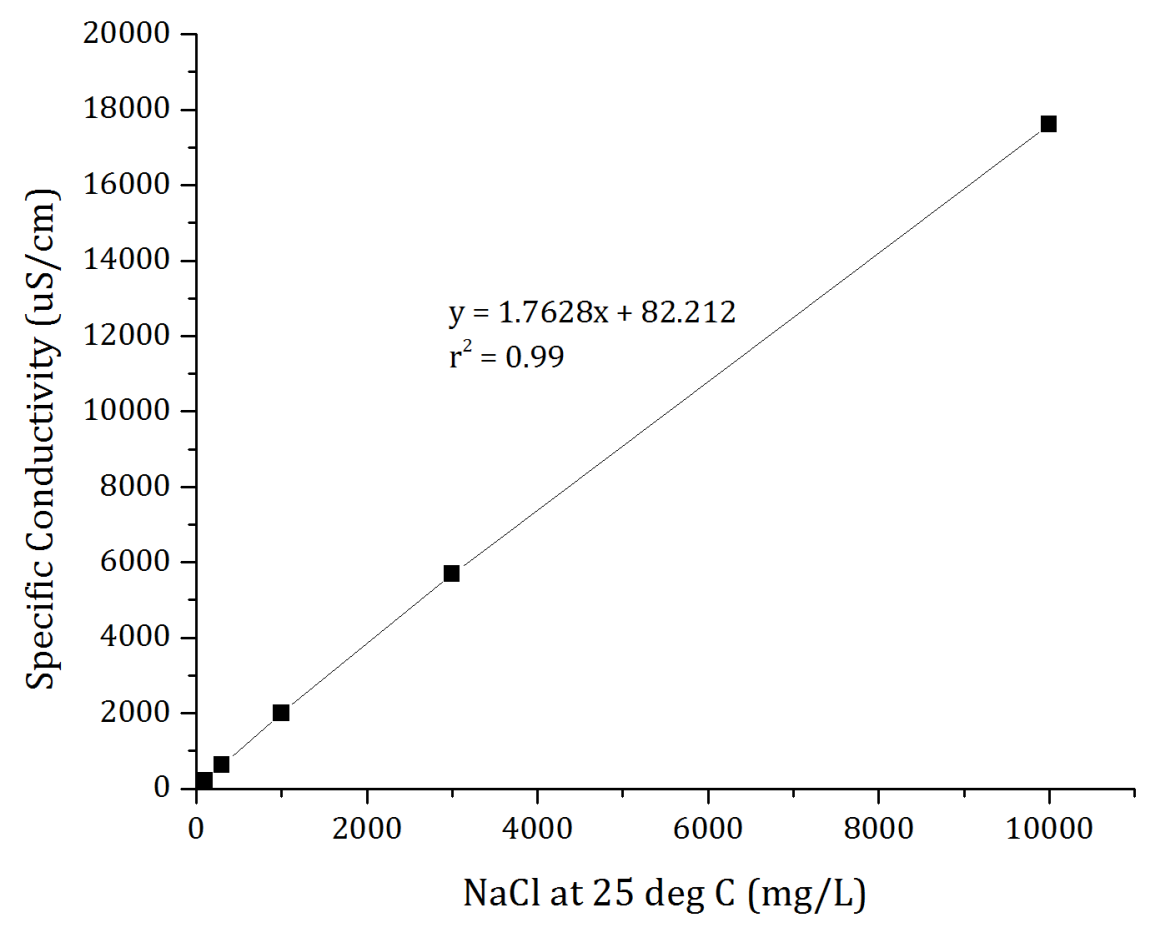

Figure 7: Relationship between specific conductivity and sodium chloride $(\mathrm{NaCl})$ concentration in solutions at $25{ }^{\circ} \mathrm{C}$. Graph made with data from OAKTOWN Instruments (1997). 
where $E C_{t}$ is electrical conductivity at temperature $t\left({ }^{\circ} \mathrm{C}\right)$, and $a\left({ }^{\circ} \mathrm{C}^{-1}\right)$ is a temperature compensation factor which is usually equal to 0.02 (Hayashi, 2004). Determining the sodium chloride concentration allowed the estimation of the salt tracer recovery.

\subsection{Data evaluation}

Analysis of variance (ANOVA) was used to determine if the results from QTRACER2 tracer tests were significantly different from each other. ANOVA is a hypothesis-testing technique used to test the equality of two or more population means by examining the variances of the samples (Urdan, 2001). It is based on comparing the variation between the data samples to variation within each particular sample. If the between variation is much larger than the within variation, the means of different samples will not be equal, but if the between and within variations are approximately the same size, then there will be no significant difference between sample means. The test statistic of ANOVA is the F-statistic, which is the ratio of the average between variation to the average within variation. The Fstatistic is compared to a tabulated critical F-value in order to determine if the data is significantly different. If F-statistic is larger than the critical F-value, then the data are significantly different (null hypothesis rejected). On the contrary, if the F statistic is smaller than the critical F-value, then the data are not significantly different (null hypothesis accepted). ANOVA are made with a certain level of statistical significance $(\alpha)$, which is defined as the likelihood that a result or relationship is caused by something other than random chance (Urdan, 2001). In this study, $\alpha$ was set to 0.05. ANOVA makes three assumptions. These are: (a) all populations involved follow a normal distribution, (b) all populations have the same variance (or standard deviation), and (c) the samples are 
randomly selected and independent of one another (Urdan, 2001). In this study, the data were close to normality, but given the small number of data points, they were not adjusted.

The results of the following tracer transport parameters were examined with ANOVA: time of first detection, time of peak concentration, mean tracer velocity, peak tracer velocity, mean transit time and longitudinal dispersion. Tracer recovery could not be examined because it cannot be calculated with the optical quantification method.

\subsection{Research sites}

\subsubsection{Laboratory site}

The optical quantification method was tested in the U.S. Environmental Protection Agency's Experimental Stream Facility in Milford, $\mathrm{OH}$. This facility has eight experimental flumes constructed in stainless-steel. Each one is $12 \mathrm{~m}$ long and is divided into four sections: (1) head tank, (2) tile section, (3) gravel section, and (4) tail tank. The (1) head tank is a $126 \mathrm{~L}$ tank that drains water through a rectangular weir into the tile section. The (2) tile section is $30 \mathrm{~cm}$ wide, $9 \mathrm{~cm}$ deep and $4 \mathrm{~m}$ long. The (3) gravel section is $50 \mathrm{~cm}$ wide, $17 \mathrm{~cm}$ deep and $4.5 \mathrm{~m}$ long. The (4) tail tank is a $222 \mathrm{~L}$ tank that simulates conditions of a pool in a natural stream channel. The water that feeds the flumes can be supplied by different sources, such as city water, waste water, and stream water. The water used in this study was supplied by two different surface streams, both rich in carbon and nutrients. The flow rates of each flume can be adjusted from a minimum value of $6.0 \times 10^{-3} \mathrm{~L} / \mathrm{s}$ to a maximum value of $3.2 \mathrm{~L} / \mathrm{s}$. The streambed of each flume can be modified as well. Tiles or gravel can be used as substrate in the middle sections of the flume. Tiles result in a laminar flow regime, whereas gravel results in a more turbulent flow regime. Each of these flumes 
is divided into halves lengthwise in order to double the number of possible experiments. The flumes are also designed with overhead structures on which a video camera and other tools can be mounted.

Tracer tests were conducted in a single half of a flume. In order to attempt to replicate a natural environment, well-rounded pebble-sized clasts were placed in the tile and gravel sections of the flume (Figure 8a-b). The streambed of the gravel section was completely covered in pebbles, but that of the tile section was not because the flow of water pushed small pebbles towards the gravel section of the flume. Therefore, a smaller amount of larger pieces of pebble-sized clasts were placed in the tile section. The pebbles in both of these sections of the flume served as a potential trapping mechanism for the HTBs. The water depth relative to the gravel was about $3.8 \mathrm{~cm}$.

Tracer tests were conducted at a low- $(1.9 \mathrm{~L} / \mathrm{s})$ and a high-flow rate $(3.2 \mathrm{~L} / \mathrm{s})$. In each test, 4500 HTBs were mixed with $250 \mathrm{~mL}$ of the $15 \%$ salt tracer for 20 seconds before being instantaneously released at the start of the tile section of the flume. The experimental system and the conductivity meter were placed $5.9 \mathrm{~m}$ downstream from the tracer release point (Figure 9). The camera was set at a height of $32 \mathrm{~cm}$ from the water surface. For each test, video recordings were obtained from the time the HTBs were released into the flume until 20 seconds after they passed the experimental system. The videos were recorded at a resolution of $1280 \times 720$ pixels and an acquisition rate of $120 \mathrm{fps}$. In each test, the HTBs that moved past the experimental system were collected with fishing nets in order to determine the percent recovery. The HTBs that remained trapped in between the pebbles 
were freed by gently tapping the water surface and discarded in order to lessen the interference in subsequent tests.

The goals of conducting tests in the Experimental Stream Facility were threefold. The first goal was to determine the precision of the optical quantification method. The second goal was to determine which of the pigments used to make the HTBs were better detected by the camera. The pigments that were used were pink, yellow, and tropical orange. The third and final goal was to compare the transport behavior of the HTBs with a solute tracer. 

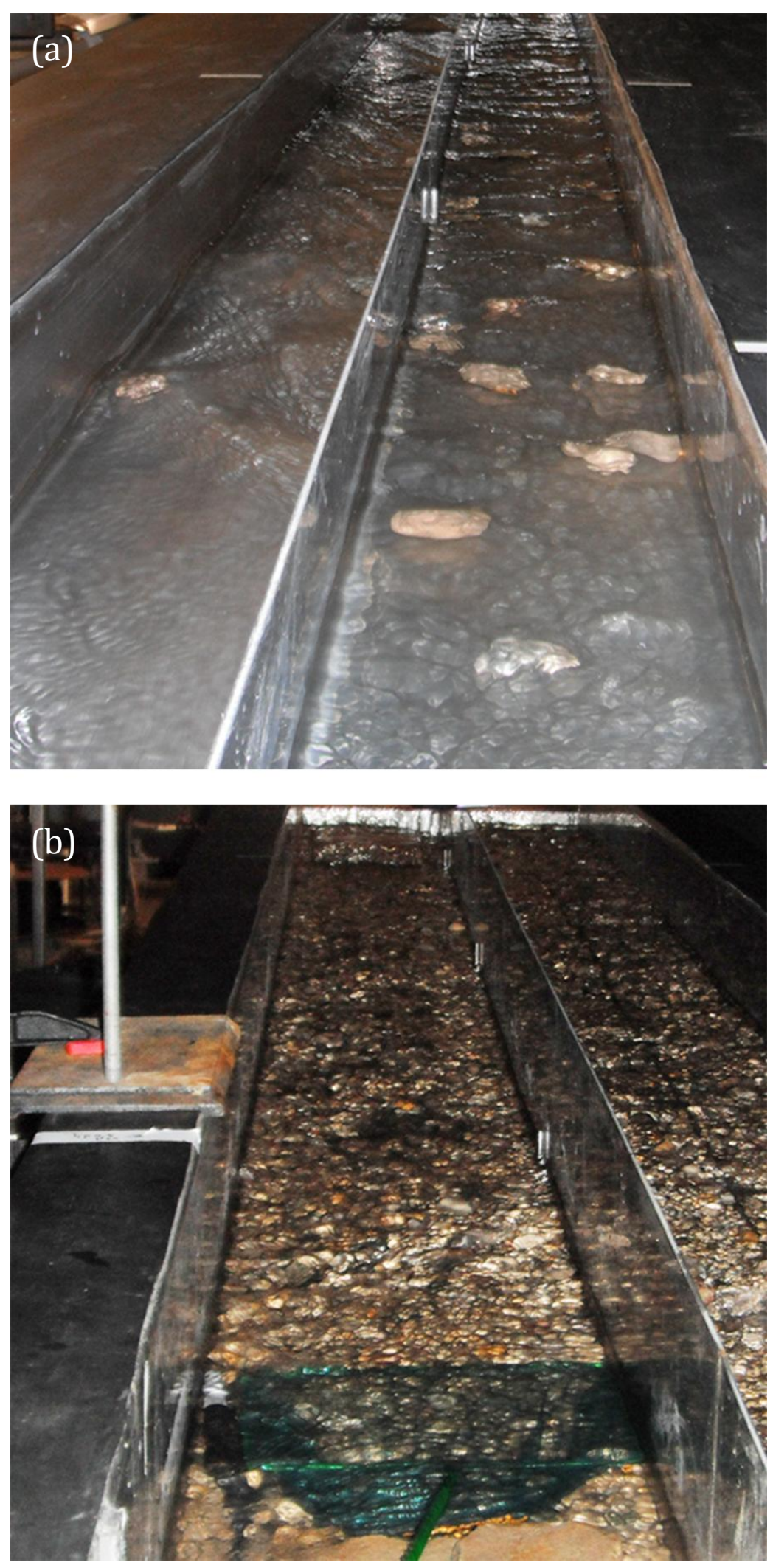

Figure 8: Setup in the (a) tile section and (b) and gravel section of a flume in the Experimental Stream Facility. 

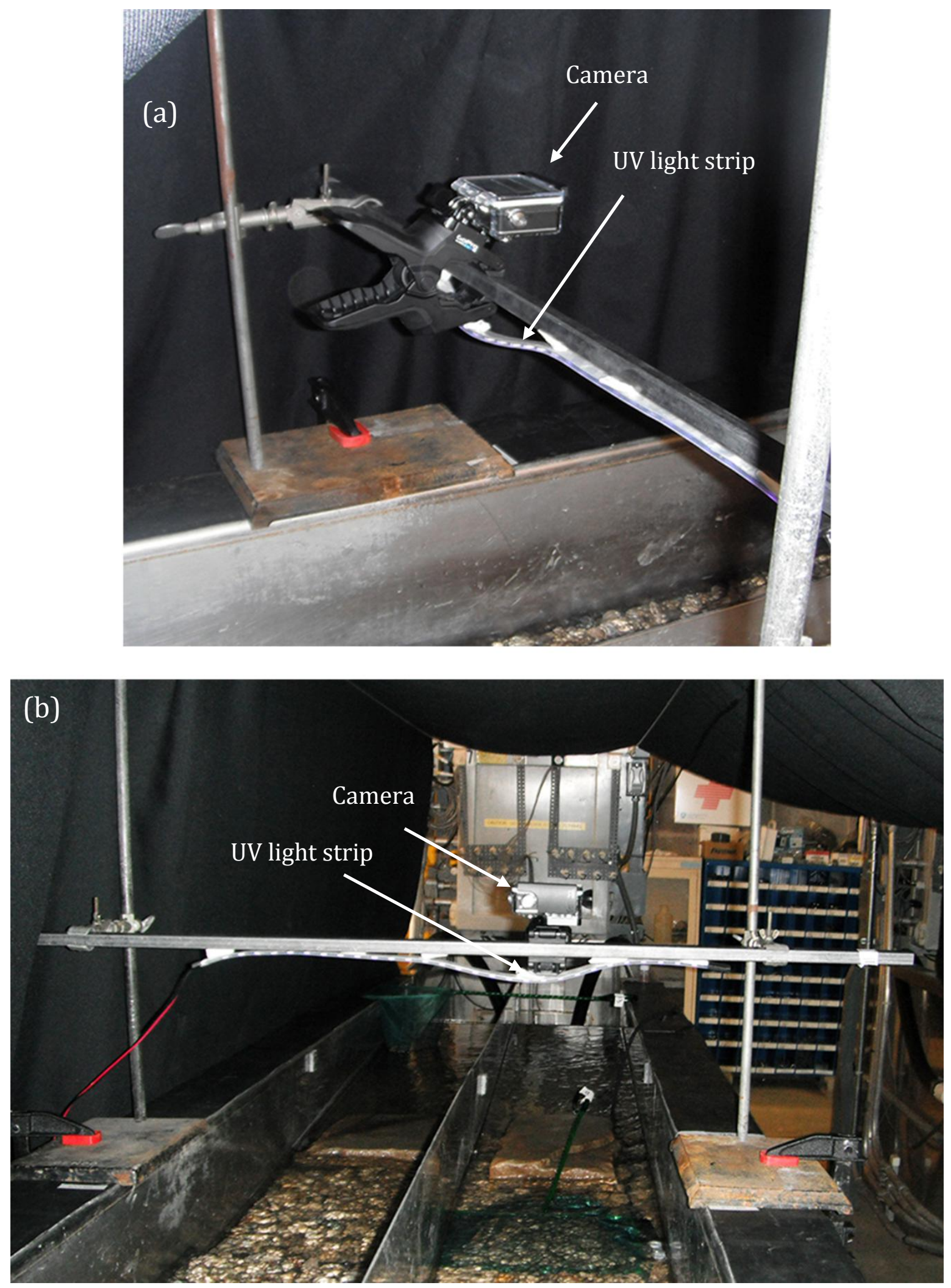

Figure 9: (a) Oblique- and (b) side-view of the experimental system setup in the Experimental Stream Facility. 


\subsubsection{Field site}

The optical quantification method was applied in Buckeye Creek Cave. This cave is located in the Greenbrier Valley karst region of southern West Virginia (Figure 10). The Greenbrier Valley developed in the Greenbrier Series, which is a Mississippian age deposit composed of medium to dark-gray fossiliferous limestone and calcareous shale (Figure 11, Dasher and Balfour, 1994). Buckeye Creek Cave developed in the Union limestone member of the Greenbrier Series, which is described as being a $60 \mathrm{~m}$ thick, gray to dark, fossiliferous to oolitic limestone, which weathers white (Dasher and Balfour, 1994). The cave is conduittype with a stream that has an approximate length of $1830 \mathrm{~m}$.

Tracer tests were conducted in the canyon section of Buckeye Creek Cave (Figure 12), where the stream is about $1 \mathrm{~m}$ wide and it is constricted on the sides and lined on the bottom by bedrock. The length of the traced transect was $59 \mathrm{~m}$. During the tests the water level was about $0.75 \mathrm{~m}$ at the deepest. The section of streambed had a minimal amount of sediment, with the majority of what was present being pebble to sand sized. Trapping mechanisms were limited in the canyon section, but included eddies and scallops in the passage wall.

Discharge was measured in two sections of the traced transect following the U.S. Geological Survey standard method described by Buchanan and Somers (1969). A Swoffer current meter (Swoffer Instruments Inc., Seattle, WA) was used to acquire velocity measurements using the midsection method, which says that the velocity of the measurement location is the velocity of a rectangular area (Buchanan and Somers, 1969). Since the water level in the canyon less than $0.7 \mathrm{~m}$ in some areas, velocity was measured at 
one point, which is 0.6 of the depth below the water surface. Discharge was calculated using the equation described by Buchanan and Somers (1969), that is:

$$
\mathrm{q}_{\mathrm{x}}=\mathrm{v}_{\mathrm{x}}\left[\frac{\mathrm{b}_{(\mathrm{x}+1)}+\mathrm{b}_{(\mathrm{x}-1)}}{2}\right] \mathrm{d}_{\mathrm{x}} \text {; }
$$

where $\mathrm{q}_{\mathrm{x}}$ is the discharge of the section $\mathrm{x}, \mathrm{v}_{\mathrm{x}}$ is the measured velocity of the section $\mathrm{x}, \mathrm{b}_{(\mathrm{x}-1)}$ is the distance from the velocity measurement to the previous measurement point, $b_{(x+1)}$ is the distance from the velocity measurement to the next measurement point, and $d_{x}$ is the depth of the water.

Two tracer tests were conducted in Buckeye Creek Cave. In both test, 4500 HTBs were mixed with $3 \mathrm{~L}$ of the $15 \% \mathrm{NaCl}$ tracer for 20 seconds before being instantaneously released into the water system. The experimental system and the YSI 556 were placed 59 $\mathrm{m}$ away from the release point (Figure 13). The camera was set $42.5 \mathrm{~cm}$ above the water surface. In both tests, the videos were recorded sometime after the HTBs were released in order to save the battery life of the camera. They were recorded at a resolution of $1980 \mathrm{x}$ 1080 pixels and an acquisition rate of $60 \mathrm{fps}$. The HTBs that moved past the experimental system were collected with fishing nets in order to determine the recovery, and create BTCs that were compared to those of the optical quantification method. For the first test, the HTBs were collected for 60 -second intervals. For the second test, the HTBs were collected for 120 -second intervals.

The goals of conducting tests in Buckeye Creek Cave were threefold. The first goal was to determine if the optical quantification method could be applied in tests of longer distance and duration. The second goal was to compare the results from the optical 
quantification method to the manual collection and counting of HTBs in order to determine the relative effectiveness of the two approaches. The third goal was to compare the transport behavior of the HTBs with a solute tracer in larger-scale tests. 


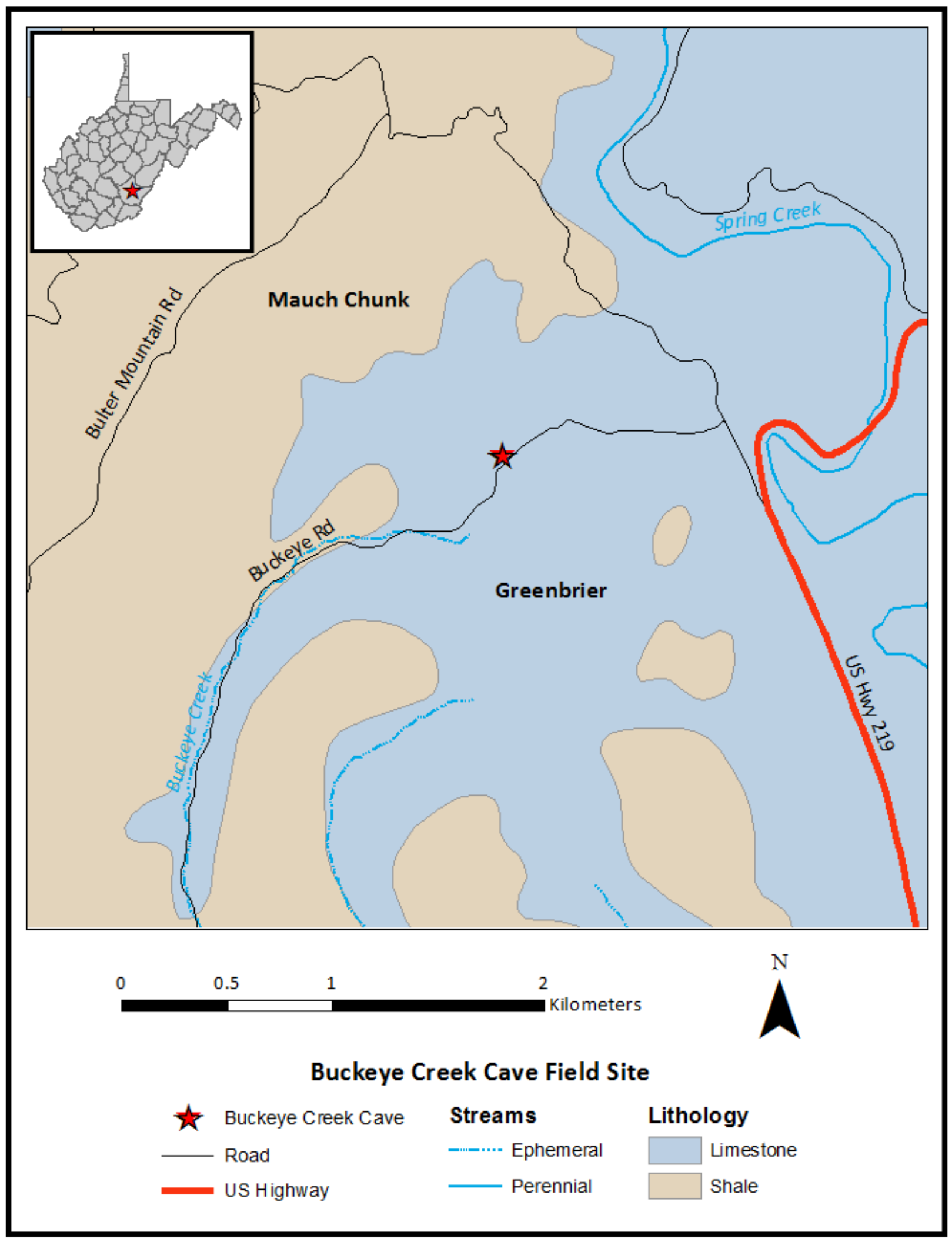

Figure 10: Map of field research site. 


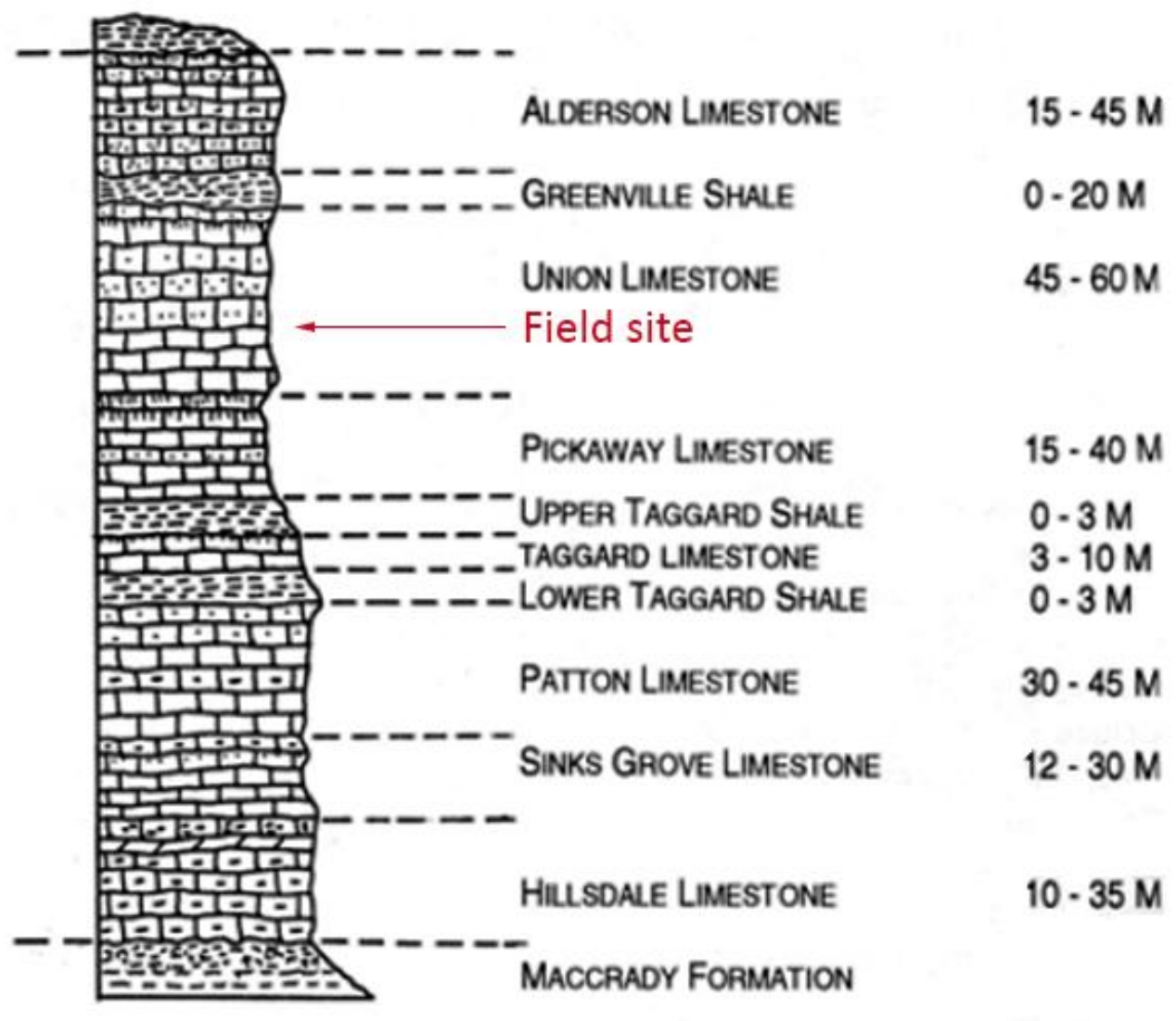

Figure 11: Stratigraphy of the field research site - The Greenbrier series. Modified from Dasher and Balfour (1994). 


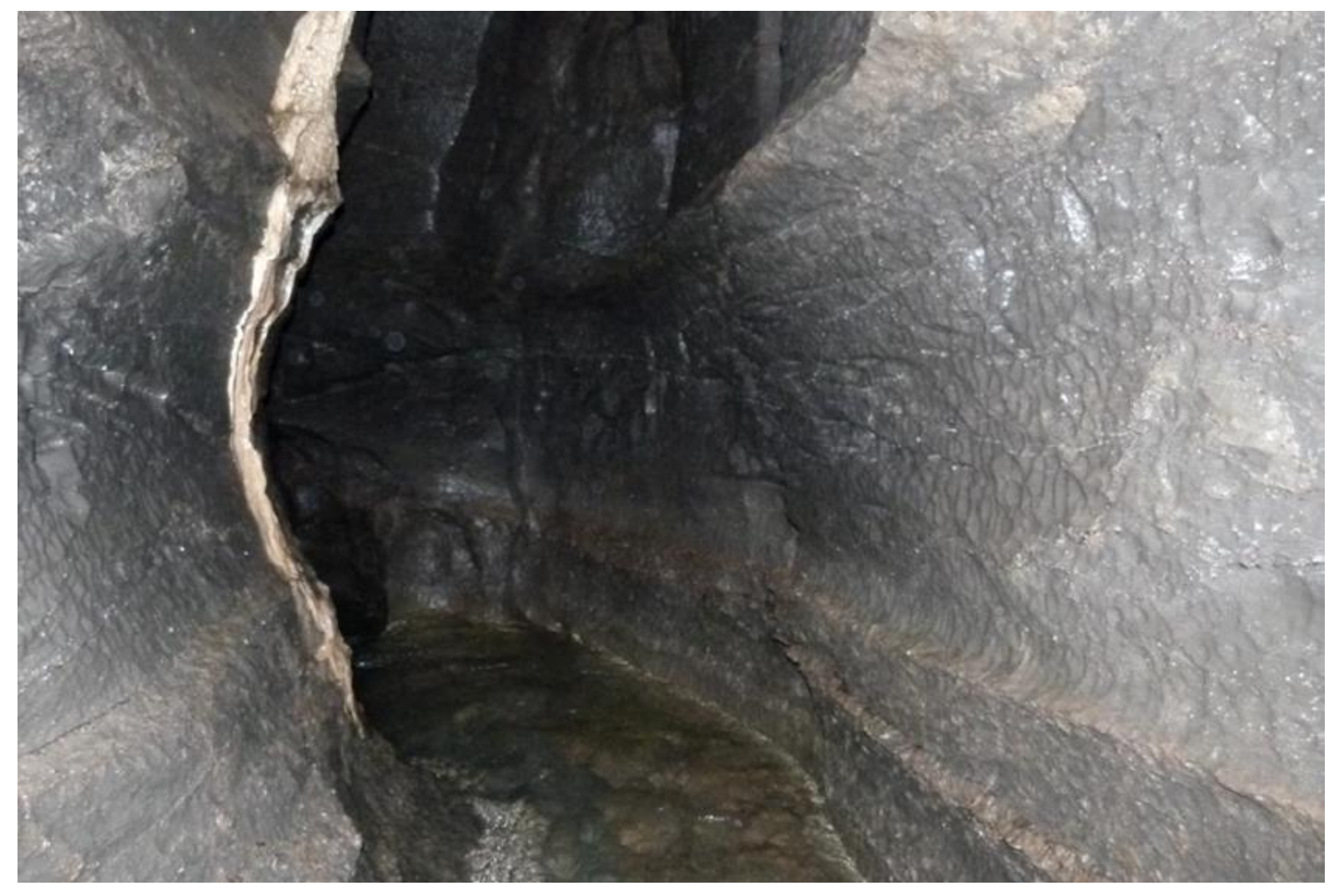

Figure 12: Canyon section in Buckeye Creek Cave. The width of this section is approximately 1 meter (Photo taken by Ellen Herman). 


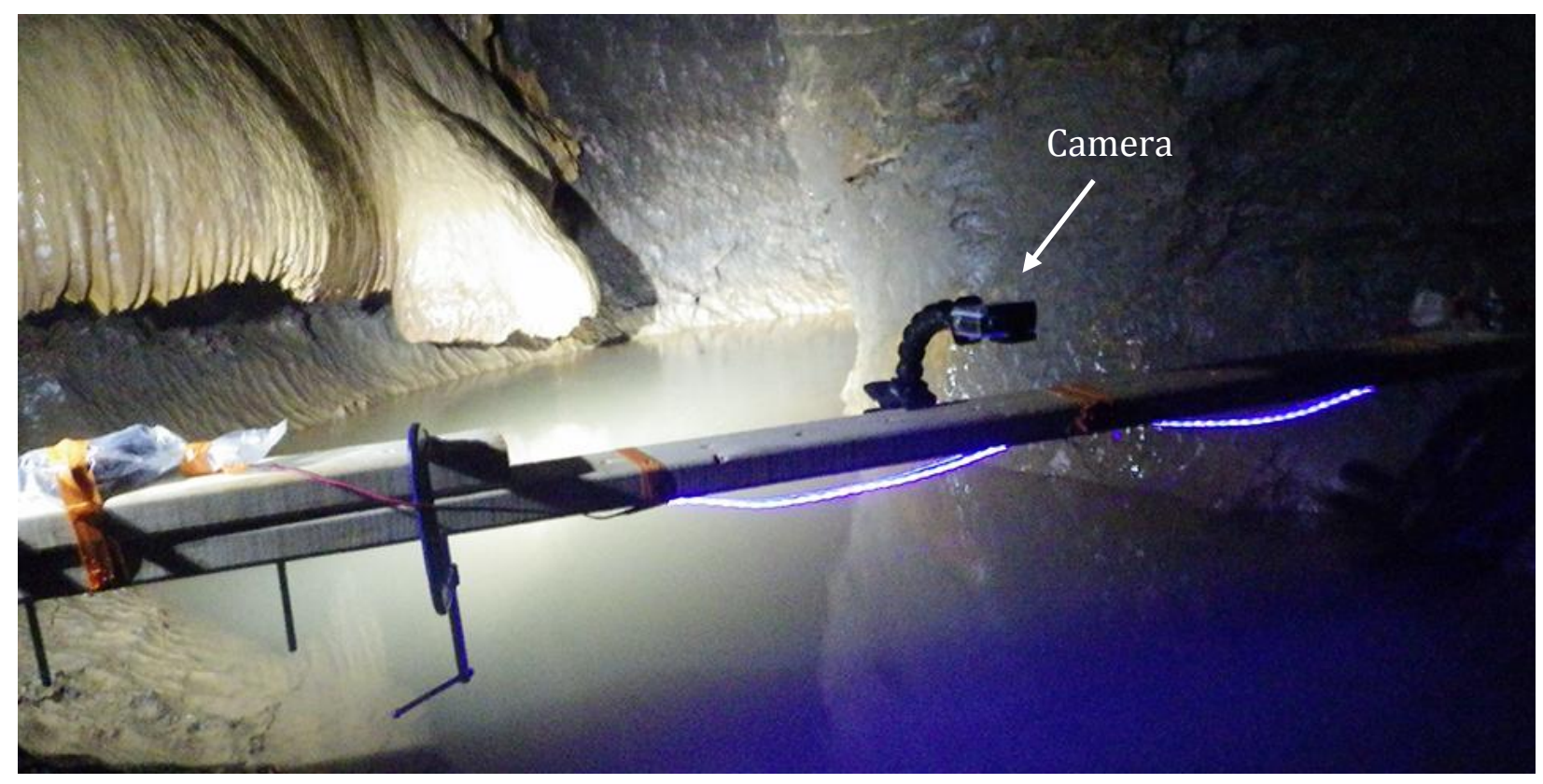

Figure 13: Setup of the experimental system in Buckeye Creek Cave. 


\section{Chapter 4 Method validation and application}

\subsection{Experimental design}

A total of 30 tests were conducted in the Experimental Stream Facility (Figure 14). Of these 30 tests, 21 were made at a low-flow rate $(1.9 \mathrm{~L} / \mathrm{s})$ and 9 were made at a high-flow rate $(3.2 \mathrm{~L} / \mathrm{s})$. The tests at the low-flow rate were conducted with groups of different quantities of HTBs. Despite that the HTBs trapped in the flume were freed and discarded between each test in order to lessen the interference, different pigment colors were used in each group in order to prevent the interference in subsequent tests. The tests at the highflow rate were conducted with groups of HTBs made with different pigments (Table 2). In all 30 tests, the HTBs were released together with $250 \mathrm{~mL}$ of the solute tracer made up of $15 \% \mathrm{NaCl}$. The traced section had a length of $5.9 \mathrm{~m}$.

Only two tracer tests were completed in Buckeye Creek Cave (Figure 14).In each of these tests 4,500 HTBs were released together with $3 \mathrm{~L}$ of a solute tracer made up of $15 \%$ $\mathrm{NaCl}$. The released HTBs were collected for 60-second intervals in test 1 and 120 -second intervals in test 2 . These HTBs were manually counted twice for comparison with the results of the optical quantification method. The traced section had a length of $59 \mathrm{~m}$. 


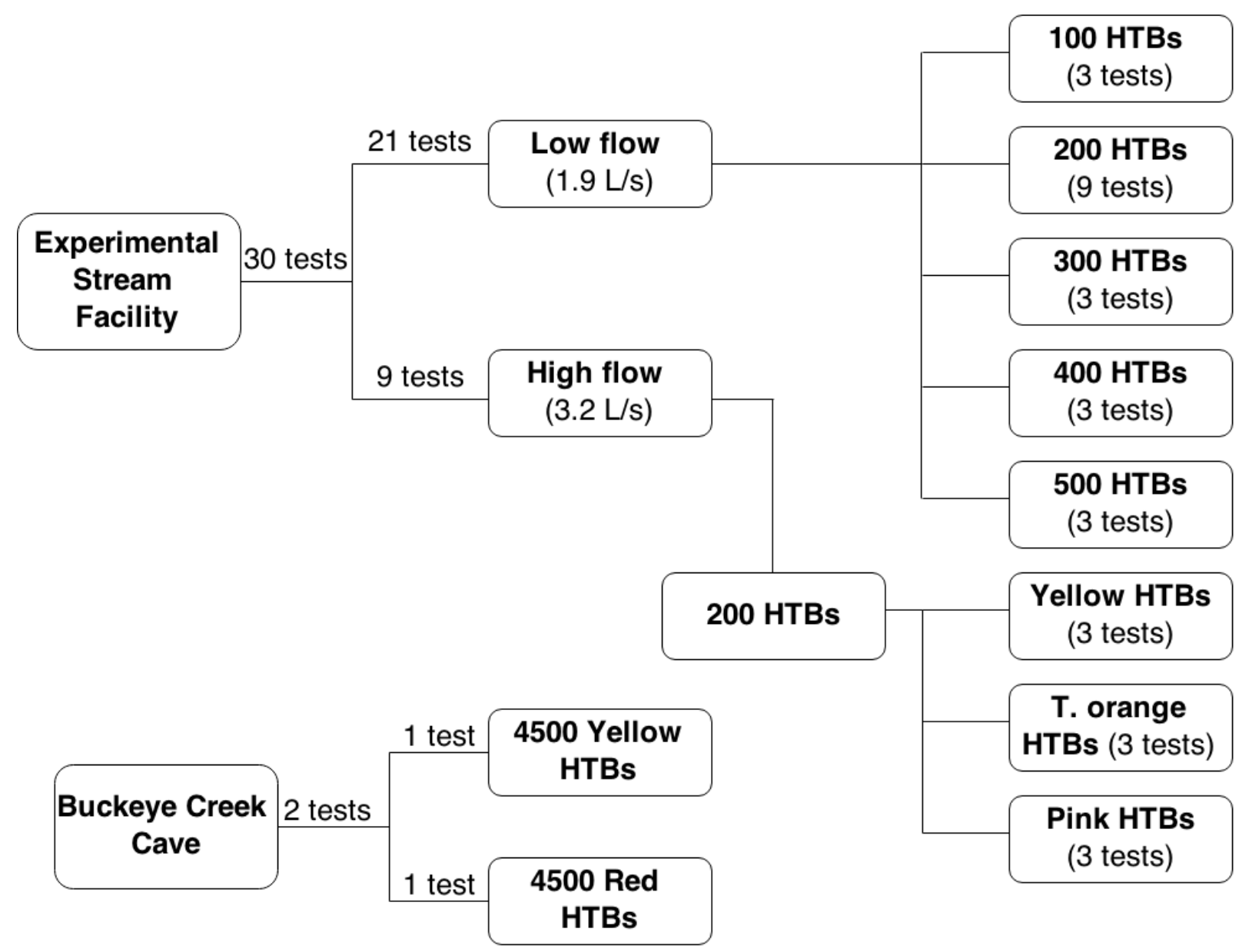

Figure 14: Experimental design for tests conducted in the Experimental Stream Facility and Buckeye Creek Cave. The low flow tests in the Experimental Stream Facility were conducted with HTBs of different color (see Table 2). 
Table 2: Description of tracer tests conducted in the Experimental Stream Facility during the $12^{\text {th }}$ and $13^{\text {th }}$ of March, 2014 . Tests $1-21$ were conducted at a lower flow rate $(1.9 \mathrm{~L} / \mathrm{s})$, whereas tests $22-30$ were conducted at a higher flow rate $(3.2 \mathrm{~L} / \mathrm{s})$.

\begin{tabular}{|c|c|c|c|c|}
\hline Group \# & Test \# & \# of Tests & \# of HTBs & Pigment \\
\hline \multirow{3}{*}{1} & 1 & \multirow{3}{*}{3} & \multirow{3}{*}{100} & Yellow \\
\hline & 2 & & & T. orange \\
\hline & 3 & & & Pink $\left.{ }^{*}\right)$ \\
\hline \multirow{9}{*}{2} & 4 & \multirow{9}{*}{9} & \multirow{9}{*}{200} & Yellow \\
\hline & 5 & & & T. orange \\
\hline & 6 & & & $\operatorname{Pink}\left(^{(*)}\right.$ \\
\hline & 7 & & & Yellow \\
\hline & 8 & & & T. orange \\
\hline & 9 & & & $\operatorname{Pink}\left({ }^{*}\right)$ \\
\hline & 10 & & & Yellow \\
\hline & 11 & & & T. orange \\
\hline & 12 & & & Pink ${ }^{(*)}$ \\
\hline \multirow{3}{*}{3} & 13 & \multirow{3}{*}{3} & \multirow{3}{*}{300} & Yellow \\
\hline & 14 & & & T. orange \\
\hline & 15 & & & $\operatorname{Pink}\left(^{*}\right)$ \\
\hline \multirow{3}{*}{4} & 16 & \multirow{3}{*}{3} & \multirow{3}{*}{400} & Yellow \\
\hline & 17 & & & T. orange \\
\hline & 18 & & & Pink ${ }^{(*)}$ \\
\hline \multirow{3}{*}{5} & 19 & \multirow{3}{*}{3} & \multirow{3}{*}{500} & Yellow \\
\hline & 20 & & & T. orange \\
\hline & 21 & & & Pink ${ }^{(*)}$ \\
\hline \multirow{3}{*}{1} & 22 & \multirow{3}{*}{3} & \multirow{3}{*}{200} & \multirow{3}{*}{ Yellow } \\
\hline & 25 & & & \\
\hline & 28 & & & \\
\hline \multirow{3}{*}{2} & 23 & \multirow{3}{*}{3} & \multirow{3}{*}{200} & \multirow{3}{*}{ T. orange } \\
\hline & 26 & & & \\
\hline & 29 & & & \\
\hline \multirow{3}{*}{3} & 24 & \multirow{3}{*}{3} & \multirow{3}{*}{200} & \multirow{3}{*}{ Pink } \\
\hline & 27 & & & \\
\hline & 30 & & & \\
\hline
\end{tabular}

${ }^{(*)}$ Results for these tests were not shown because the HTBs were not visible. 


\subsection{Laboratory experiments in the Experimental Stream Facility}

\subsubsection{Results from the optical quantification method}

Each of the tests in the Experimental Stream Facility was less than 40 seconds in duration. For each test, two BTCs were generated using the mean pixel intensity data of the red and green color channels. These two BTCs usually had similar shapes (Figure 15). Therefore, most of the BTCs that were analyzed in QTRACER2 were those generated with the pixel intensity data of the red color channel. In all the tests, the BTCs had some minor peaks together with a main peak. The minor peaks were not smoothed out before QTRACER2 analysis. The BTCs generated using the mean pixel intensity data of the red color channel for all the tests conducted at the low-flow rate were consistent in shape (Figure 16a). The same consistency was found with most of the BTCs of the tests conducted at high-flow rate (Figure 16b). Only two tests (\#22 and \#28), had red color channel BTCs different from the others (Figure 17). The different BTCs of these two tests were caused by reflection of UV light on the water surface. This UV light reflection was only present in the red color channel images of the two tests. The green color channel images were not affected and BTCs from their mean pixel intensity data were more consistent with the BTCs of the other tests (Figure 17).

The pink HTBs were not detected by the camera because they did not emit sufficient fluorescence in the tests conducted at the low-flow rate. A possible explanation for this may be that the energy level in the batteries of the UV light strip was not at its maximum. The raw mean pixel intensity value of images with pink HTBs was low (0.01 a.u.) compared to that of images with yellow (0.47a.u.) or tropical orange (0.46 a.u.) HTBs. Since the pink 
HTBs were not detected at this flow rate, only the results of the tests made with the yellow and tropical orange HTBs were shown. For the tests conducted at the high-flow rate, new batteries were used to supply energy to the UV light strip, which resulted in the pink HTBs being successfully detected by the camera.

The QTRACER2 results from the tests conducted at the lower flow rate agreed within $8 \%$ for all the tracer transport parameters except longitudinal dispersion (Table 3). The HTBs were detected for the first time after an average of 19.7 seconds and their concentration peaked after an average of 24.6 seconds. The mean tracer velocity and peak tracer velocity were 799 and $1083 \mathrm{~m} / \mathrm{h}$, respectively. The QTRACER2 results from the tests conducted at the higher flow rate agreed within $8 \%$ only for time of first detection, time of peak concentration, and peak tracer velocity (Table 4). The HTBs were detected after an average of 13.8 seconds and their concentration peaked after an average of 16.7 seconds. The average mean tracer velocity and peak tracer velocity were 1059 and $1545 \mathrm{~m} / \mathrm{h}$, respectively. At both flow rates, the HTBs traveled from the release point to the collection point in less than 30 seconds and the average longitudinal dispersion was less than $5 \mathrm{~cm}$.

Not all the released HTBs were transported past the experimental system hosting the UV light strip and the camera. The pebbles placed along the base of flume trapped some of the HTBs and/or retarded their movement. Trapping and retardation occurred more frequently in the gravel section of the flume, where there was a higher density of pebbles. HTBs that moved past the experimental system occasionally missed the fishing net as they moved along the edges of the flume. These HTBs were not collected or counted. The 
average recoveries of the HTBs that moved past the experimental system and were collected were $48 \%$ at the low-flow rate and $52 \%$ at the high-flow rate (Table 5).

\subsubsection{Precision of the optical detection method}

ANOVA was used to determine if the means of the transport parameters calculated by QTRACER2 were different within and between the various quantities of HTBs and fluorescent pigments. The tracer tests conducted at the low-flow rate were made with five groups of different quantities of HTBs of various fluorescent pigments, whereas the tracer tests conducted at the high-flow rate were completed with three groups of HTBs made with different fluorescent pigments (Table 2).

In the tests conducted at the low-flow rate, ANOVA indicated that the results of each of the transport parameters were statistically equal with $95 \%$ confidence (Table 6). ANOVA also indicated that for each of the transport parameters, the variation within a group (e.g. tests with 100 HTBs) was larger than the variation between the groups (e.g. tests with 100 - 500 HTBs).

In the tests conducted at the high-flow rate, ANOVA indicated that the results of four of the six transport parameters were statistically equal with 95\% confidence (Table 7). The parameters whose results was significantly different were mean tracer velocity (single factor ANOVA, $\mathrm{F}=9.23, \mathrm{p}=0.01$ ) and mean transit time (single factor ANOVA, $\mathrm{F}=5.68, \mathrm{p}=$ 0.04). For both of these parameters, the variation within a group was smaller than the variation between the groups. 
In QTRACER2, the shapes of the BTCs have an influence in the results of a test. The red color channel BTCs of tests 22 and 28 were different from the BTCs of the other seven tests due to UV light reflection on the water surface. The UV light reflection did not affected the green color channel images and BTCs from their data are more consistent (Figure 17). For the two tests, QTRACER2 results from the BTCs generated with the data of the green color channel were compared withQTRACER2 results from the BTCs generated with data of the red color channel using percent difference:

$$
\text { absolute \% difference }=\left|\frac{\text { Method } A-\text { Method B }}{\text { Method } A}\right| \times 100
$$

In both tests, the results of time of first detection, time of peak concentration and peak velocity agreed within $10 \%$ regardless of the color channel used (Table 8 ), but the results of mean tracer velocity, mean transit time and longitudinal dispersion disagreed by at least 27\%. When the original ANOVA analysis was repeated incorporating the QTRACER2 results from the BTCs generated the data of the green color channel of tests 22 and 28, there was no significant difference in the results of mean tracer velocity (single factor ANOVA, $\mathrm{F}=$ $0.82, \mathrm{p}=0.49$ ) and mean transit time (single factor ANOVA, $\mathrm{F}=0.75, \mathrm{p}=0.51$ ) (Table 9).

Based on the ANOVA, it can be implied that using different quantities and/or colors of HTBs does not have a significant effect on the results calculated by QTRACER2 from the analysis of BTCs generated with the data of the optical quantification method. What this means is that the results from tracer tests with 100 HTBs are not statistically different from the results from tracer tests made with 500 HTBs. It can also be implied that the optical quantification method is precise. However, its results can be affected by any sources of light 
(e.g. UV light) reflecting on the water surface or any object present on the water surface (e.g. wood chip). 


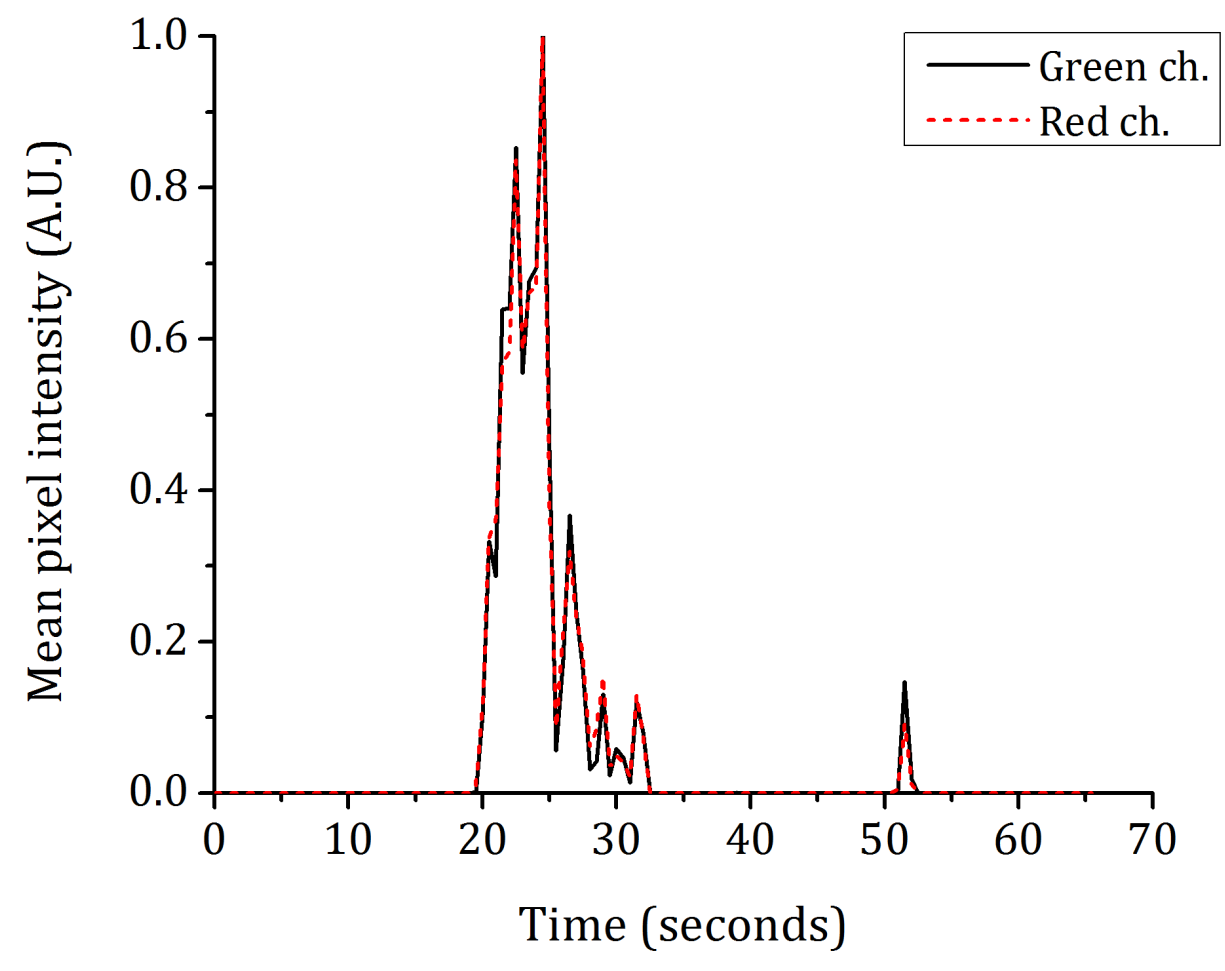

Figure 15: Example results from test \#2 showing that the normalized pixel intensity data of the red color channel is almost equal to that of the green color channel. 
(a)

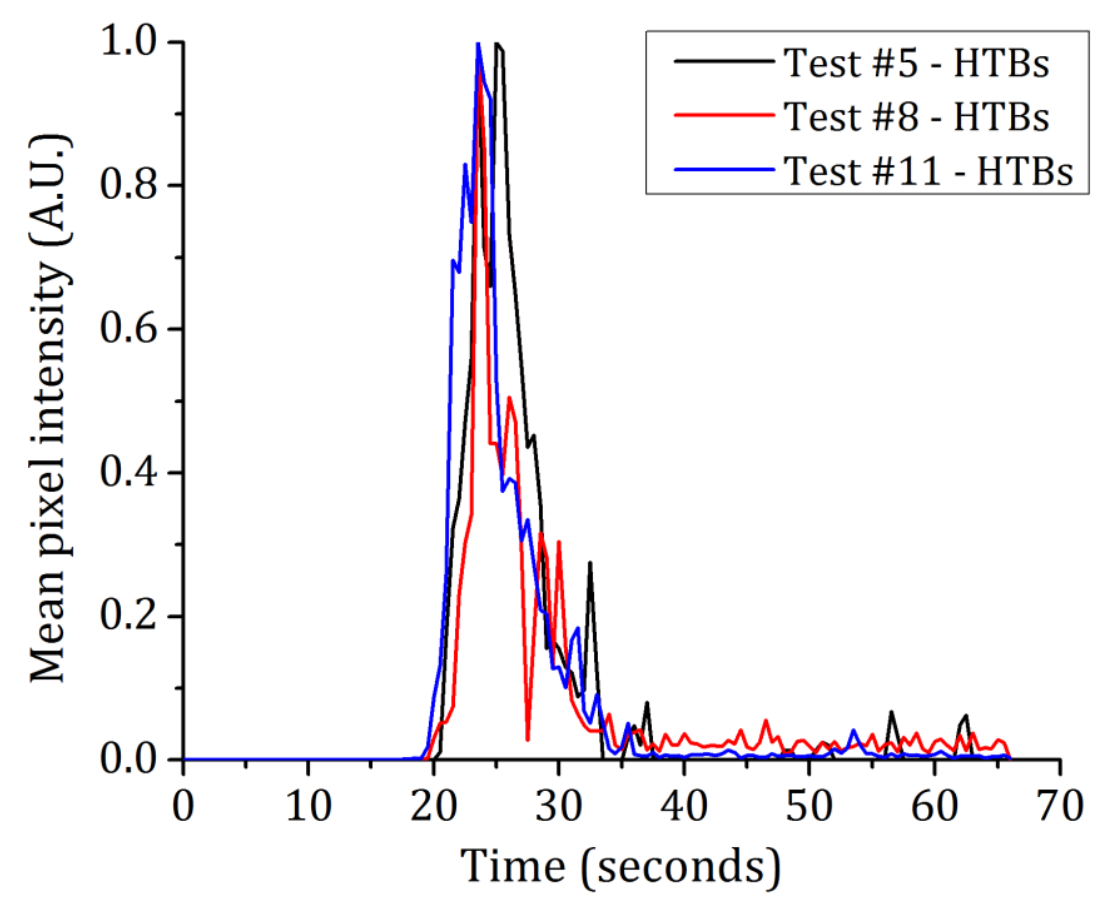

(b)

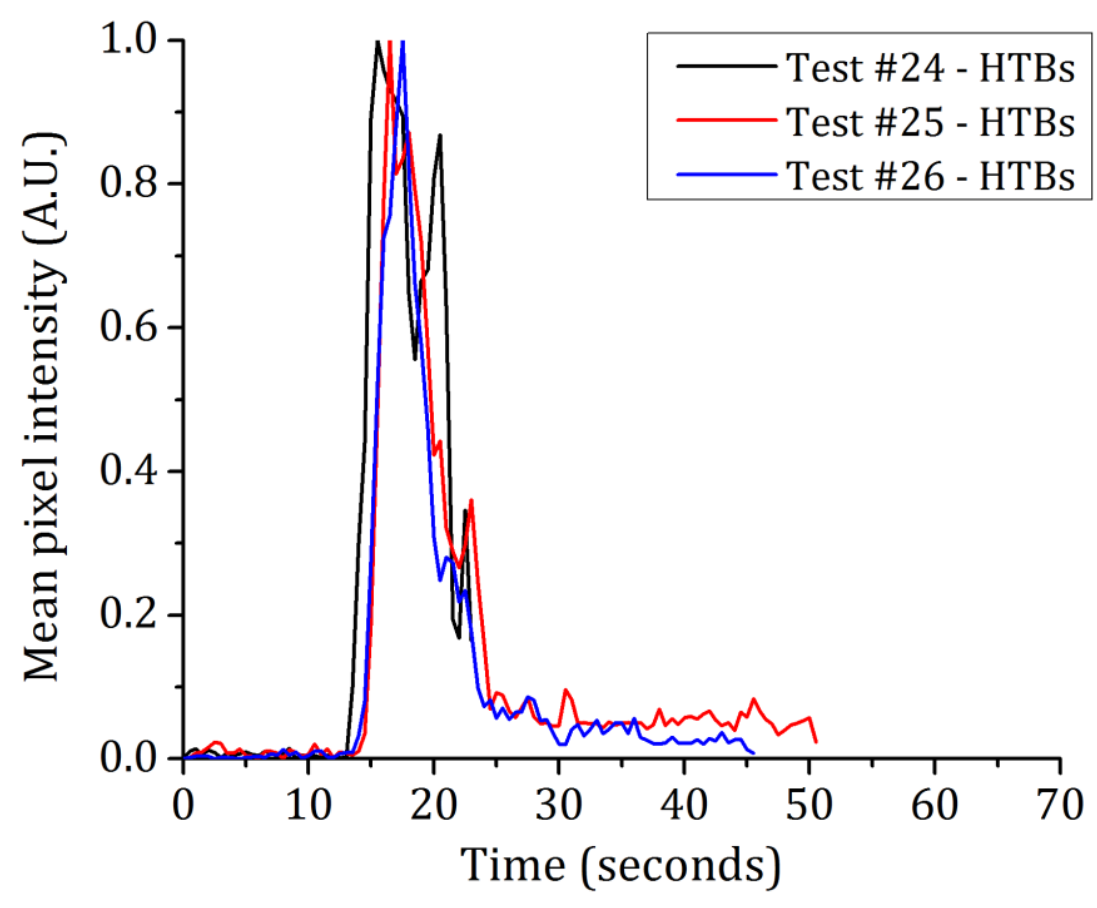

Figure 16: Breakthrough curves from selected tests conducted at (a) the low and (b) the high flow rate with the HTBs. These breakthrough curves are of from the mean pixel intensity results of the red channel. 


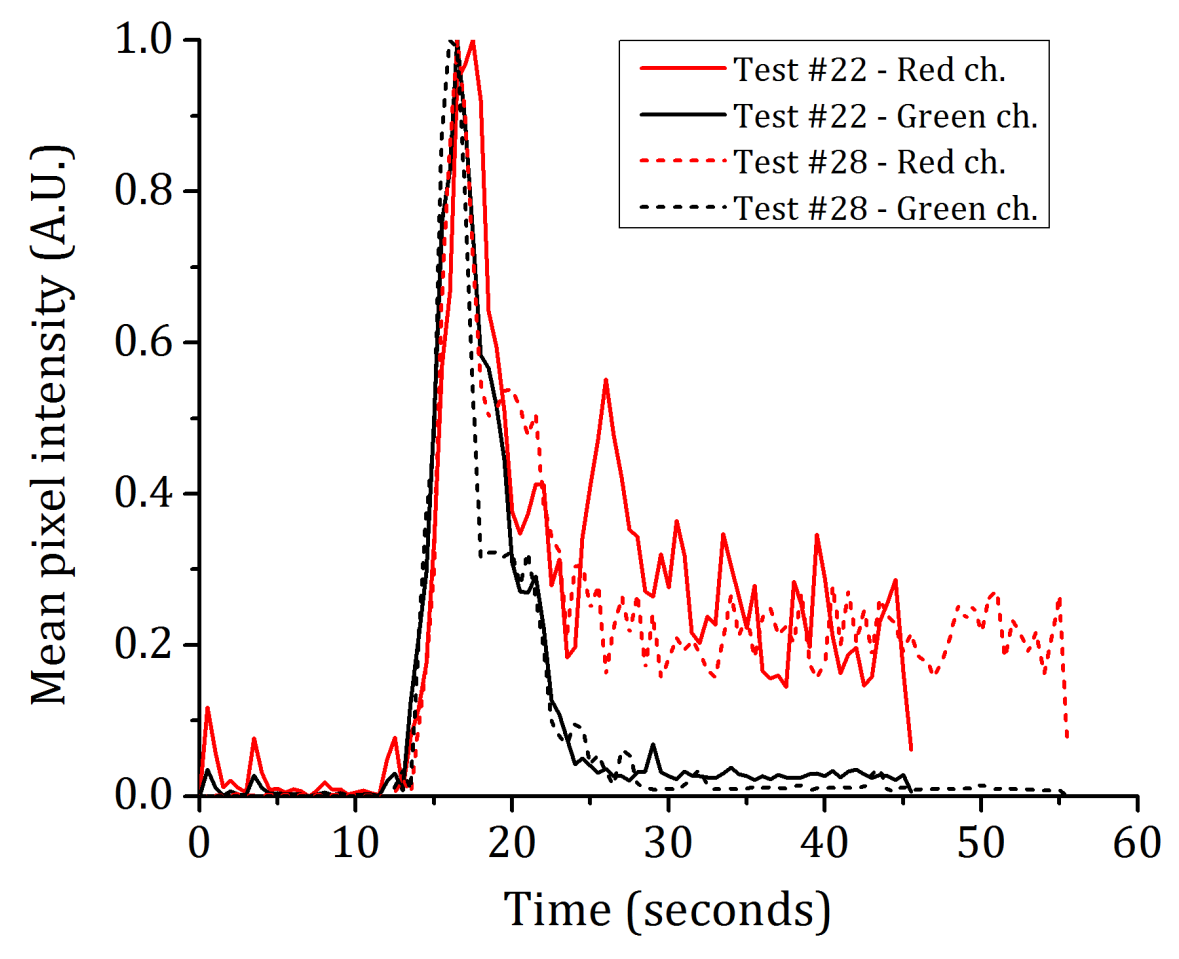

Figure 17: Breakthrough curves from tests \#22 and \#28 - Comparing results from the red color channel to the green color channel. 
Table 3: Results of the HTB traces as calculated by QTRACER2 for experiments conducted at the lower flow rate $(1.9 \mathrm{~L} / \mathrm{s})$ in the Experimental Stream Facility.

\begin{tabular}{cccccccc}
\hline Test \# & $\begin{array}{c}\text { \# of } \\
\text { HTBs }\end{array}$ & $\begin{array}{c}\text { Time of } \\
\text { first } \\
\text { detection } \\
\text { (sec) }\end{array}$ & $\begin{array}{c}\text { Time of } \\
\text { peak } \\
\text { conc. } \\
\text { (sec) }\end{array}$ & $\begin{array}{c}\text { Mean } \\
\text { tracer } \\
\text { velocity } \\
\text { (m/h) }\end{array}$ & $\begin{array}{c}\text { Peak } \\
\text { tracer } \\
\text { velocity } \\
\text { (m/h) }\end{array}$ & $\begin{array}{c}\text { Mean } \\
\text { transit } \\
\text { time } \\
\text { (sec) }\end{array}$ & $\begin{array}{c}\text { Long. } \\
\text { disp. } \\
\text { (cm) }\end{array}$ \\
\hline 1 & 100 & 20.0 & 24.0 & 881 & 1064 & 24.1 & 3.8 \\
2 & 100 & 19.5 & 24.5 & 878 & 1091 & 24.2 & 2.8 \\
4 & 200 & 20.0 & 26.0 & 755 & 1064 & 28.1 & 1.7 \\
5 & 200 & 20.5 & 25.0 & 805 & 1038 & 26.4 & 1.8 \\
7 & 200 & 19.0 & 26.5 & 790 & 1120 & 26.9 & 4.5 \\
8 & 200 & 20.0 & 23.5 & 751 & 1064 & 28.3 & 1.2 \\
10 & 200 & 20.0 & 25.0 & 825 & 1064 & 25.7 & 2.4 \\
11 & 200 & 19.5 & 23.5 & 851 & 1091 & 25.0 & 1.4 \\
13 & 300 & 19.0 & 26.5 & 694 & 1120 & 30.7 & 2.6 \\
14 & 300 & 20.5 & 23.5 & 810 & 1038 & 26.2 & 1.5 \\
16 & 400 & 20.5 & 28.0 & 747 & 1038 & 28.4 & 9.0 \\
17 & 400 & 19.5 & 22.5 & 765 & 1091 & 27.8 & 3.3 \\
\hline 19 & 500 & 17.5 & 23.0 & 872 & 1216 & 24.4 & 1.7 \\
Mean & & 20.0 & 23.5 & 758 & 1064 & 28.0 & 2.1 \\
\hline STD & & 19.7 & 24.6 & 799 & 1083 & 26.7 & 2.8 \\
\hline
\end{tabular}

STD: standard deviation, RSD: relative standard deviation, Time of peak conc.: time of peak concentration, Long. disp.: longitudinal dispersion. Results from BTCs made with the mean pixel intensity data of the red color channel. 
Table 4: Results of HTB traces as calculated by QTRACER2 for experiments conducted at the higher flow rate $(3.2 \mathrm{~L} / \mathrm{s})$ in the Experimental Stream Facility.

\begin{tabular}{|c|c|c|c|c|c|c|c|}
\hline Test \# & Pigment & $\begin{array}{c}\text { Time of } \\
\text { first } \\
\text { detection } \\
\text { (sec) }\end{array}$ & $\begin{array}{c}\text { Time of } \\
\text { peak } \\
\text { conc. } \\
\text { (sec) }\end{array}$ & $\begin{array}{c}\text { Mean } \\
\text { tracer } \\
\text { velocity } \\
(\mathrm{m} / \mathrm{h}) \\
\end{array}$ & $\begin{array}{c}\text { Peak } \\
\text { tracer } \\
\text { velocity } \\
(\mathrm{m} / \mathrm{h}) \\
\end{array}$ & $\begin{array}{c}\text { Mean } \\
\text { transit } \\
\text { time } \\
\text { (sec) }\end{array}$ & $\begin{array}{l}\text { Long. } \\
\text { disp. } \\
(\mathrm{cm})\end{array}$ \\
\hline 22 & Green & 14.5 & 17.5 & 896 & 1467 & 23.7 & 4.6 \\
\hline 23 & C. Orange & 14.0 & 17.5 & 1088 & 1520 & 19.5 & 2.4 \\
\hline 24 & Red & 13.5 & 15.5 & 1190 & 1576 & 17.8 & 3.9 \\
\hline 25 & Green & 14.5 & 16.5 & 1020 & 1467 & 20.8 & 3.0 \\
\hline 26 & C. Orange & 14.0 & 17.5 & 1083 & 1520 & 19.6 & 2.2 \\
\hline 27 & Red & 14.5 & 16.0 & 1173 & 1467 & 18.1 & 1.7 \\
\hline 28 & Green & 14.0 & 16.5 & 715 & 1520 & 29.7 & 22.2 \\
\hline 29 & C. Orange & 14.0 & 16.0 & 1164 & 1520 & 18.2 & 1.4 \\
\hline 30 & Red & 11.5 & 17.5 & 1200 & 1850 & 17.7 & 2.4 \\
\hline Mean & & 13.8 & 16.7 & 1059 & 1545 & 20.6 & 4.9 \\
\hline STD & & 0.94 & 0.79 & 162 & 120 & 3.91 & 6.6 \\
\hline RSD (\%) & & 6.76 & 4.75 & 15.3 & 7.75 & 19.0 & 135.2 \\
\hline
\end{tabular}

STD: standard deviation, RSD: relative standard deviation, Time of peak conc.: time of peak concentration, Long. disp.: longitudinal dispersion. Results from BTCs made with the mean pixel intensity data of the red color channel. 
Table 5: Percent recovery of HTBs for tracer tests conducted in the Experimental Stream Facility. Tests 1-20 were conducted at the lower flow rate $(1.9 \mathrm{~L} / \mathrm{s})$, whereas tests $22-30$ were conducted at the higher flow rate $(3.2 \mathrm{~L} / \mathrm{s})$.

\begin{tabular}{ccccc}
\hline Test \# & $\begin{array}{c}\text { HTBs } \\
\text { released }\end{array}$ & $\begin{array}{c}\text { HTBs } \\
\text { recovered }\end{array}$ & Recovery (\%) & $\begin{array}{c}\text { Mean } \\
\text { recovery (\%) }\end{array}$ \\
\hline 1 & 100 & 40 & 40 & \\
2 & 100 & 59 & 59 & \\
4 & 200 & 71 & 36 & \\
5 & 200 & 76 & 38 & \\
7 & 200 & 80 & 40 & \\
8 & 200 & 109 & 55 & \\
10 & 200 & 92 & 46 & \\
11 & 200 & 120 & 60 & \\
13 & 300 & 102 & 34 & \\
14 & 300 & 141 & 47 & \\
16 & 400 & 182 & 46 & \\
17 & 400 & 253 & 63 & \\
19 & 500 & 274 & 55 & \\
20 & 500 & 248 & 50 & \\
22 & 200 & 109 & 55 & \\
23 & 200 & 124 & 62 & \\
24 & 200 & 132 & 66 & \\
25 & 200 & 64 & 32 & \\
26 & 200 & 87 & 44 & \\
27 & 200 & 126 & 63 & \\
28 & 200 & 95 & 48 & \\
29 & 200 & 96 & 48 & \\
30 & 200 & 106 & 53 & \\
\hline
\end{tabular}


Table 6: Results of ANOVA on the transport parameters obtained from the tracer tests conducted at the lower flow rate in the Experimental Stream Facility.

\begin{tabular}{lccccc}
\hline Parameter & $\begin{array}{c}\text { Between } \\
\text { variation } \\
\text { MSTR }\end{array}$ & $\begin{array}{c}\text { Within } \\
\text { variation } \\
\text { MSE }\end{array}$ & $\begin{array}{c}\text { F- } \\
\text { value }\end{array}$ & $\begin{array}{c}\text { P- } \\
\text { value }\end{array}$ & $\begin{array}{c}\text { ANOVA } \\
\text { Outcome }\end{array}$ \\
\hline $\begin{array}{l}\text { Time of first } \\
\text { detection }\end{array}$ & 0.52 & 0.69 & 0.76 & 0.58 & $\begin{array}{c}\text { No } \\
\text { significant } \\
\text { difference } \\
\text { No }\end{array}$ \\
$\begin{array}{l}\text { Time of peak } \\
\text { concentration }\end{array}$ & 1.4 & 3.1 & 0.46 & 0.76 & $\begin{array}{c}\text { significant } \\
\text { difference } \\
\text { No }\end{array}$ \\
$\begin{array}{l}\text { Mean tracer } \\
\text { velocity }\end{array}$ & $5.3 \mathrm{E}^{*} 10^{3}$ & $2.3^{*} 10^{3}$ & 2.3 & 0.14 & $\begin{array}{c}\text { significant } \\
\text { difference } \\
\text { No }\end{array}$ \\
$\begin{array}{l}\text { Peak tracer } \\
\text { velocity }\end{array}$ & $1.9 \mathrm{E}^{*} 10^{3}$ & $2.3^{*} 10^{3}$ & 0.84 & 0.53 & $\begin{array}{c}\text { significant } \\
\text { difference } \\
\text { No }\end{array}$ \\
$\begin{array}{l}\text { Mean transit } \\
\text { time }\end{array}$ & 5.9 & 2.8 & 2.1 & 0.17 & $\begin{array}{c}\text { significant } \\
\text { difference } \\
\text { No }\end{array}$ \\
$\begin{array}{l}\text { Longitudinal } \\
\text { Dispersion }\end{array}$ & $7.2 \mathrm{E}^{*} 10^{-4}$ & $2.7^{*} 10^{-4}$ & 2.6 & 0.11 & $\begin{array}{c}\text { significant } \\
\text { difference }\end{array}$ \\
\hline
\end{tabular}

MSTR and MSE stand for mean square treatment and mean square error, respectively. MSTR is the average between variations and MSE is the average within variations. The critical F-value for $\alpha=0.05, \mathrm{df} 1=4$, and df2 $=9$ is 3.63. For each parameter $n=14$. 
Table 7: Results of ANOVA on the transport parameters obtained from the tracer tests conducted at the higher flow rate in the Experimental Stream Facility.

\begin{tabular}{|c|c|c|c|c|c|}
\hline Parameter & $\begin{array}{c}\text { Between } \\
\text { variation } \\
\text { MSTR }\end{array}$ & $\begin{array}{c}\text { Within } \\
\text { variation } \\
\text { MSE }\end{array}$ & $\begin{array}{c}\text { F- } \\
\text { value }\end{array}$ & $\begin{array}{c}P \text { - } \\
\text { value }\end{array}$ & $\begin{array}{c}\text { ANOVA } \\
\text { Outcome }\end{array}$ \\
\hline $\begin{array}{l}\text { Time of first } \\
\text { detection }\end{array}$ & 1.1 & 0.81 & 1.3 & 0.33 & $\begin{array}{c}\text { No } \\
\text { significant } \\
\text { difference }\end{array}$ \\
\hline $\begin{array}{l}\text { Time of peak } \\
\text { concentration }\end{array}$ & 0.36 & 0.72 & 0.50 & 0.63 & $\begin{array}{c}\text { No } \\
\text { significant } \\
\text { difference }\end{array}$ \\
\hline $\begin{array}{l}\text { Mean tracer } \\
\text { velocity }\end{array}$ & $7.8 * 10^{4}$ & $2.3^{*} 10^{3}$ & 9.2 & 0.01 & $\begin{array}{l}\text { Significant } \\
\text { difference }\end{array}$ \\
\hline $\begin{array}{l}\text { Peak tracer } \\
\text { velocity }\end{array}$ & $1.7 * 10^{4}$ & $1.3^{*} 10^{4}$ & 1.3 & 0.33 & $\begin{array}{c}\text { No } \\
\text { significant } \\
\text { difference }\end{array}$ \\
\hline $\begin{array}{l}\text { Mean transit } \\
\text { time }\end{array}$ & 40 & 7.1 & 5.7 & 0.04 & $\begin{array}{l}\text { Significant } \\
\text { difference }\end{array}$ \\
\hline $\begin{array}{l}\text { Longitudinal } \\
\text { Dispersion }\end{array}$ & $5.8^{*} 10^{-3}$ & $3.8^{*} 10^{-3}$ & 1.5 & 0.29 & $\begin{array}{c}\text { No } \\
\text { significant } \\
\text { difference }\end{array}$ \\
\hline
\end{tabular}

MSTR and MSE stand for mean square treatment and mean square error, respectively. MSTR is the average between variations and MSE is the average within variations. The critical F-value for $\alpha=0.05, \mathrm{df} 1=2 \mathrm{and}$ df2 $=6$ is 5.14 . For each parameter $n=9$. 
Table 8: Results of tests 22 and 28 as calculated by QTRACER2 from BTCs made with data from the red and green color channels. Absolute percent difference between the results of the red and green color channels is also shown.

\begin{tabular}{ccccccc}
\hline Test \# & $\begin{array}{c}\text { Color } \\
\text { Channel }\end{array}$ & $\begin{array}{c}\text { Time of } \\
\text { first } \\
\text { detection } \\
\text { (sec) }\end{array}$ & $\begin{array}{c}\text { Time of } \\
\text { peak conc. } \\
\text { (sec) }\end{array}$ & $\begin{array}{c}\text { Mean } \\
\text { tracer } \\
\text { velocity } \\
\text { (m/h) }\end{array}$ & $\begin{array}{c}\text { Peak } \\
\text { tracer } \\
\text { velocity } \\
\text { (m/h) }\end{array}$ & $\begin{array}{c}\text { Mean } \\
\text { transit } \\
\text { time (sec) }\end{array}$ \\
\hline \multirow{2}{*}{22} & Red & 14.5 & 17.5 & 896 & 1467 & 23.7 \\
& Green & 14.0 & 16.5 & 1229 & 1520 & 17.3 \\
\hline Abs. \% difference & 3.57 & 6.06 & 27.1 & 3.45 & 37.0 \\
\hline & Red & 14.0 & 16.5 & 715 & 1520 & 29.7 \\
\hline & Green & 14.0 & 16.0 & 1220 & 1520 & 17.5 \\
\hline Abs. \% difference & 0.00 & 3.13 & 41.4 & 0.00 & 69.7 \\
\hline
\end{tabular}

Time of peak conc.: time of peak concentration 
Table 9: Results of ANOVA on mean travel velocity and mean transit time after analyzing the BTCs of the green channel for tests 22 and 28 in QTRACER2.

\begin{tabular}{lccccc}
\hline Parameter & $\begin{array}{c}\text { Between } \\
\text { variation } \\
\text { MSTR }\end{array}$ & $\begin{array}{c}\text { Within } \\
\text { variation } \\
\text { MSE }\end{array}$ & F-value & P-value & $\begin{array}{c}\text { ANOVA } \\
\text { Outcome }\end{array}$ \\
\hline $\begin{array}{l}\text { Mean tracer } \\
\text { velocity }\end{array}$ & $4.4^{*} 10^{3}$ & $5.4^{*} 10^{3}$ & 0.82 & 0.49 & $\begin{array}{c}\text { No } \\
\text { significant } \\
\text { difference } \\
\text { No }\end{array}$ \\
$\begin{array}{l}\text { Mean transit } \\
\text { time }\end{array}$ & 1.2 & 1.5 & 0.75 & 0.51 & $\begin{array}{c}\text { significant } \\
\text { difference }\end{array}$ \\
\hline
\end{tabular}

MSTR and MSE stand for mean square treatment and mean square error, respectively. MSTR is the average between variations and MSE is the average within variations. The critical F-value for $\alpha=0.05, \mathrm{df} 1=2$ and df2 $=6$ is 5.14. For each parameter $n=9$. 


\subsubsection{Comparison of bead and solute tracers in the Experimental Stream Facility}

The results from the solute traces were precise (Table 10-11). In tests conducted at the low-flow rate, the solute tracer was detected for the first time after an average of 20.3 seconds and its concentration peaked after an average of 28.5 seconds. Whereas in tests conducted at the high-flow rate, it was detected after an average of 11.1 seconds and their concentration peaked after an average of 18.0 seconds. At both flow rates, the solute tracer traveled from the release point to the collection point in less than 31 seconds and its average longitudinal dispersion was less than $9 \mathrm{~cm}$. The average tracer recovery was $65 \%$ at the low-flow rate and $54 \%$ at the high-flow rate. The lower recovery at the high-flow rate can be attributed to the dilution of the tracer.

In order to compare the transport of the HTBs to the solute tracer, some assumptions were made with regards to the QTRACER2 results from the tests with HTBs. For the tests conducted at the low-flow rate, it was assumed that the results were from tests in which the same quantities and pigments of HTBs were used. For the tracer tests conducted at the high-flow rate, it was assumed that the results were from tests in which HTBs made of the same pigment were used. These assumptions are justifiable because ANOVA analyses indicated that there was no significant difference in the means of the transport parameters calculated by QTRACER2.

In tests conducted at the low-flow rate, the HTBs traveled faster than the solute tracer (Figure 18a). The HTBs were first detected an average of 19.7 seconds after being released and 0.6 seconds before the solute tracer (Table 12). The concentration of the HTBs was at its highest at an average of 24.6 seconds after tests began and 3.9 seconds before 
that of the solute tracer. The mean and peak velocity of the HTBs was higher than that of the solute tracer by an average of 109 and $33 \mathrm{~m} / \mathrm{h}$, respectively. The HTBs traveled from the release point to the collection point 4.1 seconds faster than the solute tracer.

In the tests conducted at the high-flow rate, the HTBs also traveled faster than the solute tracer (Figure 18b). The HTBs were detected an average of 13.8 seconds after being released, but differently from the tests at the low-flow rate, they were detected 2.7 seconds after the solute tracer (Table 12). Despite that the HTBs were detected 2.7 seconds after the solute tracer; their concentration was at its highest an average of 1.3 seconds before that of the solute tracer. Mean velocity results showed that the HTBs traveled slightly faster than the solute tracer, but peak velocity results showed that the solute tracer traveled at a faster maximum velocity. The difference in the time it took the tracers to travel from the release to collection point was small ( 0.2 seconds). The average longitudinal dispersion of the HTBs and the solute tracer were $6 \mathrm{~cm}$ and $8 \mathrm{~cm}$, respectively.

At both flow rates the HTBs traveled faster than the solute tracer. The difference in travel time between the tracers decreased from low-flow to high-flow conditions. In highflow conditions, the solute tracer was detected for the first time before the HTBs, but the concentration of the HTBs peaked before that of the solute tracer, which suggests that the solute tracer traveled in more of a dispersive manner. 
Table 10: Results of the solute traces as calculated by QTRACER2 for experiments conducted at the lower flow rate $(1.9 \mathrm{~L} / \mathrm{s})$ in the Experimental Stream Facility.

\begin{tabular}{ccccccc}
\hline Test \# & $\begin{array}{c}\text { Time of } \\
\text { first } \\
\text { detection } \\
\text { (sec) }\end{array}$ & $\begin{array}{c}\text { Time of } \\
\text { peak } \\
\text { conc. } \\
\text { (sec) }\end{array}$ & $\begin{array}{c}\text { Mean } \\
\text { tracer } \\
\text { velocity } \\
\text { (m/h) }\end{array}$ & $\begin{array}{c}\text { Peak } \\
\text { tracer } \\
\text { velocity } \\
\text { (m/h) }\end{array}$ & $\begin{array}{c}\text { Mean } \\
\text { transit } \\
\text { time (sec) }\end{array}$ & $\begin{array}{c}\text { Long. } \\
\text { disp. (cm) }\end{array}$ \\
\hline 1 & 20 & 27 & 733 & 1064 & 29 & 3.7 \\
2 & 20 & 28 & 705 & 1064 & 30.1 & 3.9 \\
4 & 20 & 29 & 681 & 1064 & 31.2 & 3.6 \\
5 & 20 & 29 & 715 & 1064 & 29.7 & 3.5 \\
7 & 20 & 29 & 669 & 1064 & 31.7 & 4.3 \\
8 & 21 & 30 & 683 & 1013 & 31.1 & 3.8 \\
10 & 21 & 25 & 696 & 1013 & 30.5 & 2.4 \\
11 & 20 & 29 & 680 & 1064 & 31.3 & 3.5 \\
13 & 20 & 29 & 699 & 1064 & 30.4 & 3.7 \\
14 & 21 & 30 & 675 & 1013 & 31.5 & 3.9 \\
16 & 21 & 28 & 688 & 1013 & 30.9 & 4.2 \\
17 & 20 & 29 & 668 & 1064 & 31.8 & 4.0 \\
19 & 19 & 28 & 695 & 1120 & 30.6 & 3.3 \\
20 & 21 & 29 & 677 & 1013 & 31.4 & 3.8 \\
\hline Mean & 20.3 & 28.5 & 690 & 1050 & 30.8 & 3.7 \\
STD & 0.61 & 1.29 & 18.4 & 32.0 & 0.80 & 0.5 \\
RSD (\%) & 3.01 & 4.51 & 2.66 & 3.05 & 2.61 & 12.5 \\
\hline
\end{tabular}

STD: standard deviation, RSD: relative standard deviation, Time of peak conc.: time of peak concentration, Long. disp.: longitudinal dispersion 
Table 11: Results of the solute traces as calculated by QTRACER2 for experiments conducted at the higher flow rate $(3.2 \mathrm{~L} / \mathrm{s})$ in the Experimental Stream Facility.

\begin{tabular}{|c|c|c|c|c|c|c|}
\hline Test \# & $\begin{array}{c}\text { Time of } \\
\text { first } \\
\text { detection } \\
\text { (sec) }\end{array}$ & $\begin{array}{c}\text { Time of } \\
\text { peak } \\
\text { conc. } \\
\text { (sec) } \\
\end{array}$ & $\begin{array}{c}\text { Mean } \\
\text { tracer } \\
\text { velocity } \\
(\mathrm{m} / \mathrm{h}) \\
\end{array}$ & $\begin{array}{c}\text { Peak } \\
\text { tracer } \\
\text { velocity } \\
(\mathrm{m} / \mathrm{h}) \\
\end{array}$ & $\begin{array}{c}\text { Mean } \\
\text { transit } \\
\text { time }(s e c)\end{array}$ & $\begin{array}{c}\text { Long. } \\
\text { disp. }(\mathrm{cm})\end{array}$ \\
\hline 22 & 12 & 20 & 996 & 1773 & 21.3 & 7.7 \\
\hline 23 & 11 & 17 & 1081 & 1934 & 19.7 & 7.0 \\
\hline 24 & 12 & 18 & 1026 & 1773 & 20.7 & 7.5 \\
\hline 25 & 10 & 16 & 1159 & 2128 & 18.4 & 8.9 \\
\hline 26 & 11 & 17 & 1068 & 1934 & 19.9 & 8.8 \\
\hline 27 & 10 & 18 & 1026 & 2128 & 20.7 & 9.5 \\
\hline 28 & 11 & 18 & 1051 & 1934 & 20.2 & 7.7 \\
\hline 29 & 11 & 19 & 987 & 1934 & 21.5 & 8.3 \\
\hline 30 & 12 & 19 & 1015 & 1773 & 20.9 & 6.8 \\
\hline Mean & 11.1 & 18.0 & 1045 & 1923 & 20.4 & 8.0 \\
\hline STD & 0.78 & 1.22 & 52.6 & 137.7 & 0.97 & 0.9 \\
\hline RSD (\%) & 7.04 & 6.80 & 5.03 & 7.16 & 4.76 & 11.3 \\
\hline
\end{tabular}

STD: standard deviation, RSD: relative standard deviation, Time of peak conc.: time of peak concentration, Long. disp.: longitudinal dispersion 
(a)

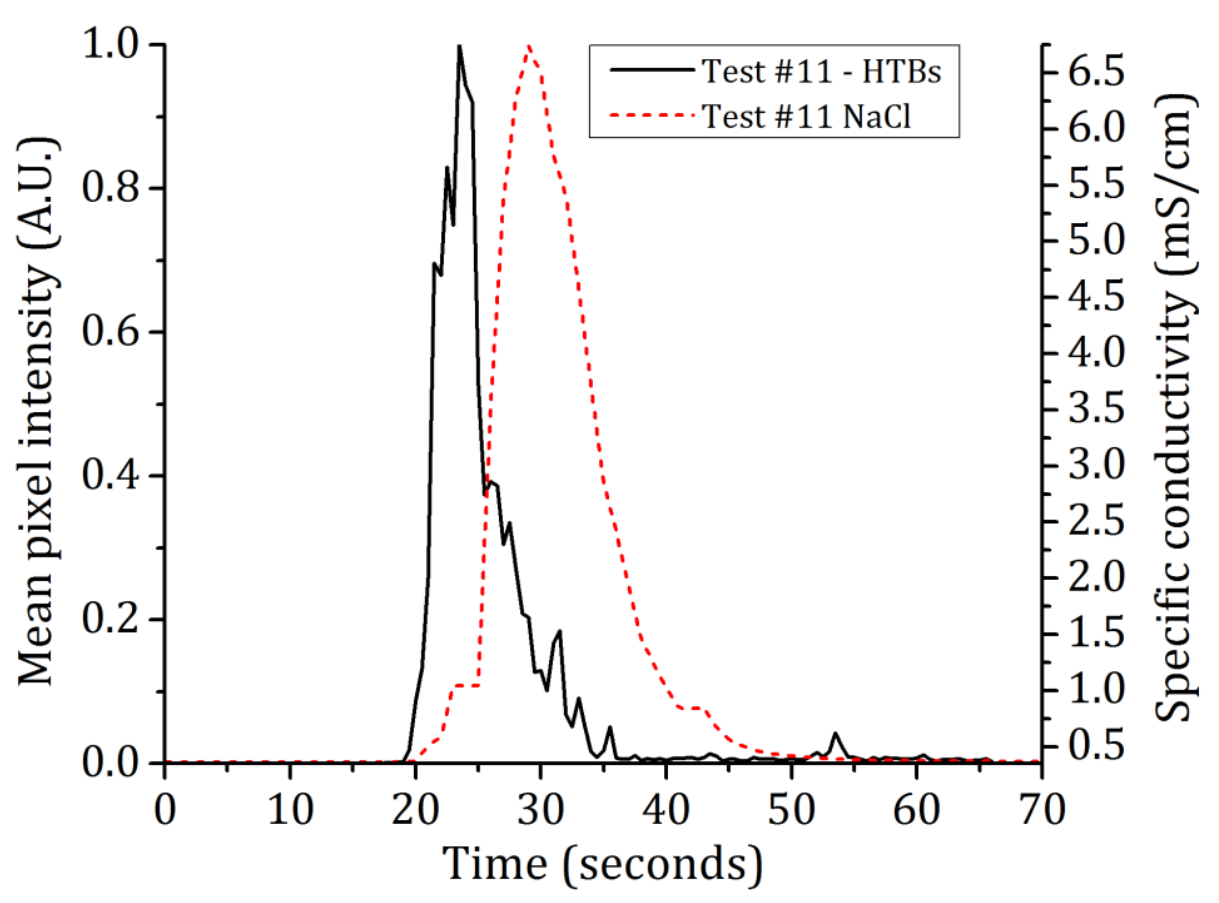

(b)

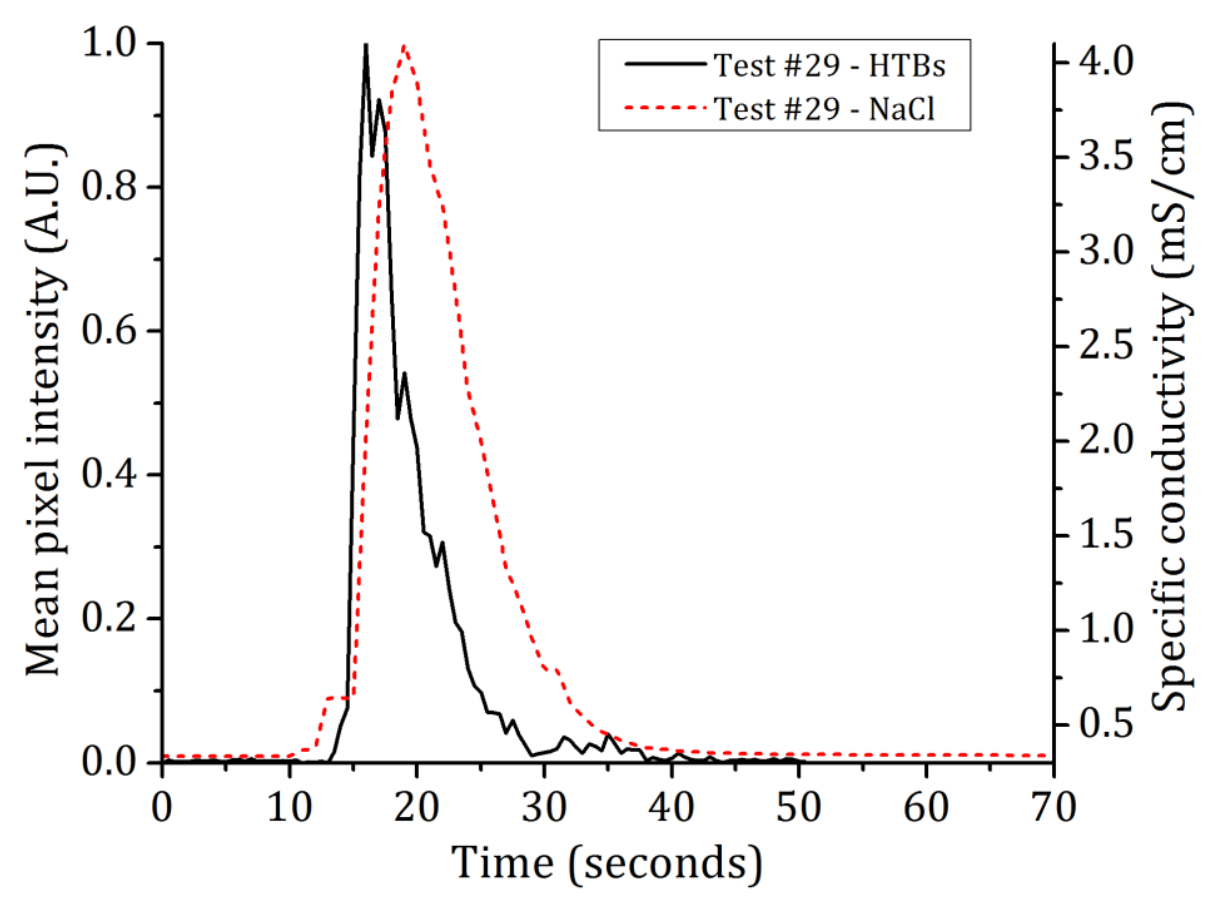

Figure 18: Example breakthrough curves of a tests (a) \#19 and (b) \#29 - Comparing the transport of the HTBs to the solute tracer. 
Table 12: Mean results from QTRACER2 for the tracer tests conducted with HTBs and solutes at the low- and high-flow rates in the Experimental Stream Facility. The absolute \% difference between the tracers each shown for each of the transport parameters.

\begin{tabular}{|c|c|c|c|c|c|c|c|}
\hline Flow rate & Tracer & $\begin{array}{c}\text { Time of } \\
\text { first } \\
\text { detection } \\
\text { (sec) } \\
\end{array}$ & $\begin{array}{c}\text { Time of } \\
\text { peak } \\
\text { conc. } \\
\text { (sec) }\end{array}$ & $\begin{array}{c}\text { Mean } \\
\text { tracer } \\
\text { velocity } \\
(\mathrm{m} / \mathrm{h}) \\
\end{array}$ & $\begin{array}{c}\text { Peak } \\
\text { tracer } \\
\text { velocity } \\
(\mathrm{m} / \mathrm{h}) \\
\end{array}$ & $\begin{array}{c}\text { Mean } \\
\text { transit } \\
\text { time } \\
\text { (sec) } \\
\end{array}$ & $\begin{array}{l}\text { Long. } \\
\text { disp. } \\
\text { (cm) }\end{array}$ \\
\hline \multirow{3}{*}{$\begin{array}{l}\text { Lower } \\
(n=14)\end{array}$} & $\begin{array}{c}\text { Mean } \\
\text { (HTBs) }\end{array}$ & 19.7 & 24.6 & 799 & 1083 & 26.7 & 2.8 \\
\hline & $\begin{array}{c}\text { Mean } \\
\text { (Solutes) }\end{array}$ & 20.3 & 28.5 & 690 & 1050 & 30.8 & 3.7 \\
\hline & $\begin{array}{c}\text { Abs. } \\
\text { difference }\end{array}$ & 0.6 & 3.9 & 109 & 33 & 4.1 & 0.9 \\
\hline \multirow{3}{*}{$\begin{array}{c}\text { Higher } \\
(n=9)\end{array}$} & $\begin{array}{c}\text { Mean } \\
\text { (HTBs) }\end{array}$ & 13.8 & 16.7 & 1059 & 1545 & 20.6 & 4.9 \\
\hline & $\begin{array}{c}\text { Mean } \\
\text { (Solutes) }\end{array}$ & 11.1 & 18.0 & 1045 & 1923 & 20.4 & 8.0 \\
\hline & $\begin{array}{c}\text { Abs. } \\
\text { difference }\end{array}$ & 2.7 & 1.3 & 14 & 378 & 0.2 & 3.1 \\
\hline
\end{tabular}

Time of peak conc.: time of peak concentration, Long. disp.: longitudinal dispersion 


\subsection{Field experiments in Buckeye Creek Cave}

\subsubsection{Applicability of the optical quantification method}

The duration of the two field tests in Buckeye Creek Cave was approximately 50 minutes each. Both tests were conducted on the same day and assumed to be at the same discharge, which was measured in only two sections of the studied transect. The average discharge at the time of testing was $9.1 \mathrm{~L} / \mathrm{s}$. The low-flow conditions during the time of the tests allowed for the collection of most of the HTBs that passed by the experimental system. The recoveries were $77 \%$ in test 1 and $71 \%$ in test 2 . Many of the remaining HTBs were seen immobile along the walls of the canyon in the traced section.

The BTCs generated from the mean pixel intensity results of the red color channel are shown in Figure 19. It took about ca. 16.5 minutes for the HTBs to travel from the release point to the experimental system. In order to save battery-life, videos of the transport of the HTBs were obtained from a minute before the HTBs reached the experimental system until the tests concluded. During test 1 , the camera was accidentally turned-off once for ca. 2minutes. The data lost during the initial ca. 16.5 minutes and during the accidental turn-off of the camera in test 1 were interpolated using a linear method. The data interpolation was made in MATLAB using the exact number of data points (e.g. images) in the videos of each test.

Before analyzing the interpolated BTCs in QTRACER2, the noise in the data was removed using a Savitzky-Golay smoothing filter (Savitzky and Golay, 1964). The data were smoothed in MATLAB using 50, 100, 150, and 200 central points and a $2^{\text {nd }}$ degree polynomial to create four BTCs (Figure 20). For both tests, the four BTCs were analyzed in 
QTRACER2 in order to determine how their shape influenced the results calculated by the program. Table 13 shows that there is not much difference in the calculated results. The parameters whose results show a slight difference are time of first detection, time of peak concentration, peak tracer velocity, and longitudinal dispersion.

The video recordings were visually inspected to determine which BTCs gave a closely accurate time of first detection and time of peak concentration. The HTBs were visible for the first time 16.5 minutes into test 1 and 18.5 minutes into test 2 . The highest quantity of visible HTBs occurred between 28.5 and 28.8 minutes in test 1 and between 27.4 and 27.8 minutes in test 2 . When these findings are compared to the results outputted by QTRACER2 (Table 13), they indicate that the BTCs smoothed with 100 central points are the most accurate.

The mean and peak tracer velocities calculated by QTRACER2 from BTCs smoothed with 100 central points were 110 and $213 \mathrm{~m} / \mathrm{h}$, respectively in test 1, and 102 and 191 $\mathrm{m} / \mathrm{h}$, respectively in test 2 (Table 14 ). The time it took the HTBs to travel from the release point to the collection point was 32.3 minutes in test 1 and 34.7 minutes in test 2 . The longitudinal dispersion of the HTBs in test 1 was $1.2 \mathrm{~m}$. However, a warning message in QTRACER2 indicated this value was most likely overestimated. The longitudinal dispersion in test 2 was $1.0 \mathrm{~m}$ and no overestimation warning message appeared. The QTRACER2 results from the BTCs smoothed with 100 points were used in the next sections.

The results indicate that the optical quantification method can be applied in tests of longer duration. However, the limited battery-life of the camera was a problem which led to the interpolation of missing data points. In addition, the data from the field tests had 
much more noise than that from the laboratory tests. The noise had to be filtered out in order to analyze the data in QTRACER2. Both data interpolation and smoothing added error to the results obtained from QTRACER2. The degree of this error is not quantifiable and thus unknown.

\subsubsection{Optical quantification method versus manual counting}

The HTBs transported past the optical detection system were collected and manually counted. In test 1 , the HTBs were collected for 60 -second intervals, but in test 2 they were collected for 120 -second intervals. BTCs were generated after the HTBs were manually counted twice (Figure 21). Missing data points were interpolated using a linear method. These interpolated BTCs were analyzed in QTRACER2.

QTRACER2 results from test 1 and 2 indicated that the manually collected HTBs were detected for the first time after an average of 18.2 and 21.0 minutes, respectively (Table 14). The concentration of the HTBs peaked after an average of 28.2 minutes in test 1and after 33 minutes in test 2. In both tests, the HTBs traveled from the release point to the collection point in less than 36minutes. A warning message indicated that QTRACER2 overestimated the longitudinal dispersion of the HTBs in test 1. The overestimated dispersion was $1.0 \mathrm{~m}$. In test 2, the longitudinal dispersion was estimated to be $0.1 \mathrm{~m}$ without a warning message.

Percent difference was used to compare the difference between and within the results of the optical and manual methods (Figure 22, Table 15). With exception of longitudinal dispersion, the results of both methods agreed within $10 \%$ in test 1 . The agreement between the results of both methods was particularly good for peak 
concentration time, mean tracer velocity and mean transit time (e.g. agreement was within $3 \%)$. In contrast, only the results of two parameters agreed within $10 \%$ in test 2 . These were mean tracer velocity and mean transit time.

Within the results from the optical quantification method, the agreement was within $10 \%$ for all parameters, except for time of first detection and longitudinal dispersion (Table 15). On the other hand, within the results from manual counting, no parameter agreed by less than $10 \%$. The disagreement between the results of the optical and manual method in test 2 and within the results of the manual method in both tests can be attributed to the fact that the collection interval was changed from 60 to 120 seconds in test 2 .

Based on the results from the two field tests, the optical quantification method may be more precise for quantifying the transport of the HTBs than manual collection and counting. However, the optical quantification method has its disadvantages. These disadvantages being that (1) it does not yield actual tracer recovery data, (2) it generates a large amount of raw data, (3) the raw data it generates may require interpolation and smoothing, both which add a certain degree of error, and (4) it is limited by the battery-life of the camera and the UV light strip. 


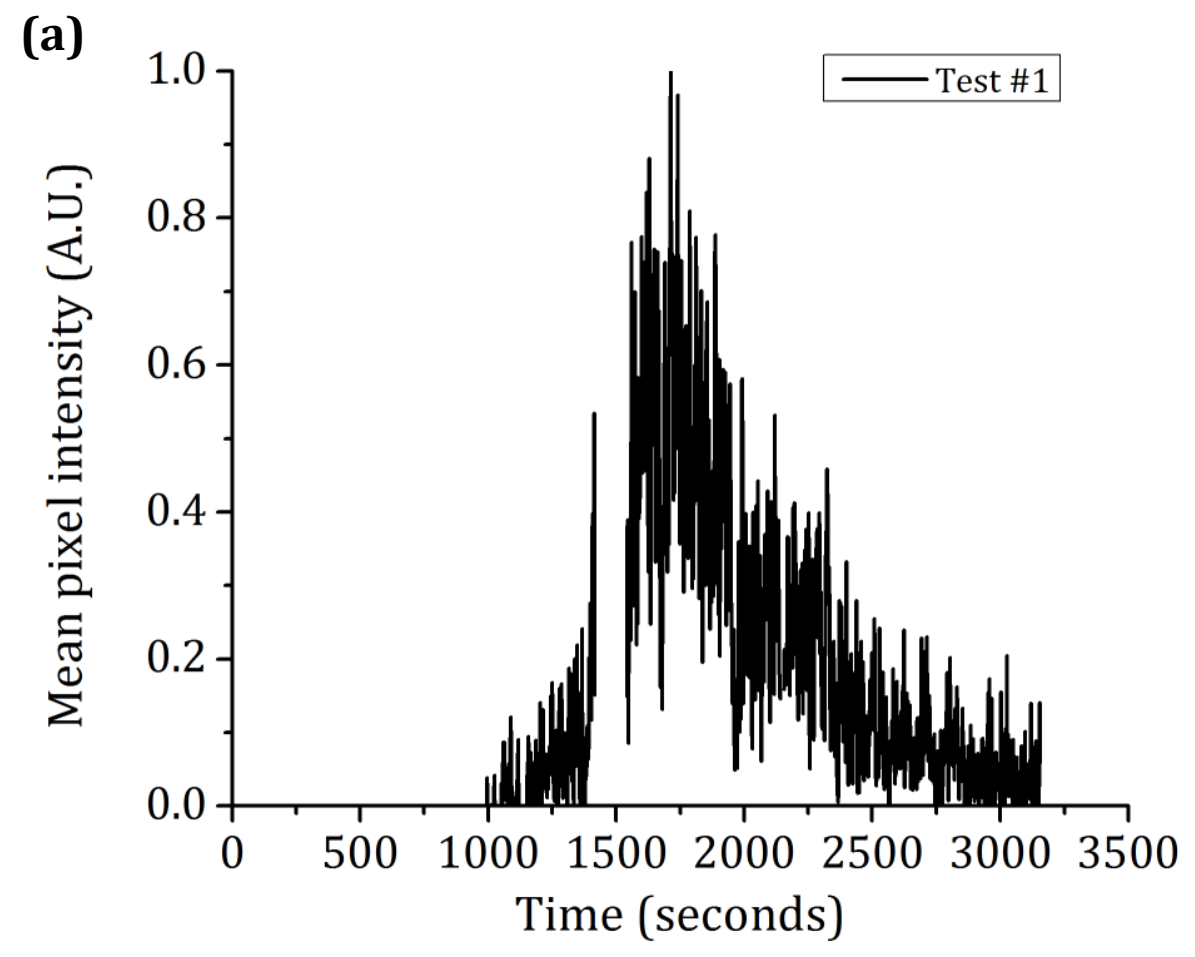

(b)

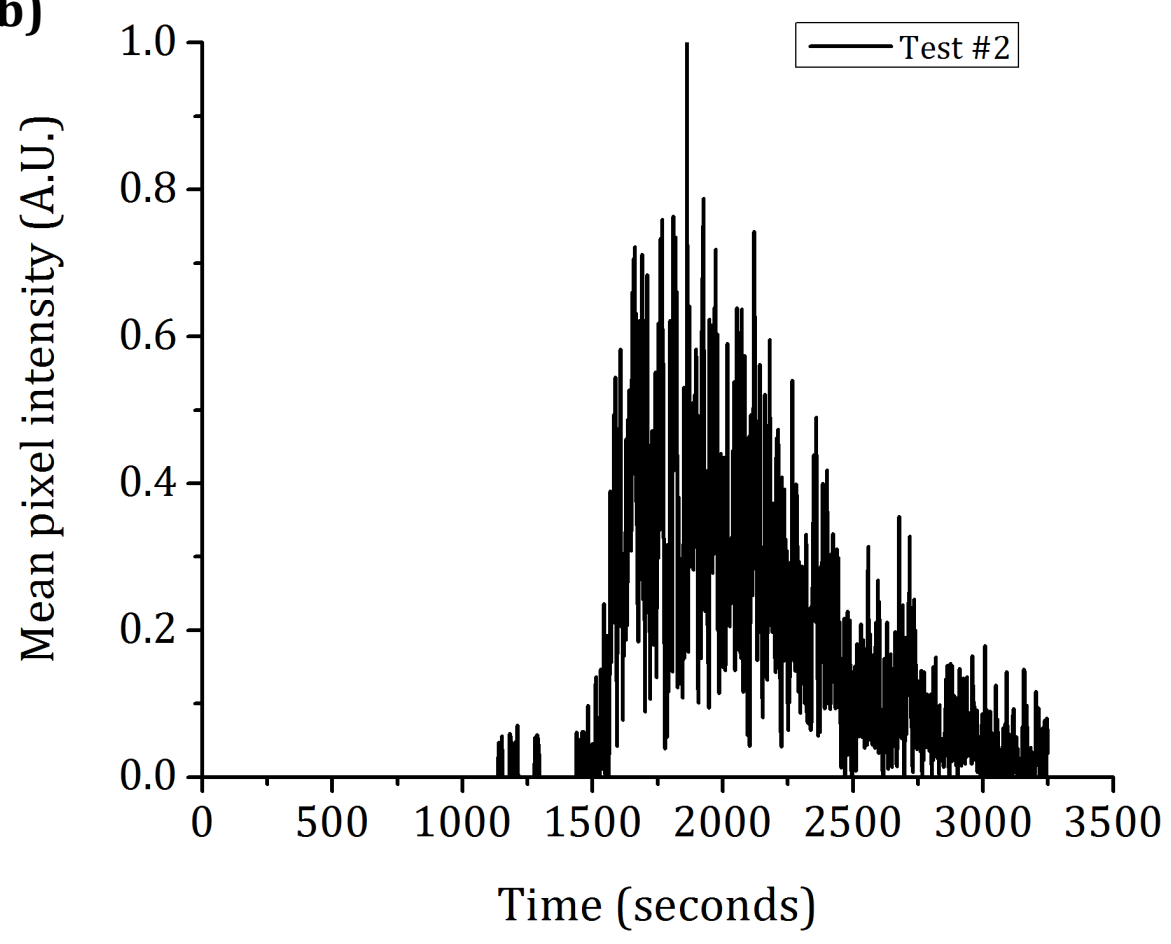

Figure 19: Normalized results of the tests conducted in Buckeye Creek Cave. Plot (a) is from test \#1 and plot (b) is from test \#2. 

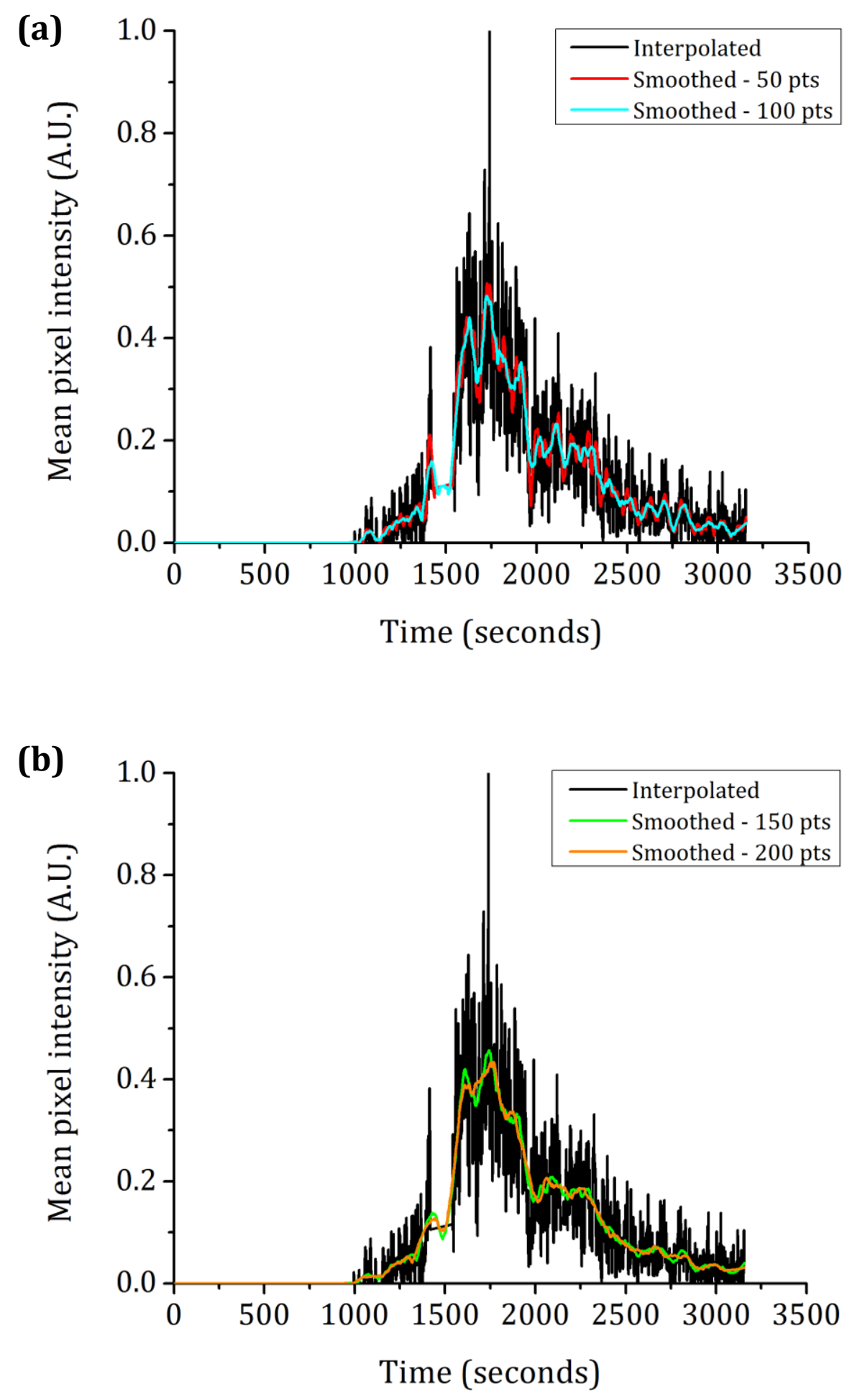

Figure 20: Results of the optical method for test \#1 in Buckeye Creek Cave after the normalized data was interpolated, and then smoothed with (a) 50, 100, (b) 150, and 200 points. 
Table 13: QTRACER2 results from the analysis of BTCs generated with different quantities of central points for the tests conducted in Buckeye Creek Cave.

\begin{tabular}{|c|c|c|c|c|c|c|c|}
\hline Test \# & $\begin{array}{c}\text { Central } \\
\text { points }\end{array}$ & $\begin{array}{c}\text { Time of } \\
\text { first } \\
\text { detection } \\
\text { (min) }\end{array}$ & $\begin{array}{c}\text { Time of peak } \\
\text { concentration } \\
\text { (min) }\end{array}$ & $\begin{array}{c}\text { Mean } \\
\text { tracer } \\
\text { velocity } \\
(\mathrm{m} / \mathrm{h})\end{array}$ & $\begin{array}{c}\text { Peak } \\
\text { tracer } \\
\text { velocity } \\
(\mathrm{m} / \mathrm{h}) \\
\end{array}$ & $\begin{array}{c}\text { Mean } \\
\text { transit } \\
\text { time } \\
\text { (min) }\end{array}$ & $\begin{array}{l}\text { Long } \\
\text { disp. } \\
\text { (m) }\end{array}$ \\
\hline \multirow{7}{*}{1} & 50 & 16.5 & 28.8 & 110 & 215 & 32.3 & $1.2^{*}$ \\
\hline & 100 & 16.7 & 28.7 & 110 & 213 & 32.3 & $1.2^{*}$ \\
\hline & 150 & 16.8 & 29.1 & 110 & 211 & 32.3 & $1.2^{*}$ \\
\hline & 200 & 16.7 & 29.5 & 110 & 212 & 32.3 & $1.2^{*}$ \\
\hline & Mean & 16.7 & 29.0 & 110 & 213 & 32.3 & 1.2 \\
\hline & STD & 0.13 & 0.36 & 0 & 1.71 & 0 & 0 \\
\hline & $\begin{array}{l}\text { RSD } \\
(\%) \\
\end{array}$ & 0.75 & 1.24 & 0 & 0.80 & 0 & 0 \\
\hline \multirow{7}{*}{2} & 50 & 18.7 & 30.2 & 102 & 189 & 34.7 & 0.1 \\
\hline & 100 & 18.5 & 27.7 & 102 & 191 & 34.7 & 1.0 \\
\hline & 150 & 18.3 & 27.8 & 102 & 193 & 34.7 & 0.1 \\
\hline & 200 & 18.5 & 32.1 & 102 & 191 & 34.7 & 0.1 \\
\hline & Mean & 18.5 & 29.5 & 102 & 191 & 34.7 & 0.3 \\
\hline & STD & 0.16 & 2.11 & 0 & 1.80 & 0 & 0.5 \\
\hline & $\begin{array}{l}\text { RSD } \\
(\%)\end{array}$ & 0.88 & 7.17 & 0 & 0.94 & 0 & 145 \\
\hline
\end{tabular}

$\left.{ }^{*}\right)$ Indicates that the calculation was overestimated by QTRACER2. STD: standard deviation, RSD: relative standard deviation, Long. disp.: longitudinal dispersion 
Table 14: Parameters as calculated by QTRACER2 for the tracer tests conducted in Buckeye Creek Cave.

\begin{tabular}{|c|c|c|c|c|c|c|c|c|}
\hline $\begin{array}{c}\text { Test } \\
\#\end{array}$ & Tracer & Method & $\begin{array}{c}\text { Time of first } \\
\text { detection } \\
\text { (min) }\end{array}$ & $\begin{array}{c}\text { Time of peak } \\
\text { concentration } \\
\text { (min) }\end{array}$ & $\begin{array}{c}\text { Mean tracer } \\
\text { velocity } \\
(\mathrm{m} / \mathrm{h}) \\
\end{array}$ & $\begin{array}{c}\text { Peak tracer } \\
\text { velocity } \\
(\mathrm{m} / \mathrm{h}) \\
\end{array}$ & $\begin{array}{c}\text { Mean } \\
\text { transit } \\
\text { time (min) } \\
\end{array}$ & $\begin{array}{l}\text { Long. } \\
\text { disp. } \\
\text { (m) }\end{array}$ \\
\hline \multirow{3}{*}{1} & \multirow{2}{*}{ HBTs } & Optical & 16.7 & 28.7 & 110 & 213 & 32.4 & $1.2^{*}$ \\
\hline & & Manual & 18.2 & 28.2 & 112 & 195 & 31.5 & $1.0^{*}$ \\
\hline & $\mathrm{NaCl}$ & Conductivity & 19.2 & 25.4 & 115 & 184 & 30.9 & 0.4 \\
\hline \multirow{3}{*}{2} & \multirow{2}{*}{ HBTs } & Optical & 18.5 & 27.7 & 102 & 191 & 34.6 & 0.9 \\
\hline & & Manual & 21.0 & 33.0 & 100 & 169 & 35.3 & 0.1 \\
\hline & $\mathrm{NaCl}$ & Conductivity & 19.1 & 26.4 & 111 & 186 & 31.8 & 0.5 \\
\hline \multirow{3}{*}{ Mean } & HBTs & Optical & 17.6 & 28.2 & 106 & 202 & 33.5 & 1.1 \\
\hline & & Manual & 19.6 & 30.6 & 106 & 182 & 33.4 & 0.6 \\
\hline & $\mathrm{NaCl}$ & Conductivity & 19.2 & 25.9 & 113 & 185 & 31.4 & 0.5 \\
\hline
\end{tabular}

$\left({ }^{*}\right)$ Indicates that the calculation was overestimated by QTRACER2. Long. disp.: longitudinal dispersion. 
(a)

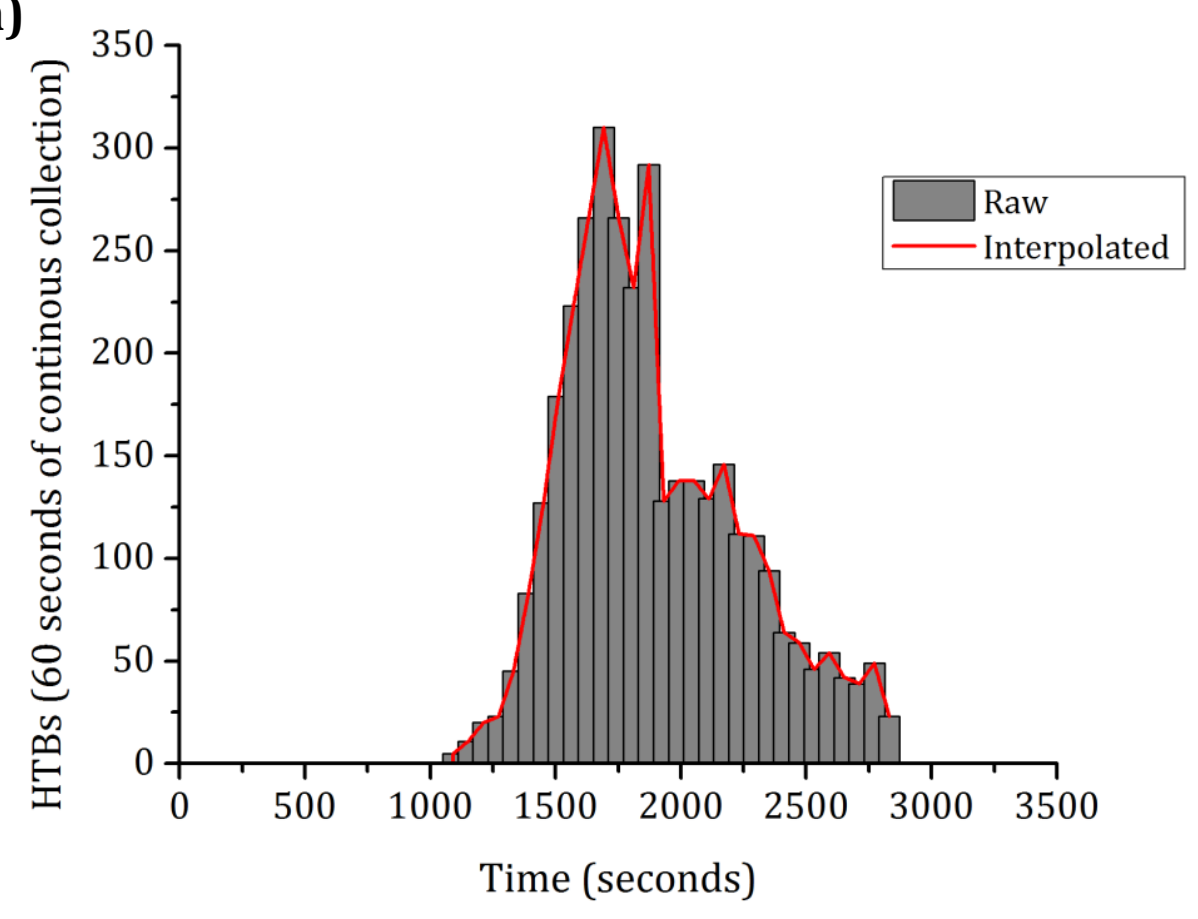

(b)

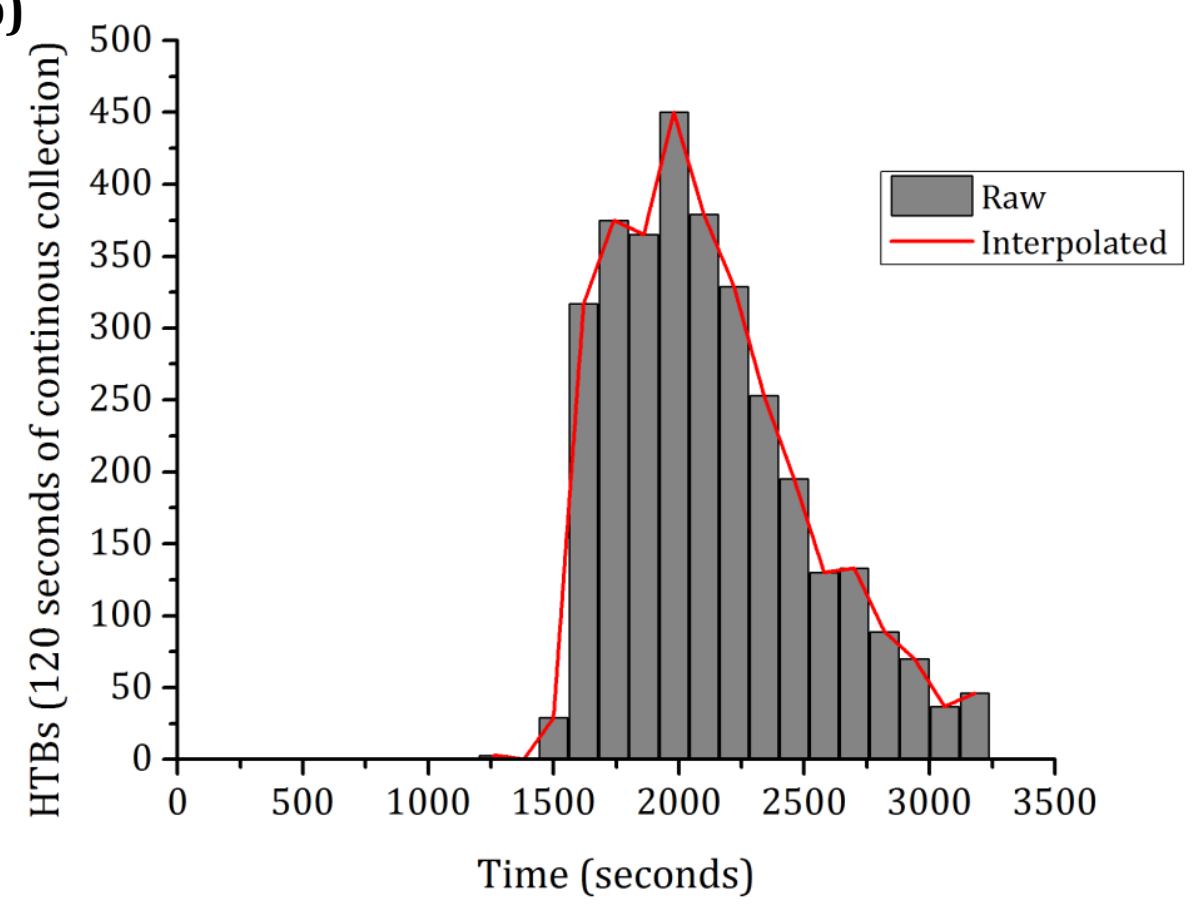

Figure 21: Raw and interpolated manual counting results for (a) test \#1 and (b) test \#2 in Buckeye Creek Cave. 

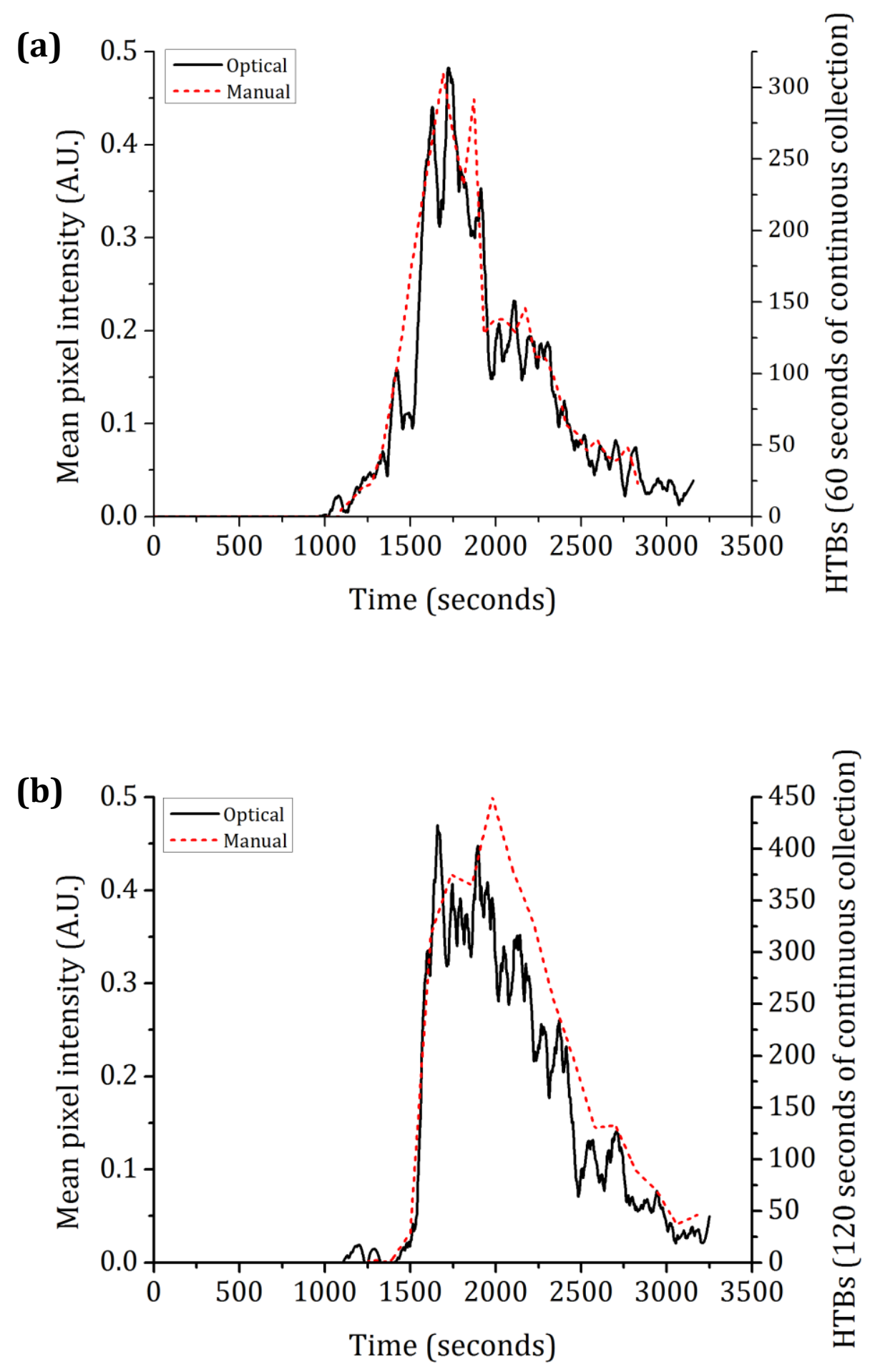

Figure 22: BTCs for Buckeye Creek Cave test (a) \#1 and (b) \#2 including data from optical method and manual counting of HBTs. 
Table 15: Absolute percent difference between and within the results of the optical and manual methods as well as within the results of the solute traces in Buckeye Creek Cave.

\begin{tabular}{|c|c|c|c|c|c|c|c|}
\hline & & $\begin{array}{c}\text { Time of } \\
\text { first } \\
\text { detection }\end{array}$ & $\begin{array}{l}\text { Time of peak } \\
\text { concentration }\end{array}$ & $\begin{array}{c}\text { Mean } \\
\text { tracer } \\
\text { velocity } \\
\end{array}$ & $\begin{array}{l}\text { Peak tracer } \\
\text { velocity }\end{array}$ & $\begin{array}{l}\text { Mean transit } \\
\text { time }\end{array}$ & $\begin{array}{l}\text { Longitudinal } \\
\text { dispersion }\end{array}$ \\
\hline \multirow{2}{*}{$\begin{array}{c}\% \\
\text { difference } \\
\text { between: }\end{array}$} & $\begin{array}{l}\text { The results of the } \\
\text { optical and manual } \\
\text { method from test } 1\end{array}$ & 8.5 & 1.8 & 2.6 & 9.3 & 2.6 & 19.3 \\
\hline & $\begin{array}{l}\text { The results of the } \\
\text { optical and manual } \\
\text { methods from test } \\
2\end{array}$ & 11.8 & 16.2 & 1.7 & 13.4 & 1.7 & 512.4 \\
\hline \multirow{3}{*}{$\begin{array}{c}\% \\
\text { difference } \\
\text { within: }\end{array}$} & $\begin{array}{l}\text { The results of the } \\
\text { optical method }\end{array}$ & 11.2 & 3.7 & 6.7 & 10.1 & 7.2 & 18.2 \\
\hline & $\begin{array}{l}\text { The results of the } \\
\text { manual method }\end{array}$ & 15.4 & 17.0 & 10.6 & 13.3 & 11.9 & 84.2 \\
\hline & $\begin{array}{l}\text { The results of the } \\
\text { solute traces }\end{array}$ & 0.8 & 4.1 & 2.9 & 0.8 & 2.9 & 24.4 \\
\hline
\end{tabular}




\subsubsection{Comparison of bead and solute tracers in the field}

In Buckeye Creek Cave, the solute tracer was first detected 19.2 and 19.1 seconds into tests 1 and 2, respectively (Table 14). The solute tracer traveled at an average mean velocity of $113 \mathrm{~m} / \mathrm{h}$ and an average peak velocity of $185 \mathrm{~m} / \mathrm{h}$. It took the tracer an average of 31.4 minutes to travel through the traced section. Tracer recovery exceeded $100 \%$ in both tests, which indicates that the discharge may have been overestimated. The discharge was measured in only two sections of the studied transect. The relative standard error of the two discharge measurements is $4.4 \%$.

Percent difference was used to compare the transport of the solute tracer in the two tests (Table 15). Results showed that all parameters agreed within 10\%. The agreement was within $3 \%$ for time of first detection, mean tracer velocity, peak tracer velocity, and mean transit time.

The results of the solute traces were compared to those of the optical quantification method. The results of the manual counting were not used for comparison purposes. Results indicate that the solutes traveled faster than the HTBs despite that the HTBs were detected before the solutes (Figure 23, Table 14). The HTBs were first detected after 16.7 and 18.5 minutes in test 1 and 2, respectively, whereas the solutes were first detected after ca. 19 minutes in both tests. The mean velocity of the solute tracer was on average, $7 \mathrm{~m} / \mathrm{h}$ greater than that of the HTBs, but the peak velocity of the HTBs was, on average, $17 \mathrm{~m} / \mathrm{h}$ greater than that of the solute tracer, which may explain why they were detected first. However, the solutes took less time to travel through the system, the average mean transit time being ca. 31.3 minutes. 

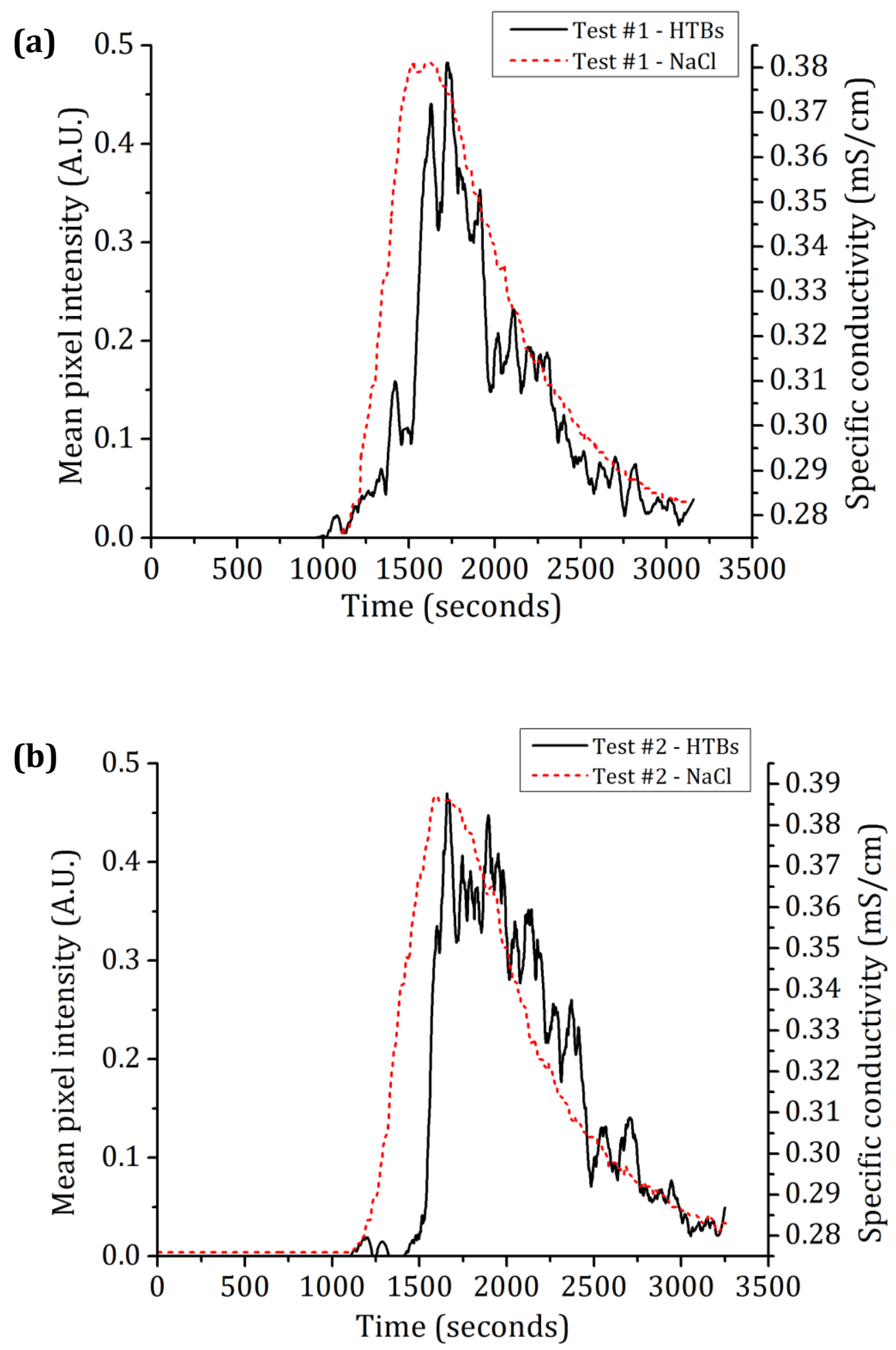

Figure 23: BTCs for Buckeye Creek tests (a) \#1 and (b) \#2 including data from the solute tracer and the optical method. 


\section{Chapter 5 Discussion}

\subsection{Optical quantification method for the transport of HTBs}

\subsubsection{Method evaluation}

The tests conducted in the Experimental Stream Facility demonstrate the use of the optical quantification method. A total of 23 tests were successful completed; 14 at a lowflow rate $(1.9 \mathrm{~L} / \mathrm{s})$ and 9 high-flow rate $(3.2 \mathrm{~L} / \mathrm{s})$. In the tests conducted at the low-flow rate, results of all the transport parameters calculated QTRACER2 agreed within 10\% except for longitudinal dispersion. In contrast, in the tests conducted at the high-flow rate, results of only three transport parameters agreed within $10 \%$; those being time of first detection, time of peak concentration, and peak tracer velocity.

ANOVA was used to determine if the results transport parameters calculated QTRACER2 were significantly different when tracer tests were made with different quantities or pigments of HTBs. Only two transport parameters (mean travel velocity and mean transit time) for the high-flow tests had results that were significantly different according to ANOVA. Further examination of the data showed that two tests (\#22 and \#28) had BTCs with unusual shapes. Analyses of these BTCs with QTRACER2 yielded outlying results. In most tests, the pixels belonging to low-intensity UV light being reflected on the water surface were only present in the blue color channel images, which were not analyzed for their mean pixel intensity values. However, pixels belonging to UV light or any other source of light being reflected on the water surface can be present in two or in the three color channels and can lead to deceptive results. In the two tests whose results were different, the reflection of UV light on the water surface gave the pixels of the red color 
channel high values, which caused the mean pixel intensity values of the images as a whole to fluctuate above background levels (Figure $24 \mathrm{a}-\mathrm{b}$ ). The bright pixels belonging to the UV light reflection on the water surface were only present in the red color channel images. The green color channels images (Figure 24c) were not affected and their mean pixel intensity data generated BTCs that yielded similar QTRACER2 results according to ANOVA.

Only 14 of the 21 tests conducted at the low-flow rate were successfully completed. In the remaining 7 tests, the HTBs made with the pink pigment, which absorbs light at higher wavelengths than the other pigments (Figure 2), were not detected by the camera because they did not emit sufficient fluorescence. It is believed that this happened because the battery pack of the UV light strip did not have enough energy for it to emit light at its maximum potential. For the tests conducted at the high-flow rate, the battery pack of the UV light strip was changed, which resulted in a successful completion of all of the 9 tests made, including those with pink HTBs.

The optical quantification method was tested in Buckeye Creek Cave. Two tests were conducted at this site. These lasted approximately 50 minutes each. In order to conserve the battery power of the camera, it was only turned on when the HTBs were approaching the experimental system. As a consequence, the data obtained for the two tests were incomplete. The missing data points were interpolated using a linear method, which introduced a certain degree of error because it connected missing data points with a straight line. The data obtained in the two tests was also noisy, thus a filter was used to smooth the data. The smoothing filter also introduced a certain degree of error because it suppressed the peaks in the normalized data. Noise, which is defined as any undesired 
artifact that contaminants an image, can be due to various sources (e.g. acquisition device) and these sources may result in different types of noise (e.g. thermal noise) (Marques, 2011). The degrees of error introduced by both data interpolation and data smoothing are not easily quantifiable. Therefore, the tests conducted in Buckeye Creek Cave highlight the fact that the optical quantification method is not suitable for tests of long duration (e.g. $>30$ minutes) unless the camera has better battery life or energy management capabilities. 

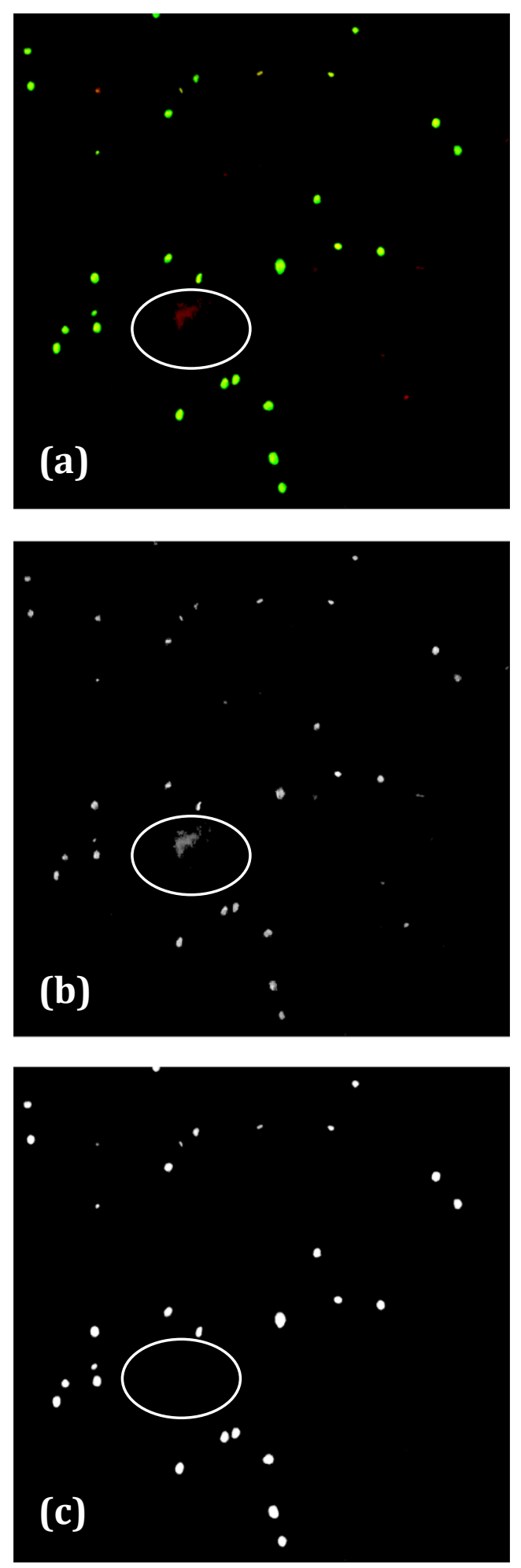

Figure 24: Ultraviolet light reflection of the water surface is present in (a) enhanced images and (b) red color channel image, but not in (c) green color channel images of test \#22 in the Experimental Stream Facility. 
The tests conducted in the Experimental Stream Facility and in Buckeye Creek revealed some advantages and disadvantages of the optical quantification method. The advantages include that: (a) it can be applied easily and affordably (b) its results are consistent even if different bead amounts or bead colors are used, (c) it collects data at high temporal resolutions (e.g. every 0.008 or 0.02 seconds). The disadvantages include that: (a) the results can be influenced by any object present in an image (e.g. a wood chip) or any source of light (e.g. sun light, UV light, etc.), (b) it generates a large amount of raw data, (c) the raw data it generates may require some processing that introduces error, (d) it does not yield true tracer recovery data, (e) yields unreliable results for longitudinal dispersion, (f) it is a slow process (it takes about an hour to analyze a 10 minute video), and (f) it is limited by the battery-life of the camera and the UV light strip. The first six disadvantages may be eliminated by detecting and tracking the transport of the HTBs with a more sophisticated image analysis algorithm. The sixth disadvantage may be reduced by using a camera and UV light strip with better energy management capabilities or by letting the camera and UV light trigger remotely and automatically as the HTBs approach the experimental system.

\subsubsection{Optical quantification method versus manual counting}

The results of the optical quantification method were compared to those of manual counting of HTBs to determine the relative effectiveness of the two approaches. In the two tests that were conducted at Buckeye Creek Cave, the shapes of the BTCs of the optical quantification method were similar to those of the manual counting of HTBs, which indicates that the optical quantification method measures what it is supposed to, that being 
the transport of the HTBs. The QTRACER2 results between both methods were slightly different though. Particularly, the times at which the HTBs were detected, and the times at which the concentration of HTBs peaked. These disparities might be due to the different temporal resolutions of data acquisition. The data from the optical quantification method that was analyzed in this study was collected for intervals of 0.5 seconds, but it could also have been collected for shorter time intervals (e.g. 0.008 seconds). On the other hand, the data from the manual method that was analyzed in this study was collected for longer time intervals, those being 60 and 120 seconds. Therefore, it is believed that the optical quantification method may provide a better estimate of the transport of HTBs than manual counting because it acquires data at a higher temporal resolution. The optical quantification method does have a disadvantage over the manual counting of HTBs. This disadvantage is that it does not yield true tracer recovery data because it does not count the HTBs. Instead, it quantifies the transport based on the brightness of pixels.

\subsection{Comparative tracer tests}

\subsubsection{Comparative tracer tests with HTBs}

Tracer tests were conducted to compare the transport behavior of HTBs with a solute tracer. The tracer tests were conducted in the laboratory (Experimental Stream Facility) as well as in the field (Buckeye Creek Cave). In both of these sites, the systems have an air-water interface, but other than that, the sites are not directly comparable to each other. Differences between the two sites include, but are not limited to, experimental flume versus cave stream, amount of discharge, amount of trapping mechanisms, type of trapping mechanisms, width of the channel, and depth of the channel. The results of the 
tests at each site yielded contrasting results. The results of the tests conducted in the Experimental Stream Facility indicate that the buoyant HTBs travel faster than the solute tracer, but the results of the tests conducted in Buckeye Creek Cave indicate otherwise.

The results of the comparative tracer tests conducted in Experimental Stream Facility agree with what Laskoskie (2013) reported using similar tracers at two field sites. The author used buoyant HTBs and fluorescein to conduct two comparative tracer tests in Buckeye Creek Cave. The author also conducted two comparative tracer tests at Rhine Creek, a surface stream located in Terra Alta, WV. The tests were conducted over the same length of stream at both sites (ca. $60 \mathrm{~m}$ ). Discharge at the time of the tests were $140 \mathrm{~L} / \mathrm{s}$ in Buckeye Creek Cave and 85 L/s in Rhine Creek. According to Laskoskie (2013), some differences between the two sites at the time other than discharge included the amount of trapping mechanisms, type of trapping mechanisms, amount of streambed sediments, size of streambed sediments, width of the channel, depth of the channel, and the presence of alternate flow paths. Even with all of the differences between both sites, Laskoskie (2013) found that the buoyant HTBs traveled faster than the solute tracer.

The two Buckeye Creek Cave comparative tracer tests conducted in the present study were made in the same stream section used by Laskoskie (2013). Despite that, the solute tracer traveled faster than the particle tracer. The main differences between the Buckeye Creek Cave tracer tests conducted by Laskoskie (2013) and those conducted in the present study are: (a) the solute tracer used and (b) water discharge. The solute tracer used by Laskoskie (2013) was fluorescein, while in the present study, the solute tracer used was sodium chloride. Both of these tracers are conservative, which means that they 
do not interact chemically or physically with the system they are in and follow water movement. Therefore, it is assumed that the discharge was the main factor that had an effect on the results of the tests. Discharge was $140 \mathrm{~L} / \mathrm{s}$ during the tests conducted by Laskoskie (2013), whereas only 9 L/s during the 2014 tests. In Laskoskie's (2013) tests, it took the tracers only 7 minutes to travel through the ca. $60 \mathrm{~m}$ transect, whereas in the present study, it took the tracers ca. 50 minutes to travel through the same ca. $60 \mathrm{~m}$ transect. Also, in the 2014 Buckeye Creek Cave tests the HTBs traveled differently from what Laskoskie (2013) reported. The author reported that the HTBs traveled in cohesive groups and attributed it to attraction between the HTBs by intermolecular forces. In the present study, instead of traveling in more cohesive groups, the HTBs dispersed and traveled separately.

\subsubsection{Comparative tracer tests with other particle tracers}

The results of the comparative tracer tests conducted in Experimental Stream Facility agree with has been reported in other studies with various particle tracers (e.g. microspheres, clay, and bacteria) that are different from the HTBs in physical and chemical properties. These studies were made in natural water systems that are not comparable to the flumes in the Experimental Stream Facility. For example, Göppert and Goldscheider (2008) conducted comparative tests using $1-\mu \mathrm{m}$ microspheres as particle tracers and sodium fluoresce in (e.g. uranine) as a solute tracer. They conducted the tests over a $9.6 \mathrm{~km}$ section in Hölloch Cave of the Austro-German Alps. The stream in Hölloch Cave is similar to the stream in Buckeye Creek Cave in that both have an air-water interface, but other than that, it is different because it has siphons that obstruct the flow of water. The authors 
completed two comparative tracer tests during different hydrologic conditions in Hölloch Cave; one at low-flow conditions (172 L/s) and the other at high-flow conditions (580$2691 \mathrm{~L} / \mathrm{s}$ ). They found that the particles traveled at higher velocities than the solutes in both tests, and that the difference in velocities was less at the high-flow conditions.

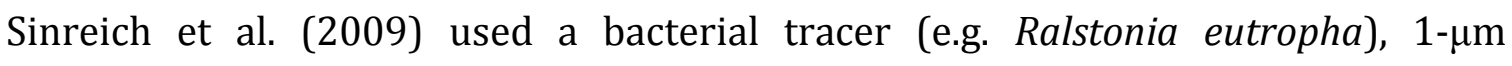
microspheres, and iodide to conduct comparative tracer tests at the Gännsbrunnen test site in the Jura Mountains of Switzerland. The authors conducted the tests in the vadose zone, through $10 \mathrm{~m}$ of soil and epikarst. The three tracers were released in the soil, under steadystate flow conditions. Sinreich et al. (2009) found that the particle tracers traveled faster through the system than the solute tracer.

Mähler et al. (1998a) conducted two comparative tracer tests using lanthanidelabeled clay as particle tracer, and rhodamine WT as solute tracer. They conducted the two tests in a 219 m long subsurface karst conduit that discharges at Sirena Spring in Salado, TX. The authors conducted the two tests during different hydrologic conditions at Sirena Spring; one test during lower flow rate conditions (14 L/s), and the other during higher flow rate conditions $(27 \mathrm{~L} / \mathrm{s})$. Additionally, they conducted a third comparative tracer test using lanthanide-labeled clay and sodium chloride. They conducted this third test at Waller Creek, a small surface stream in Austin, TX. For this test, they collected water samples 15 and $65 \mathrm{~m}$ downstream from the tracer release point. The flow condition at Waller Creek during the time of the test was not reported. Mähler et al. (1998a) recovered no clay in the test conducted during the lower flow rate conditions at Sirena Spring. They attributed this to gravitational sedimentation of the clay. In the test conducted during the high flow rate 
conditions at Sirena Spring and in the test conducted at Wallace Creek, the authors found that the clay particles arrived at collection station before the solute tracer.

Toran and Palumbo (1992) used laboratory sand columns to study colloid transport through fractured and unfractured media. The authors artificially created the fractures in the $5-\mathrm{cm}$ diameter and $65-\mathrm{cm}$ length sand columns by inserting small tubes. They injected 1- $\mu \mathrm{m}$ microspheres, bacteria, colloidal organic matter, and a salt tracer into sand columns with tubes and sand columns without tubes. The authors found that the fractured media enhanced the transport and recovery of the particle tracers. They also found that even though the recovery of the particle tracers was lower than the recovery of the solute tracer in both, fractured and unfractured media, the particle tracers traveled faster than the solute.

The results of the comparative tracer tests conducted at the Experimental Stream Facility are supported by what has been reported in other studies (e.g. Mähler et al., 1998a; Göppert and Goldscheider, 2008; Sinreich et al., 2009; Laskoskie, 2013), which is that particle tracers travel faster than solute tracers. In contrast, in the 2014 comparative tracer tests conducted in Buckeye Creek Cave, the particle tracers traveled slower than the solute tracer. Despite the contradictory results, there are important implications regarding water sampling after a LNAPL enters a karst system.

If it is assumed that the buoyant HTBs are transported in the same way as LNAPLs, the results of the tests in the Experimental Stream Facility suggest that travel times predicted from solute traces may not truly indicate the appropriate time to collect water samples because LNAPLs can travel faster than solutes (Laskoskie, 2013). In the case- 
studies at Park City and Richmond, KY, where LNAPLs accidentally released into karst aquifers were not recovered in known discharge points (Ewers et al., 1991; Stephenson et al., 2004), LNAPL travel time was estimated based on dye traces. Since the LNAPLs can travel faster than solutes, it is possible that the LNAPLs traveled to the discharge points before water sampling began (Laskoskie, 2013), and thus their presence was not detected. The reason why LNAPLs may travel faster than solute tracers in water systems with an airwater interface is because they are restricted to flow on the water surface. Thus, they primarily flow in two dimensions (laterraly and longitudinally). In contrast, solute tracers can flow in three dimensions (laterraly, longitunadilly, and vertically) because they mix with water. As the solute tracer mixes with the water column, it intergrates a wider distribution of velocities. This distribution of velocities is caused by the roughness of the sides and bottom of a stream channel.

In contrast, the results of the 2014 tests in Buckeye Creek Cave suggest that during low-flow conditions, LNAPLs may have sufficient time to disperse laterally and/or longitudinally in the water system, resulting in a slower travel time. If this is true, travel times predicted from solute traces during low-flow conditions may indicate the appropriate time (or overestimate the appropriate time) to collect water samples because LNAPLs may travel slower than solutes. Further tracer tests need to be made in the same site to confirm if this is true. 


\section{Chapter 6 Conclusions}

\subsection{Optical quantification method for the transport of HTBs}

In the present study, an optical quantification method that quantifies the transport of buoyant and fluorescent HTBs was developed in order that makes the process of conducting tracer tests with HTBs semi-automated. More than twenty tracer tests were conducted in a laboratory flume to determine the accuracy of this method. Despite that tracer tests were conducted using different colored HTBs as well as different quantities of HTBs; the results of the tests agreed well. The optical quantification method was also applied in tracer tests of longer duration in the field. In these tests, some disadvantages of the optical quantification method surfaced. These disadvantages are that:

- It is limited by the battery-life of the camera and/or UV light strip. Thus, missing data may need to be estimated.

- Results need to be smoothed because the data may be noisy.

- It does not yield quantitative tracer recovery data.

- Results may be affected by any object or light in the field of view of the camera.

Most of these disadvantages are caused by the image analysis algorithm that the optical quantification method uses to quantify the transport of the HTBs. Thus, they can be reduced and/or eliminated with an advanced image analysis algorithm that detects and tracks the HTBs frame by frame. In its current configuration, the optical quantification method works bests in: (a) tracer tests of short duration ( $<10$ minutes), (b) water systems with no floating objects other than the HTBs, and (c) in completely dark surroundings with no source of light other than the ultraviolet light. 


\subsection{Comparative tracer tests}

Comparative tracer tests were conducted to contrast the transport behavior of buoyant HTBs with solute tracers in water systems with an air-water interface. The comparative tracer tests were conducted at a laboratory site (Experimental Stream Facility) and a field site (Buckeye Creek Cave). The results of the tests were different at each site.

The most important conclusion of the laboratory tests is that HTBs traveled faster than the solutes under slightly different flow rates (1.9 and $3.2 \mathrm{~L} / \mathrm{s})$. This is based on more than 20 separate tests and the resulting mean velocities and mean transit times. This same conclusion has been reported in a study with HTBs by Laskoskie (2013) and in multiple studies with other particulate tracers both in the field (Mähler et al., 1998a; Göppert and Goldscheider, 2008; Sinreich et al., 2009) as well as in laboratory column studies (Toran and Palumbo, 1992).

The most significant conclusion of the field tests, which were conducted in the same stream transect that Laskoskie (2013) used in Buckeye Creek Cave, is that solutes can travel faster than HTBs under some conditions. This conclusion disagrees with what is reported in literature, and it is based on only two separate tracer tests and the resulting mean velocities and mean transit times. Despite these results, there are potentially important implications regarding water sampling after a LNAPL enters the karst systems. The results of the tests in the laboratory suggest what has been already postulated by Laskoskie (2013), which is that travel times predicted from traces with solutes may not truly indicate the appropriate time to collect water samples because LNAPLs can travel 
faster than solutes. Whereas the results of the tests in the field may suggests that during low-flow conditions, travel times predicted from traces with solutes may indicate the appropriate time (or overestimate the appropriate time) to collect water samples because LNAPLs can disperse laterally and/or longitudinally and travels lower than solutes. These suggestions were made by assuming that the buoyant HTBs are transported in the same manner as LNAPLs. The results of the comparative tracer tests do not account for transport to closed systems or through soil because they were completed in water systems with an air-water interface; additional contaminant traps are likely to exist in fully submerged systems. 


\section{Chapter 7 Future work}

Future research is necessary to develop a more accurate method for quantifying the transport of the HTBs. A more accurate method could be developed with advanced image analysis algorithms, which detect and track the movement of objects based on size, shape, and/or color. These algorithms typically consist of two basic steps (Marques, 2011). These steps are (a) segmentation and (b) tracking. In segmentation, relevant objects are identified and discriminated in every frame, whereas in tracking, the displacement of the segmented objects is monitored from frame to frame (Marques, 2011). In contrast to the algorithm developed in the present study, advanced image analysis algorithms may yield results that are not influenced by anything other than the object of interests and tracer recovery information. Therefore, they can be applied in any kind of illuminated environment.

Other future research needs include:

- Determining if the HTBs are transported in a similarly manner to NAPLs.

- Determining if the HTBs truly travel slower than the solutes during low-flow rate conditions.

- Optimizing the size of the HTBs to make them usable in a laboratory-scale model of a karst aquifer. 


\section{Cited References}

Adrian, R. J., 2005, Twenty years of particle image velocimetry: Experiments in Fluids, v. 39, no. 2, p. 159-169.

Auckenthaler, A., Raso, G., and Huggenberger, P., 2002, Particle transport in a karst aquifer: natural and artificial tracer experiments with bacteria, bacteriophages and microspheres: Water Science and Technology, v. 46, no. 3, p. 131-138.

Bajpai, S. K., and Sharma, S., 2004, Investigation of swelling/degradation behaviour of alginate beads crosslinked with $\mathrm{Ca}^{2+}$ and $\mathrm{Ba}^{2+}$ ions: Reactive and Functional Polymers, v. 59, no. 2, p. 129-140.

Buchanan, T. J., and Somers, W. P., 1969, Discharge measurements at gaging stations: Washington, DC, U.S. Geological Survey Techniques of Water-Resources Investigations, p. 65.

Crawford, N. C., and Ulmer, C. S., 1994, Hydrogeologic investigations of contaminant movement in karst aquifers in the vicinity of a train derailment near Lewisburg, Tennessee: Environmental Geology, v. 23, no. 1, p. 41-52.

Dasher, G., and Balfour, W., 1994, The caves and karst of the Buckeye Creek Basin: West Virginia Speleological Society Bulletin, v. 12.

Davis, S. N., Thompson, G. M., Bentley, H. W., and Stiles, G., 1980, Ground-Water Tracers-A Short Review: Ground Water, v. 18, no. 1, p. 14-23.

Ewers, R. O., Duda, A. J., Estes, E. K., Idstein, P. J., and Johnson, K. M., 1991, The transmission of light hydrocarbon contaminants in limestone (karst) aquifers, in Proceedings 3rd Conference on Hydrogeology, Ecology, Monitoring, and Management of Ground Water in Karst Terranes, Nashville, TN, 1991, p. 287-305.

Field, M. S., 2002, The QTRACER2 program for tracer-breakthrough curve analysis for tracer tests in karstic aquifers and other hydrologic systems: U.S. Environmental Protection Agency, Office of Research and Development, National Center for Environmental Assessment, EPA/600/R-02/001.

Ford, D. C., and Williams, P., 2007, Karst hydrogeology and geomorphology, Hoboken, NJ, John Wiley \& Sons.

Fujita, I., Muste, M., and Kruger, A., 1998, Large-scale particle image velocimetry for flow analysis in hydraulic engineering applications: Journal of Hydraulic Research, v. 36, no. 3, p. 397-414. 
Goldscheider, N., Meiman, J., Pronk, M., and Smart, C., 2008, Tracer tests in karst hydrogeology and speleology: International Journal of Speleology, v. 37, no. 1, p. 2740.

Göppert, N., and Goldscheider, N., 2008, Solute and Colloid Transport in Karst Conduits under Low-and High-Flow Conditions: Ground Water, v. 46, no. 1, p. 61-68.

Harvey, R. W., Metge, D. W., Shapiro, A. M., Renken, R. A., Osborn, C. L., Ryan, J. N., Cunningham, K. J., and Landkamer, L., 2008, Pathogen and chemical transport in the karst limestone of the Biscayne aquifer: 3. Use of microspheres to estimate the transport potential of Cryptosporidium parvum oocysts: Water Resources Research, v. 44 , no. 8 , p. $1-12$.

Hayashi, M., 2004, Temperature-electrical conductivity relation of water for environmental monitoring and geophysical data inversion: Environmental Monitoring and Assessment, v. 96, no. 1-3, p. 119-128.

Käss, W., Behrens, H., Himmelsbach, T. H., and Hötzl, H., 1998, Tracing technique in geohydrology, Oxfordshire, Taylor \& Francis.

Kim, Y., Muste, M., Hauet, A., Krajewski, W. F., Kruger, A., and Bradley, A., 2008, Stream discharge using mobile large-scale particle image velocimetry: A proof of concept: Water Resources Research, v. 44, no. 9.

Laskoskie, A., 2013, Development of hydrogel tracer beads and comparative tracer tests to better understand contaminant fate and transport in karst systems [MS thesis]: West Virginia University, 108 p.

Loop, C. M., and White, W. B., 2001, A conceptual model for DNAPL transport in karst ground water basins: Groundwater, v. 39, no. 1, p. 119-127.

Mackay, D. M., Roberts, P. V., and Cherry, J. A., 1985, Transport of organic contaminants in groundwater: Environmental Science \& Technology, v. 19, no. 5, p. 384-392.

Mähler, B. J., Bennett, P. C., and Zimmerman, M., 1998a, Lanthanide-Labeled Clay: A New Method for Tracing Sediment Transport in Karst: Groundwater, v. 36, no. 5, p. 835843.

Mähler, B. J., Winkler, M., Bennett, P., and Hillis, D. M., 1998b, DNA-labeled clay: A sensitive new method for tracing particle transport: Geology, v. 26, no. 9, p. 831-834.

Marques, 0., 2011, Practical image and video processing using MATLAB, Hoboken, NJ, John Wiley \& Sons.

Moore, R. D., 2005, Slug injection using salt in solution: Streamline Watershed Management Bulletin, v. 8, no. 2, p. 1-6. 
Mull, D. S., Liebermann, T. D., Smoot, J. L., and Woosley, L. H., 1988, Application of dyetracing techniques for determining solute-transport characteristics of ground water in karst terranes: U.S. Environmental Protection Agency, EPA904/688-001.

Muste, M., Fujita, I., and Hauet, A., 2008, Large-scale particle image velocimetry for measurements in riverine environments: Water Resources Research, v. 44, no. 4.

OAKTON Instruments, 1997, Practical considerations for conductivity and total dissolved solids measurement: http://www.4oakton.com/TechTips/OAK_TT08.pdf (accessed August 2014).

Raffel, M., Willert, C. E., Wereley, S. T., and Kompenhans, J., 2007, Particle Image Velocimetry: A Practical Guide, New York, Springer.

Savitzky, A., and Golay, M. J. E., 1964, Smoothing and Differentiation of Data by Simplified Least Squares Procedures: Analytical Chemistry, v. 36, no. 8, p. 1627-1639.

Sinreich, M., Flynn, R., and Zopfi, J., 2009, Use of particulate surrogates for assessing microbial mobility in subsurface ecosystems: Hydrogeology Journal, v. 17, no. 1, p. 49-59.

Smart, P. L., and Laidlaw, I. M. S., 1977, An evaluation of some fluorescent dyes for water tracing: Water Resources Research, v. 13, no. 1, p. 15-33.

Stephenson, J. B., Kaufmann, R. D., Archer, J. A., Bertz, C., and Bradley, P., 2003, Environmental investigation of a diesel spill in a karst area of Kentucky, in Proceedings Ninth Conference on Sinkholes and the Engineering and Environmental Impacts of Karst, Huntsville, AL, 2004, ASCE, p. 415-428.

Tang, H. W., Chen, C., Chen, H., and Huang, J. T., 2008, An improved PTV system for largescale physical river model: Journal of Hydrodynamics, Series B, v. 20, no. 6, p. 669678.

Tauro, F., Grimaldi, S., Petroselli, A., and Porfiri, M., 2012a, Fluorescent particle tracers for surface flow measurements: A proof of concept in a natural stream: Water Resources Research, v. 48, no. 6, p. 1-10.

Tauro, F., Mocio, G., Rapiti, E., Grimaldi, S., and Porfiri, M., 2012b, Assessment of fluorescent particles for surface flow analysis: Sensors, v. 12, no. 11, p. 15827-15840.

Tauro, F., Pagano, C., Porfiri, M., and Grimaldi, S., 2012c, Tracing of shallow water flows through buoyant fluorescent particles: Flow Measurement and Instrumentation, v. 26, p. 93-101.

Toran, L., and Palumbo, A., 1992, Colloid transport through fractured and unfractured laboratory sand columns: Journal of Contaminant Hydrology, v. 9, no. 3, p. 289-303. 
Uhlman, K., and Barner, W., 1998, Contaminant transport mechanisms in karst terranes, in Proceedings Hydrology in the Humid Tropic Environment, Kingston, Jamaica, 1996, IAHS Publication, p. 327-335.

Urdan, T. C., 2001, Statistics in plain English, New York, NY, Taylor and Francis.

Vesper, D., 2008, Applied issues: Current research status, in Martin, J. B., and White, W., eds., Frontiers of Karst Research: Leesburg, VA, Karst Waters Institute, p. 65-73.

Vesper, D. J., Loop, C. M., and White, W. B., 2003, Contaminant transport in karst aquifers: Speleogenesis and Evolution of Karst Aquifers, v. 1, no. 2, p. 1-11. 


\section{Appendices}




\section{Appendix A: Algorithms}




\section{Algorithm A 1: Image analysis}

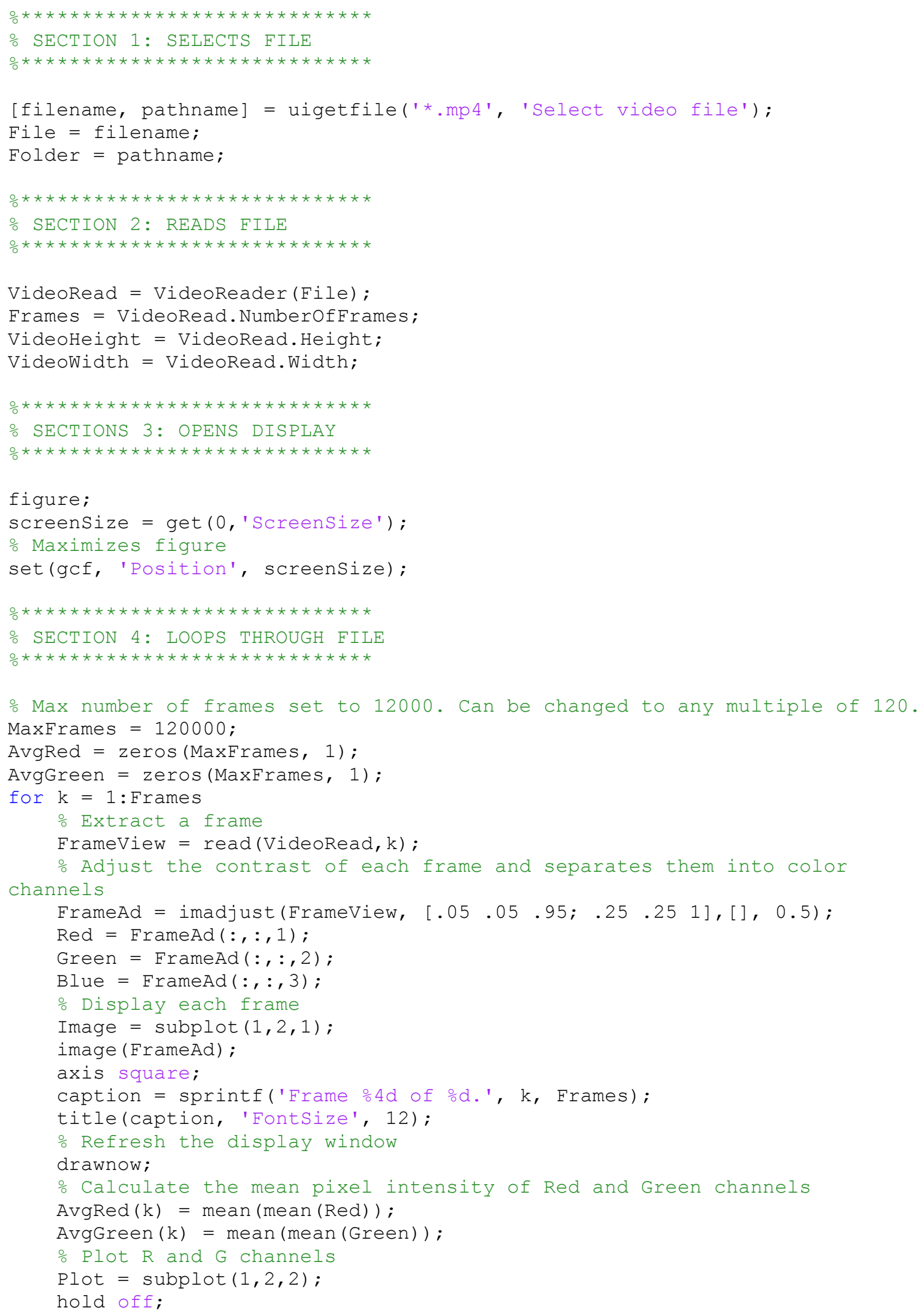




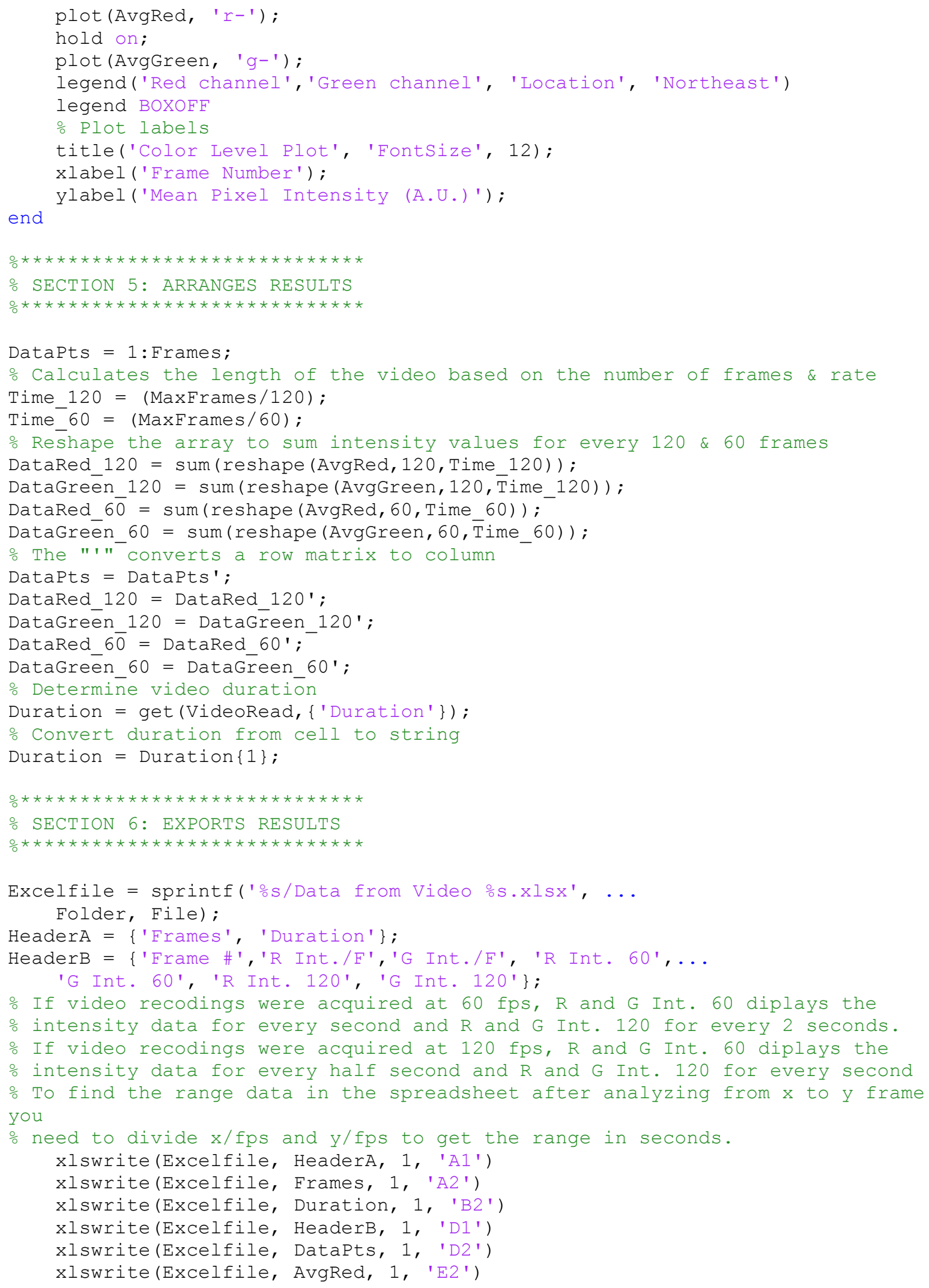


xlswrite (Excelfile, AvgGreen, 1, 'F2')

xlswrite (Excelfile, DataRed_60, 1, 'G2')

xlswrite (Excelfile, DataGreen_60, 1, 'H2')

xlswrite (Excelfile, DataRed_120, 1, 'I2')

xlswrite (Excelfile, DataGreen_120, 1, 'J2') 


\section{Algorithm A 2: Interpolation and smoothing}

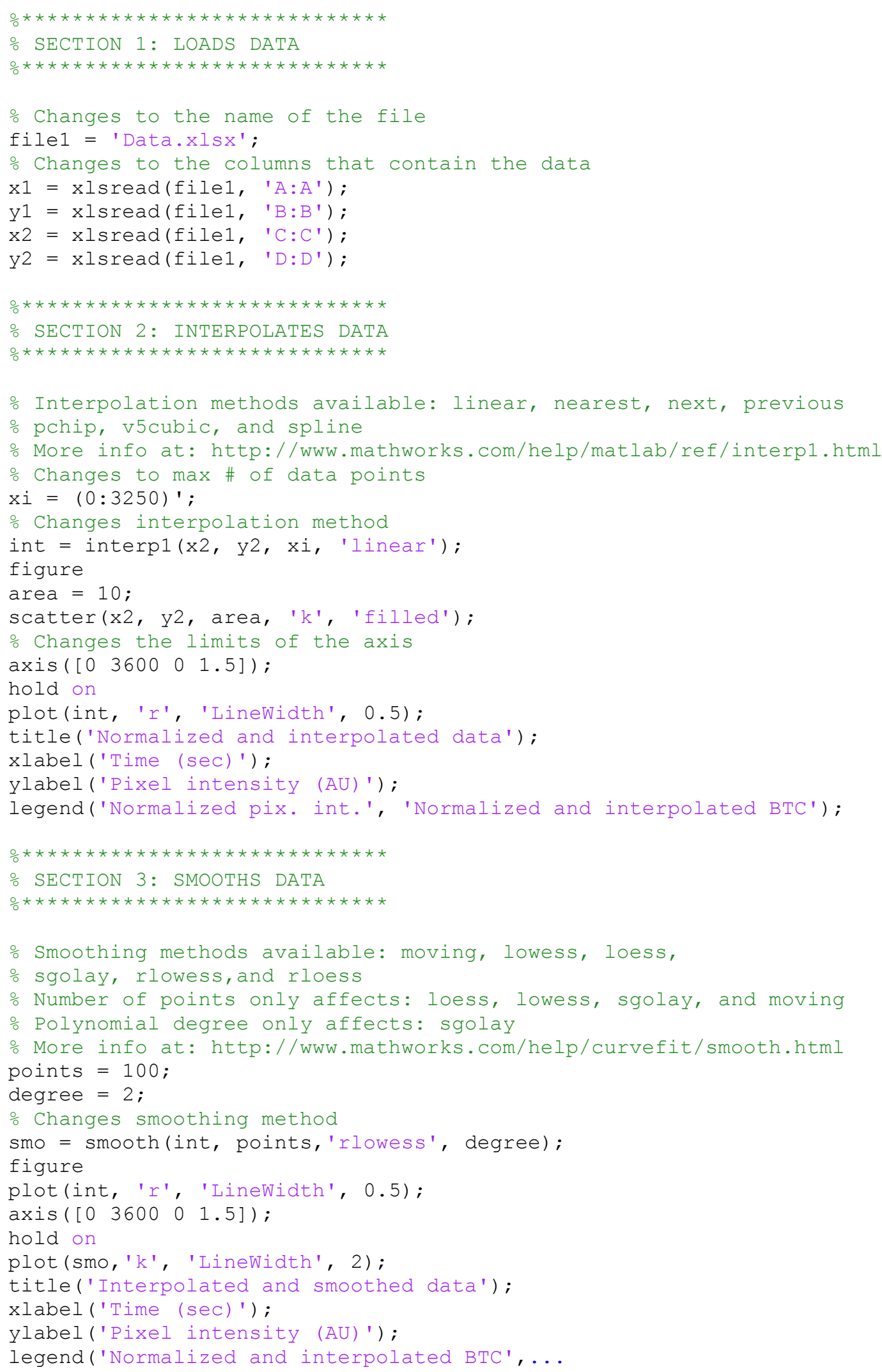




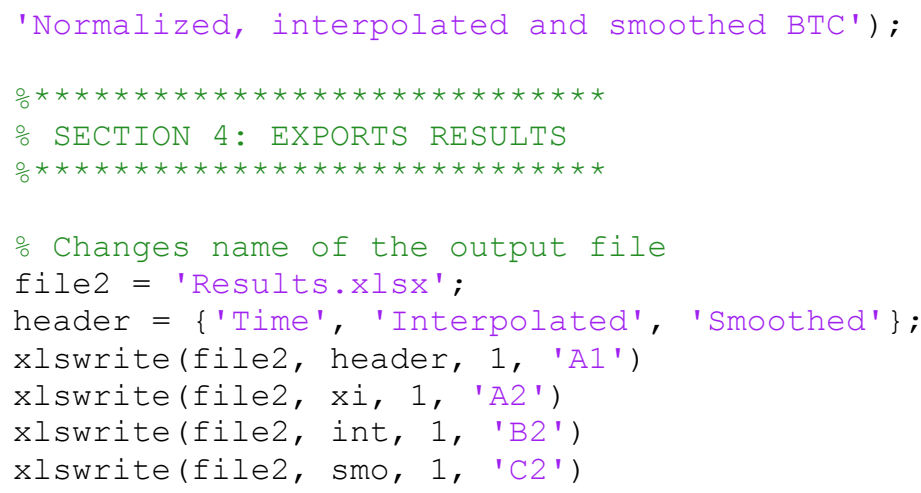




\section{Appendix B: Data}


Table B 1: Qtracer input files for tests with HTBs in the Experimental Stream Facility

\begin{tabular}{|c|c|c|}
\hline Test \# & File name & $\begin{array}{l}\text { Access to } \\
\text { input files }\end{array}$ \\
\hline 1 & ESF01 & \multirow{15}{*}{$\begin{array}{c}\text { http://bit.ly/ } \\
\text { 17mJhhT }\end{array}$} \\
\hline 2 & ESFO2 & \\
\hline 4 & ESFO4 & \\
\hline 5 & ESF05 & \\
\hline 7 & ESF07 & \\
\hline 8 & ESF08 & \\
\hline 10 & ESF010 & \\
\hline 11 & ESF011 & \\
\hline 13 & ESF013 & \\
\hline 14 & ESF014 & \\
\hline 16 & ESF016 & \\
\hline 17 & ESF017 & \\
\hline 19 & ESF019 & \\
\hline 20 & ESF020 & \\
\hline 21 & ESF021 & \\
\hline $22 \mathrm{R}$ & ESF022 & \multirow{11}{*}{$\begin{array}{c}\text { http://bit.ly/ } \\
\text { 1DmTB7I }\end{array}$} \\
\hline $22 \mathrm{G}$ & ESF022G & \\
\hline 23 & ESF023 & \\
\hline 24 & ESF024 & \\
\hline 25 & ESF025 & \\
\hline 26 & ESF026 & \\
\hline 27 & ESF027 & \\
\hline $28 \mathrm{R}$ & ESF028 & \\
\hline $28 \mathrm{G}$ & ESF028G & \\
\hline 29 & ESF029 & \\
\hline 30 & ESF030 & \\
\hline
\end{tabular}


Table B 2: Qtracer input files for tests with $\mathrm{NaCl}$ in the Experimental Stream Facility

\begin{tabular}{llc}
\hline Test \# & File name & $\begin{array}{l}\text { Access to } \\
\text { input files }\end{array}$ \\
\hline 1 & ESFS1 & \\
2 & ESFS2 & \\
4 & ESFS4 & \\
5 & ESFS5 & \\
7 & ESFS7 & \\
8 & ESFS8 & \\
10 & ESFS10 & http://bit.ly/ \\
11 & ESFS11 & 1vCSPLL \\
13 & ESFS13 & \\
14 & ESFS14 & \\
16 & ESFS16 & \\
17 & ESFS17 & \\
19 & ESFS19 & \\
20 & ESFS20 & \\
21 & ESFS21 & \\
\hline 22 & ESFS22 & \\
23 & ESFS23 & \\
24 & ESFS24 & \\
25 & ESFS25 & \\
26 & ESFS26 & \\
27 & ESFS27 & \\
28 & ESFS28 & \\
29 & ESFS29 & \\
30 & ESFS30 & \\
\hline
\end{tabular}


Table B 3: Qtracer input files for tests conducted in Buckeye Creek Cave

\begin{tabular}{cccc}
\hline Test \# & Tracer & File name & Access to input files \\
\hline \multirow{2}{*}{1} & HBTs (optical) & BCCO1_100 & \\
& HTBs (manual) & BCCC1 & http://bit.ly/1ElHPaA \\
& NaCl & BCCS1 & \\
\hline & HBTs (optical) & BCCO2_100 & \\
& HTBs (manual) & BCCC2 & http://bit.ly/1CFa985 \\
& NaCl & BCCS2 & \\
\hline
\end{tabular}




\section{Appendix C: Methods}




\section{Methods C 1: Optical quantification method - A step-by-step guide}

\section{Step 1\& 2: Fluorescent excitation of HTBs and video acquisition of their transport}

- Prepare an experimental system by attaching a ultraviolet light strip and an optical device to an elongated piece of metal or wood.

- Place the experimental system across a stream.

- Orient the ultraviolet light and optical device towards the water surface.

- Level the optical device with respect to the water surface.

- Turn on the ultraviolet light strip.

- Begin acquiring video at the same time the HTBs are released into the stream.

\section{Step 3: Data analysis with computer algorithm}

- Open MATLAB and activate the directory where the image analysis algorithm and the video files are located.

- Open the image analysis algorithm and press run in the editor tab.

- Locate the video file of interest.

- Wait while algorithm analyzes the video file. The length of this process depends on the size of the video and the performance of the computer.

- An excel file with the mean pixel intensity data will be generated in the same directory of the algorithm and video file.

\section{Step 4: Data processing}

- Open the Excel file generated by the algorithm. This file will contain some information of the video and the mean pixel intensity values of the red and green color channels. The mean pixel intensity values are available per 0.016 seconds if video was recorded at $60 \mathrm{fps}$ or 0.0083 seconds if video was recorded at $120 \mathrm{fps}$, as well as per 0.5 seconds and per 1.0 seconds.

- The mean pixel intensity values in a column of interest are normalized with the following formula in excel:

$$
z_{i}=\frac{\left(x_{i}-\min (x)\right)}{(\max (x)-\min (x))}
$$

where $x=\left(x_{1}, \ldots, x_{n}\right)$ and $z_{i}$ is the $\mathrm{i}^{\text {th }}$ normalized data and $\max (x)$ and $\min (x)$ are the maximum and minimum values, respectively.

- Create breakthrough curves with the normalized data. 
- Use the interpolation and smoothing algorithm if the normalized data is incomplete and/or noisy.

- To use the interpolation and smoothing algorithm open MATLAB and activate the directory where the algorithm and the normalized data is located.

- Open the interpolation and smoothing algorithm.

- Change the name of the excel file you want to analyze.

- Press run

- An excel file with the processed data will be generated in the same directory of the algorithm and normalized data.

\section{Step 5: BTC analysis with Qtracer}

- Open Qtracer header files (.d extension) and input files (.dat extension) using notepad.

- Adjust parameters in both files as needed.

- Copy and paste time and processed concentration data from a test to an input file.

- Open Qtracer and write the name of the header file to analyze the input file.

- Open output file (.out extension) to see results. 


\section{Method C2: Analysis of variance (ANOVA) procedure}

- State the null hypothesis $\left(\mathrm{H}_{0}\right)$ and alternate hypothesis $\left(\mathrm{H}_{\mathrm{a}}\right)$.

- In this case, the null hypothesis is that the mean transit times are statistically equal. The alternate hypothesis is that at least one mean transit time is not statistically equal.

- Calculate the test statistic.

- Determine the total sum of squares (SST), which is the total variation in the data (sum of the between and within variation).

$$
S S T=\sum_{i=1}^{r} \sum_{j=1}^{c}\left(x_{i j}-\overline{\bar{X}}\right) ;
$$

where $r$ is the number of rows in the table, $\mathrm{c}$ is the number of columns, $\bar{X}$ is the grand mean, and $x_{i j}$ is the $i$ th observation in the $j$ th column.

- Determine the treatment of sum squares (SSTR), which is the variation in the data between the different samples.

$$
S S T R=\sum r_{j}\left(\bar{X}_{j}-\overline{\bar{X}}\right) ;
$$

where $r_{j}$ is the number of rows in $j$ th column and $\bar{X}_{j}$ is the mean of the $j$ th column.

- Determine the error sum of squares (SSE), which is the variation in the data from each individual sample.

$$
S S E=S S T-S S T R
$$

- Determine the total mean squares (MST), which is the average total variation in the data.

$$
M S T=\frac{S S T}{N-1} ;
$$

$\mathrm{N}$ is the total number of observations.

- Determine mean square treatment (MSTR), which is the average between variations. 


$$
M S T R=\frac{S S T R}{c-1} ;
$$

$\mathrm{C}$ is the number of columns.

- Determine the mean square error (MSE), which is the average within variation.

$$
M S E=\frac{S S E}{N-c}
$$

- Determine the test statistic $(F)$

$$
F=\frac{M S T R}{M S E}
$$

- Obtain the critical F-value $\left(F^{C V}\right)$

$\circ$ Determine the degrees of freedom of the numerator (MSTR) and denominator (MSE).

- The numerators degrees of freedom (df1) is equal to $N-1$.

$\circ$ The denominators degrees of freedom (df2) is equal to $c-1$.

- Use the significance level $(\alpha)$ and the degrees of freedom to find the tabulated critical F-value $\left(F_{d f 1, d f 2}^{C V}\right)$

- Compare and decide

○ Null hypothesis is accepted if: $F$ (observed value) $<F^{C V}$ (critical value). If the contrary occurs, the null hypothesis is rejected. 


\section{Methods C3: Single factor ANOVA in Excel}

- In a clean Excel sheet, setup the data for a particular parameter in the following way:

\begin{tabular}{cccc}
\hline & Red HTBs & Green HTBs & Pink HTBs \\
\hline Mean transit time & 31 & 32 & 31 \\
(minutes) & 32 & 30 & 30 \\
& 31 & 31 & 31 \\
\hline
\end{tabular}

- Under the data tab, press data analysis.

- Select Anova: Single Factor from the list of tests.

- In the input range, only select the data and their labels (e.g. Red HTBs, ect.)

- Check labels in first row.

- Select an output option.

- Press enter and results will be generated. 